\title{
3-Dimensional Flow Modeling of a Proposed Hanford Waste Treatment Plant Ion-Exchange Column Design
}

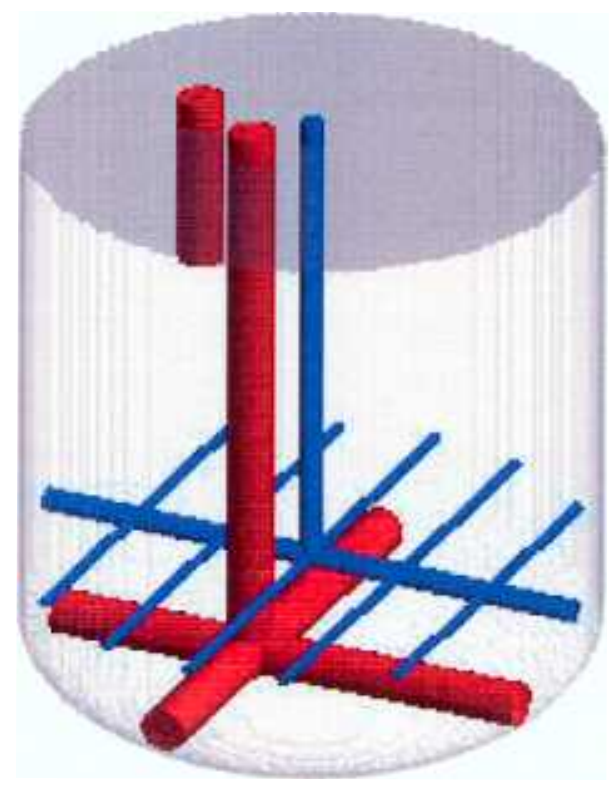

Westinghouse Savannah River Company Savannah River Site Aiken, SC 29808

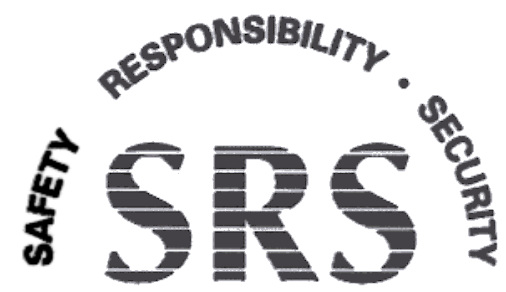


This document was prepared in conjunction with work accomplished under Contract No. DE-AC09-96SR18500 with the U. S. Department of Energy.

\section{DISCLAIMER}

This report was prepared as an account of work sponsored by an agency of the United States Government. Neither the United States Government nor any agency thereof, nor any of their employees, makes any warranty, express or implied, or assumes any legal liability or responsibility for the accuracy, completeness, or usefulness of any information, apparatus, product or process disclosed, or represents that its use would not infringe privately owned rights. Reference herein to any specific commercial product, process or service by trade name, trademark, manufacturer, or otherwise does not necessarily constitute or imply its endorsement, recommendation, or favoring by the United States Government or any agency thereof. The views and opinions of authors expressed herein do not necessarily state or reflect those of the United States Government or any agency thereof.

This report has been reproduced directly from the best available copy.

Available for sale to the public, in paper, from: U.S. Department of Commerce, National Technical Information Service, 5285 Port Royal Road, Springfield, VA 22161, phone: (800) 553-6847, fax: (703) 605-6900

email: orders@ntis.fedworld.gov

online ordering: http://www.ntis.gov/help/index.asp

Available electronically at http://www.osti.gov/bridge

Available for a processing fee to U.S. Department of Energy and its contractors, in paper, from: U.S. Department of Energy, Office of Scientific and Technical Information, P.O. Box 62, Oak Ridge, TN 37831-0062,

phone: (865)576-8401,

fax: (865)576-5728

email: $\underline{\text { reports@ adonis.osti.gov }}$ 
WSRC-TR-2002-00309

SRT-RPP-2002-00154

Revision 0

KEYWORDS:

Hanford River Protection Project Ion Exchange Technology SuperLig ${ }^{\circledR}$ Resins Technetium Cesium FACT Code Column Modeling RETENTION - Permanent

\section{3-Dimensional Flow Modeling of a Proposed Hanford Waste Treatment Plant Ion-Exchange Column Design}

SAVANNAH RIVER TECHNOLOGY CENTER

Sebastian E. Aleman

L. Larry Hamm

Publication Date: November 2002

Westinghouse Savannah River Company

Savannah River Site

Aiken, SC 29808

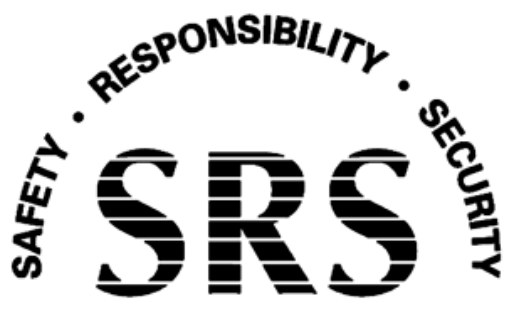

SAVANNAH RIVER SITE

Prepared for the U.S. Department of Energy under Contract No. DE-AC09-96SR18500 
This page was intentionally left blank 


\section{TABLE OF CONTENTS}

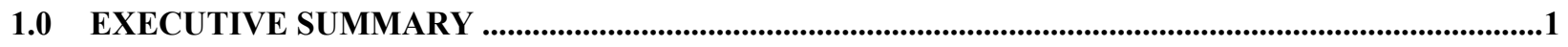

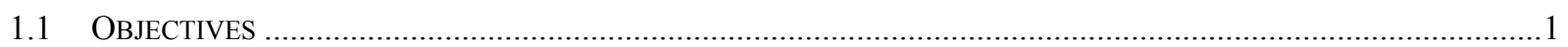

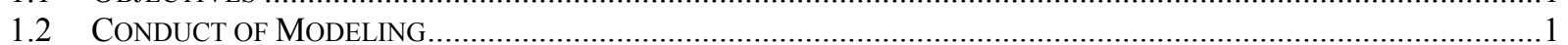

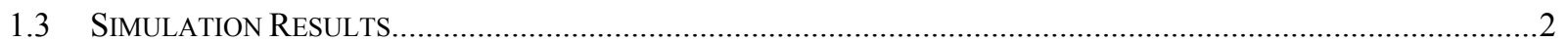

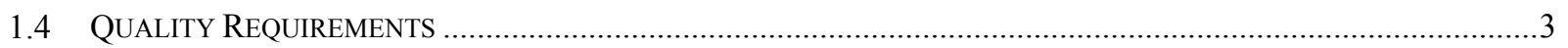

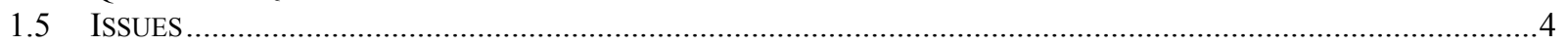

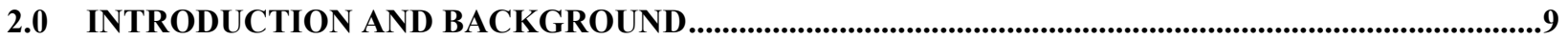

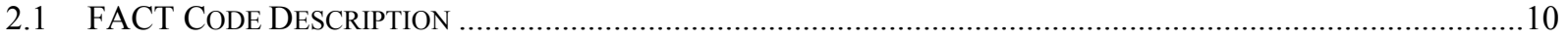

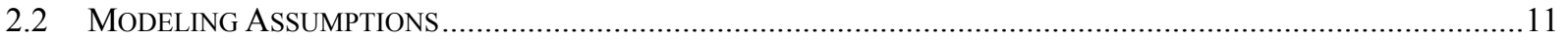

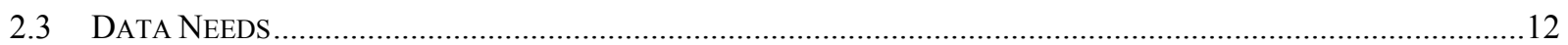

$3.0 \quad 3-D I M E N S I O N A L$ FLOW MODEL OF WTP IX COLUMN

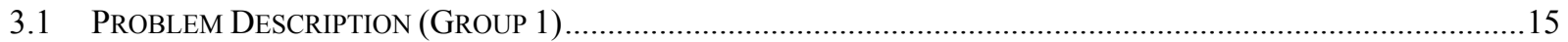

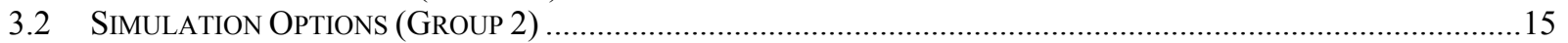

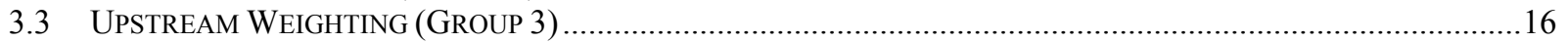

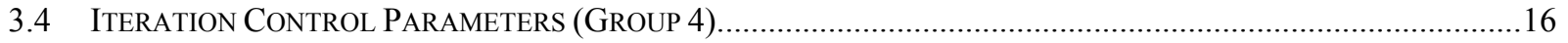

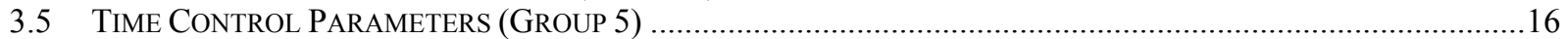

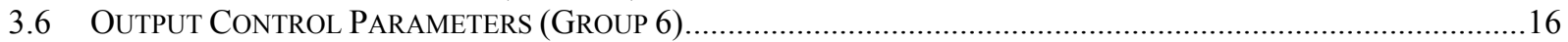

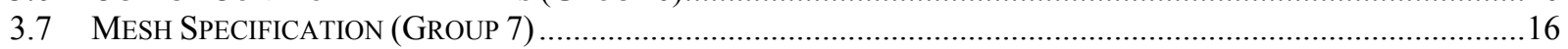

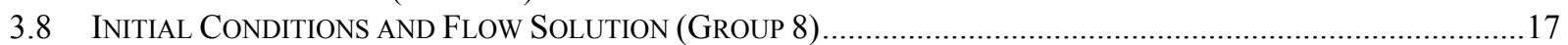

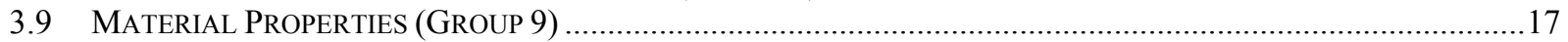

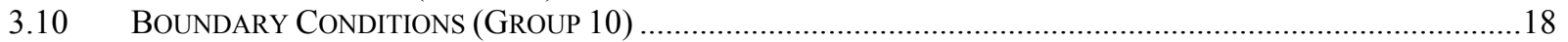

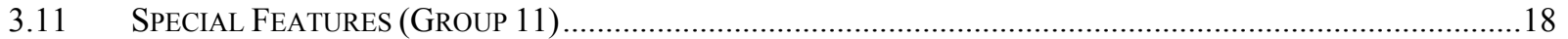

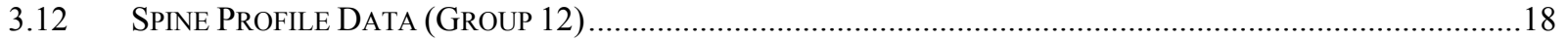

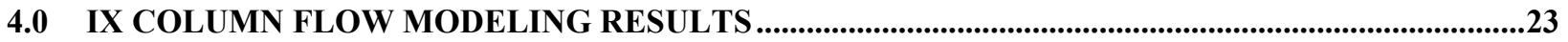

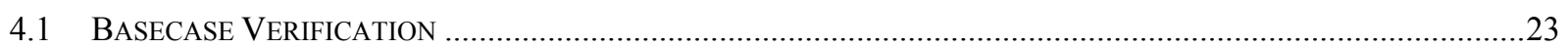

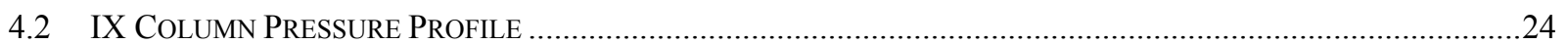

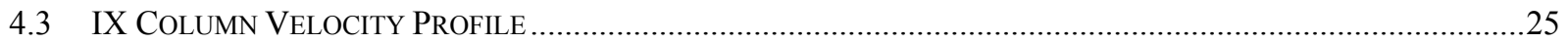

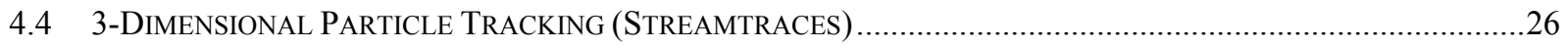

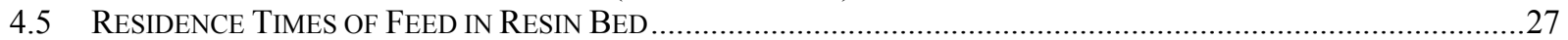

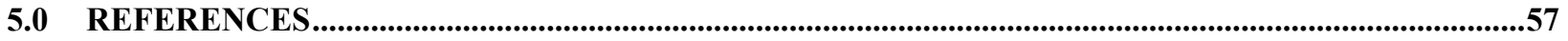

APPENDIX A (THERMAL ANALYSES OF SUPERLIG ${ }^{\circledR} 644$ RESIN BEDS),...............................................59

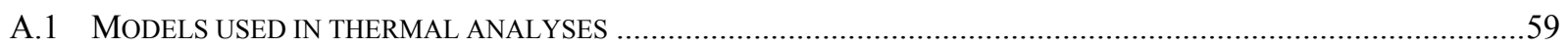

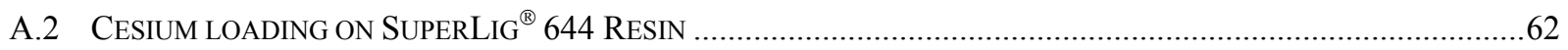

A.2.1 Maximum cesium loading on SuperLig ${ }^{\circledast} 644$ Resin .....................................................................62 62

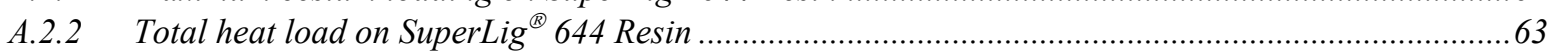

A.3 THERMAL AND PHYSICAL PROPERTIES USED IN ANALYSES _....................................................................64

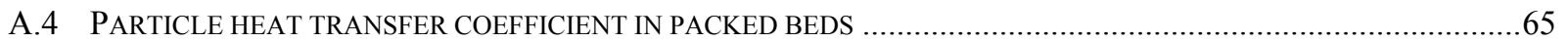

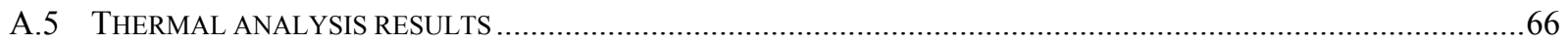

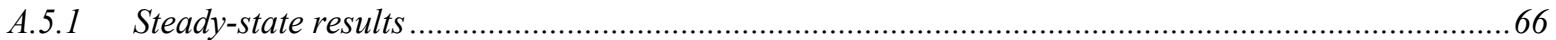

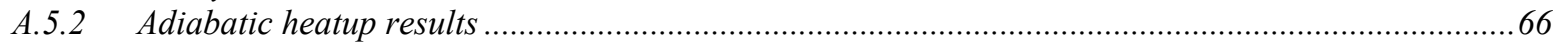

APPENDIX B (PROPOSED HANFORD WTP IX COLUMN DESIGN) .............................................................73 


\section{LIST OF TABLES}

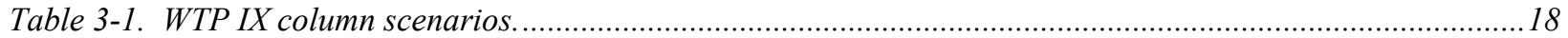

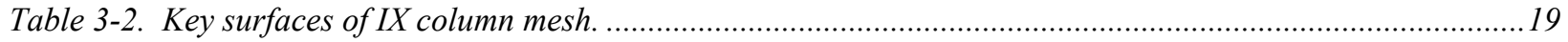

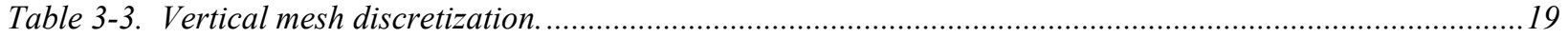

Table 3-4. Hydraulic conductivities of the WTP IX column scenarios..................................................................19

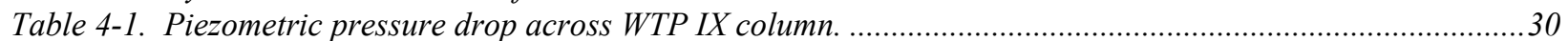

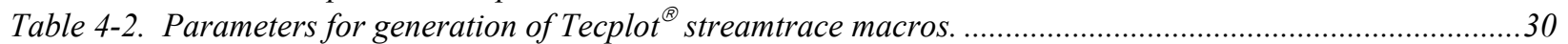

Table A-1. Physical and thermal property values ${ }^{a}$ used in the thermal analyses................................................67 


\section{LIST OF FIGURES}

Figure 1-1. The conceptual design of the proposed WTP IX column showing internal hardware. The LAW outlet distributor is shown in blue. The flush liquid inlet and spent resin outlet are shown in red. The inner wall of the vessel shell is highlighted in transparent green, where the components above the top of the resin bed are not being shown. ........................................................................... 5

Figure 1-2. $\begin{aligned} & \text { Normalized magnitude of the horizontal velocity as a function of resin bed elevation. The level } \\ & \text { of disturbance due to internal structural components and outflow boundaries is seen as peaks in }\end{aligned}$

Figure 1-2. $\quad \begin{aligned} & \text { Normalized magnitude of the horizontal velocity as a function of resin bed elevation. The level } \\ & \text { of disturbance due to internal structural components and outflow boundaries is seen as peaks in }\end{aligned}$ local horizontal velocity.

Figure 1-3. The normalized magnitude of the horizontal velocity as a function of resin bed elevation using a
semilog scale. Axial average and maximum values are plotted illustrating how local the

Figure 1-3. The normalized magnitude of the horizontal velocity as a function of resin bed elevation usin
semilog scale. Axial average and maximum values are plotted illustrating how local the disturbances are within a horizontal plane. 5

Figure 1-4. 3-D streamtraces for a bed packed with SuperLig ${ }^{\otimes} 644$ resin. The inlet liquid feed flow is 17 gpm (2.6 BV/hr or $5.6 \mathrm{~cm} /$ min superficial velocity). The LAW outlet distributor is shown in blue. The flush liquid inlet and spent resin outlet are shown in red. The inner wall of the vessel shell is highlighted in transparent green. The 3-D streamtraces are shown (black) starting at the top of the resin bed.

Figure 2-1. Proposed design for the LAW Outlet Distributor ………....................................................................... 13

Figure 2-2. Comparison of the standard Ergun equation to available SuperLig ${ }^{\circledR} 639$ hydraulic data for labscale and pilot-scale columns.

Figure 2-3. SuperLig ${ }^{\circledR} 644$ bed permeability under nearly steady-state conditions for a variety of fluid compositions and bed heights recently measured by Steimke (2002) at 20-25 ${ }^{\circ} \mathrm{C}$. Due to bed compaction, resulting primarily from osmotic feed changes, a broad range of bed permeabilities were observed. Over night soaking of beds prior to testing minimized dynamic compaction

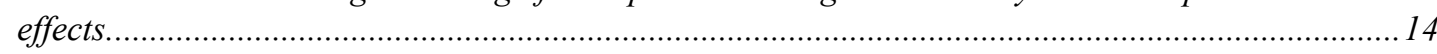

Figure 3-1. XY (horizontal) cross-sectional view of IX column mesh used as input for FACT analyses. The mesh spacing is $1 / 2$ inch by $1 / 2$ inch.

Figure 3-2. 3-D FACT mesh showing internal structures. This 90-degree chair-cut shows the internal
structures of the column. The blue structure is the LAW outlet distributor. The structures are the

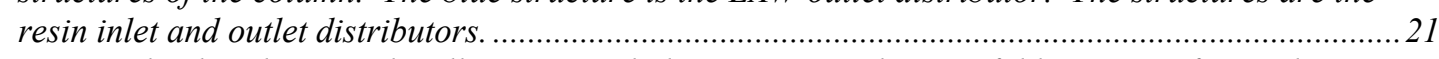

Figure 3-3. LAW outlet distributor with collection pipe hole pattern. Outlet manifold consists of a single 2". main with five 1" cross-pipes containing uniformly distributed outlet holes $1 / 2$ " in diameter.

Figure 4-1. Basecase: X-Z piezometric pressure profile slice $(Y=0)$ of WTP IX column containing SuperLig ${ }^{\circledR} 639$ during loading stage with low resin packing. The feed is AN-105 simulant flowing at $17 \mathrm{gpm}(2.6 \mathrm{BV} / \mathrm{hr})$........

Figure 4-2. Basecase: Y-Z piezometric pressure profile slice $(x=0)$ of WTP IX column containing SuperLig ${ }^{\Theta}$ 639 during loading stage with low resin packing. The feed is AN-105 simulant flowing at 17 gpm $(2.6 \mathrm{BV} / \mathrm{hr})$.

Figure 4-3. Basecase: Piezometric pressure profile of WTP IX column containing SuperLig ${ }^{\circledR} 639$ during loading stage with low resin packing. The feed is AN-105 simulant flowing at $17 \mathrm{gpm}$ (2.6 BV/hr). The average pressure drop across the bed is $1.06 \mathrm{psid...}$

Figure 4-4. Basecase: Cross-sectional view of normalized residence times in SuperLig ${ }^{\circledR} 639$ resin bed. The feed is AN-105 simulant flowing at $17 \mathrm{gpm}(2.6 \mathrm{BV} / \mathrm{hr})$.

Figure 4-5. Run-1: Piezometric pressure profile of WTP IX column containing SuperLig ${ }^{\circledast} 644$ during the elution stage and low column packing. The feed is $0.5 \mathrm{M} \mathrm{HNO}_{3}$ flowing at $17 \mathrm{gpm}(2.6 \mathrm{BV} / \mathrm{hr})$. The average pressure drop across the bed is $0.42 \mathrm{psid}$.

Figure 4-6. Run-2: Piezometric pressure profile of WTP IX column containing SuperLig ${ }^{\circledR} 644$ during the loading stage and high column packing. The feed is AZ-102 (Envelope B) simulant flowing at 17 gpm. The average pressure drop across the bed is 11.58 psid.

Figure 4-7. Run-3: Piezometric pressure profile of WTP IX column containing SuperLig ${ }^{\circledR} 644$ during the loading stage and low column packing. The feed is AZ-102 (Envelope B) simulant flowing at 17 gpm (2.6 BV/hr). The average pressure drop across the bed is $1.29 \mathrm{psid}$. 
Figure 4-8. Average piezometric pressure drop across resin bed for the four case studies considered (symbols). The lines represent estimates of the pressure drop at other flowrates where the linearity of the model is employed.

Figure 4-9. Normalized magnitude of horizontal velocity versus bed elevation in a SuperLig ${ }^{\circledR} 644$ packed column. The levels of disturbance due to structural components and outflow boundaries are seen as peaks in local horizontal velocity.

Figure 4-10. Normalized magnitude of horizontal velocity versus bed elevation in a SuperLiq ${ }^{\circledR} 644$ packed column (Semilog scale). Axial average and maximum values are plotted illustrating how local the disturbances are within a horizontal plane.

Figure 4-11. Contour plot of normalized horizontal velocity at the elevation of the LAW outlet distributor. The inlet liquid feed flow is $17 \mathrm{gpm}(2.6 \mathrm{BV} / \mathrm{hr})$ or $5.6 \mathrm{~cm} / \mathrm{min}$ superficial velocity........................... 41

Figure 4-12. Contour plot of normalized horizontal velocity $1 / 2$ inch above the elevation of the LAW outlet distributor. The inlet liquid feed flow is $17 \mathrm{gpm}(2.6 \mathrm{BV} / \mathrm{hr})$ or $5.6 \mathrm{~cm} / \mathrm{min}$ superficial velocity........ 42

Figure 4-13. Contour plot of normalized horizontal velocity 1 inch above the elevation of the LAW outlet distributor. The inlet liquid feed flow is $17 \mathrm{gpm}(2.6 \mathrm{BV} / \mathrm{hr})$ or $5.6 \mathrm{~cm} / \mathrm{min}$ superficial velocity........ 43

Figure 4-14. Contour plot of normalized horizontal velocity 9 inches below the elevation of the LAW outlet distributor. The inlet liquid feed flow is $17 \mathrm{gpm}(2.6 \mathrm{BV} / \mathrm{hr})$ or $5.6 \mathrm{~cm} / \mathrm{min}$ superficial velocity........ 44

Figure 4-15. Contour plot of normalized horizontal velocity 6 inches below the elevation of the LAW outlet distributor. The inlet liquid feed flow is $17 \mathrm{gpm}(2.6 \mathrm{BV} / \mathrm{hr})$ or $5.6 \mathrm{~cm} / \mathrm{min}$ superficial velocity........ 45

Figure 4-16. Contour plot of normalized horizontal velocity 3 inches below the elevation of the LAW outlet distributor. The inlet liquid feed flow is $17 \mathrm{gpm}(2.6 \mathrm{BV} / \mathrm{hr})$ or $5.6 \mathrm{~cm} / \mathrm{min}$ superficial velocity........ 46

Figure 4-17. Contour plot of normalized horizontal velocity at the elevation of the LAW outlet distributor. The inlet liquid feed flow is $17 \mathrm{gpm}(2.6 \mathrm{BV} / \mathrm{hr})$ or $5.6 \mathrm{~cm} / \mathrm{min}$ superficial velocity .......................... 47

Figure 4-18. Contour plot of normalized horizontal velocity 3 inch above the elevation of the LAW outlet distributor. The inlet liquid feed flow is $17 \mathrm{gpm}(2.6 \mathrm{BV} / \mathrm{hr})$ or $5.6 \mathrm{~cm} / \mathrm{min}$ superficial velocity........ 48

Figure 4-19. Contour plot of normalized horizontal velocity 6 inch above the elevation of the LAW outlet distributor. The inlet liquid feed flow is $17 \mathrm{gpm}(2.6 \mathrm{BV} / \mathrm{hr})$ or $5.6 \mathrm{~cm} / \mathrm{min}$ superficial velocity........ 49

Figure 4-20. Contour plot of normalized horizontal velocity 9 inch above the elevation of the LAW outlet distributor. The inlet liquid feed flow is $17 \mathrm{gpm}(2.6 \mathrm{BV} / \mathrm{hr})$ or $5.6 \mathrm{~cm} / \mathrm{min}$ superficial velocity........50

Figure 4-21. Contour and vector plot of normalized horizontal velocity at the elevation of the LAW outlet distributor. The inlet liquid feed flow is $17 \mathrm{gpm}(2.6 \mathrm{BV} / \mathrm{hr})$ or $5.6 \mathrm{~cm} / \mathrm{min}$ superficial velocity........51

Figure 4-22. 3-dimensional streamtraces from the inlet of the packed bed to the LAW outlet distributor. Timing markers (black circles) are plotted every 10 minutes. The inlet liquid feed flow is $17 \mathrm{gpm}$ $(2.6 \mathrm{BV} / \mathrm{hr})$ or $5.6 \mathrm{~cm} / \mathrm{min}$ superficial velocity.

Figure 4-23. $X-Z$ projection (at $Y=2$ inches) of 3-dimensional streamtraces from the inlet of the packed bed to the LAW outlet distributor. The inlet liquid feed flow is $17 \mathrm{gpm}(2.6 \mathrm{BV} / \mathrm{hr})$ or $5.6 \mathrm{~cm} / \mathrm{min}$ superficial velocity. The outlet distributor components are shown in blue and the resin distributors in red......

Figure 4-24. Normalized residence times in a SuperLig ${ }^{\circledR} 644$ packed bed. The inlet liquid feed flow is $17 \mathrm{gpm}$ $(2.6 \mathrm{BV} / \mathrm{hr})$ or $5.6 \mathrm{~cm} / \mathrm{min}$ superficial velocity.

Figure 4-25. Histogram of residence times based on superficial velocity in a SuperLig ${ }^{\circledR} 644$ packed bed. The inlet liquid feed flow is $17 \mathrm{gpm}(2.6 \mathrm{BV} / \mathrm{hr})$ or $5.6 \mathrm{~cm} / \mathrm{min}$ superficial velocity. The median value of the histogram is 18.7 min in comparison to the ideal packed bed whose residence time is 23.1 $\min$

Figure A-1. Schematic illustrating the various components considered in the thermal analyses for SuperLig ${ }^{\circledR}$ 644 resin beds and resin particles. The key temperature points are bed inlet and outlet, bed fluid, and particle centerline and surface.

Figure A-2. Total Cs loading curve and data for SuperLig ${ }^{\circledR} 644$ resin showing the maximum loading value used for estimating the expected max heat load for the bed. Data taken prior to 2001 (blue squares), data taken during 2001-2002 (red circles), solid curve the resin specification, and the dashed curve a conservative isotherm......

Figure A-3. Nusselt number correlation based on heat transfer data taken from packed beds of spheres at very low Reynolds numbers and valid for a wide range of fluids. Particle size range tested is 109-1022 $\mu \mathrm{m}$ where the Reynolds number is based on superficial velocity...... 
Figure A-4. Estimated temperature rise across a SuperLig ${ }^{\circledR} 644$ resin bed for a broad range of inlet feed flowrates and for a lead column fully saturated at the total cesium feed concentration of $5 \times 10^{-4}$ M. Results for DI water and $5 M \mathrm{Na}$ LAW feed solutions are shown......

Figure A-5. Estimated temperature rise across a SuperLig ${ }^{\circledR} 644$ resin bed for a broad range of inlet feed flowrates and for a lead column fully saturated at three different total cesium feed concentrations. Results for a 5 M Na LAW feed solutions are shown.

Figure A-6. Estimated temperature rise across a SuperLig ${ }^{\circledR} 644$ resin bed and across a 1,000 $\mu m$ sized resin particle for a broad range of inlet feed flowrates and for a lead column fully saturated at the total cesium feed concentration of $5 \times 10^{-4} \mathrm{M}$.

Figure A-7. Estimated temperature rise across a SuperLig ${ }^{\circledR} 644$ resin particle, loaded with a ${ }^{137}$ Cs heat source, as a function of particle size and degree of saturation. Temperature rise is defined as the difference from the particle centerline to the neighboring bed fluid. Results for a flowrate of 15 $L /$ min are shown.

Figure A-8. Estimated temperature rise across a SuperLig ${ }^{\circledR} 644$ resin particle, loaded with a ${ }^{137}$ Cs heat source, as a function of particle size and degree of saturation. Temperature rise is defined as the difference from the particle centerline to the neighboring bed fluid. Results for a flowrate of 30 L/min are shown.

Figure A-9. Estimated temperature rise across a SuperLig ${ }^{\otimes} 644$ resin particle, loaded with a ${ }^{137}$ Cs heat source, as a function of particle size and degree of saturation. Temperature rise is defined as the difference from the particle centerline to the neighboring bed fluid. Results for a flowrate of 65 L/min are shown.

Figure A-10. Estimated adiabatic temperature rise across the SuperLig ${ }^{\circledR} 644$ resin bed under conditions of a fully loaded (total Cs saturated) column where the feed total cesium concentration was set to $5 \times 10^{-}$ ${ }^{4} M$.

Figure B-1. Schematic diagram of proposed CXP column design provided by WGI personnel. ........................... 73

Figure B-2. Design details for the LAW feed ladder distributor and LAW outlet distributor. 


\section{TABLE OF NOTATION}

\begin{tabular}{|c|c|}
\hline 1-D & One-dimensional \\
\hline 3-D & Three-dimensional \\
\hline $\mathrm{BV}$ & Bed volume, $\mathrm{m}^{3}$ \\
\hline$c_{i}$ & Species i concentration, $\mathrm{M}$ \\
\hline $\mathrm{C}_{\mathrm{pf}}$ & Specific heat at constant pressure for inlet fluid, $\mathrm{J} / \mathrm{kg}-{ }^{\circ} \mathrm{C}$ \\
\hline CST & Crystalline silicotitanate \\
\hline$\overline{\mathrm{C}}_{\mathrm{T}}$ & Total ion-exchange capacity of resin, $\mathrm{M}$ \\
\hline$d_{\mathrm{p}}$ & Spherical equivalent diameter (SED) of particle, $\mathrm{m}$ \\
\hline$D_{\mathrm{p}}$ & Spherical particle diameter, $\mathrm{m}$ \\
\hline FACT & Flow And Contaminant Transport \\
\hline $\mathrm{G}_{0}$ & Superficial liquid mass flux, $\mathrm{kg} / \mathrm{m}^{2}-\mathrm{s}$ \\
\hline $\mathrm{G}_{\mathrm{gen}}$ & Specific heat generation rate for ${ }^{137} \mathrm{Cs}, 57.58 \mathrm{~W} /$ gmole \\
\hline$h_{f}$ & Particle film heat transfer coefficient for packed beds, $\mathrm{W} / \mathrm{m}^{2}-{ }^{\circ} \mathrm{C}$ \\
\hline IBC & Izatt-Bradshaw-Christensen Advanced Technologies, Inc. \\
\hline IX & Ion exchange \\
\hline $\mathrm{k}$ & Intrinsic permeability of porous media (resin), $\mathrm{cm}^{2}$ \\
\hline K & Hydraulic conductivity of porous media (resin), $\mathrm{cm} / \mathrm{s}$ \\
\hline $\mathrm{K}_{\mathrm{d}}$ & Distribution coefficient, $\mathrm{ml} / \mathrm{g}$ \\
\hline$\widetilde{\mathrm{K}}_{\mathrm{ji}}$ & Selectivity coefficient between species $\mathrm{j}$ and $\mathrm{i}$ \\
\hline $\mathrm{k}_{\mathrm{f}}$ & Thermal conductivity of the feed solution, $\mathrm{W} / \mathrm{m}-{ }^{\circ} \mathrm{C}$ \\
\hline $\mathrm{k}_{\mathrm{p}}$ & Composite thermal conductivity of particles, $\mathrm{W} / \mathrm{m}-{ }^{\circ} \mathrm{C}$ \\
\hline $\mathrm{k}_{\text {resin }}$ & Thermal conductivity of the solid resin, $\mathrm{W} / \mathrm{m}-{ }^{\circ} \mathrm{C}$ \\
\hline $\mathrm{L}$ & Column length, $\mathrm{m}$ \\
\hline LAW & Low Activity Waste \\
\hline $\mathrm{Nu}_{\mathrm{p}}$ & Particle Nusselt number \\
\hline $\mathrm{Pe}_{\mathrm{f}}$ & Fluid Prandlt number \\
\hline $\mathrm{Q}_{\mathrm{Cs}}$ & Total Cs surface solid-phase concentration, mmole/g \\
\hline $\mathrm{Q}_{\text {flow }}$ & Volumetric flowrate of inlet fluid, $\mathrm{m}^{3} / \mathrm{s}$ \\
\hline $\mathrm{q}_{\mathrm{gen}}^{\prime \prime \prime}$ & Average volumetric heat generation rate within bed, $\mathrm{W} / \mathrm{m}^{3}$ \\
\hline $\operatorname{Re}_{\mathrm{p}}$ & Particle superficial Reynolds number \\
\hline RPP & River Protection Program \\
\hline SL-639 & SuperLig $^{\circledR} 639$ resin \\
\hline SL-644 & SuperLig $^{\circledR} 644$ resin \\
\hline
\end{tabular}




$\begin{array}{ll}\text { SRTC } & \text { Savannah River Technology Center } \\ \mathrm{t} & \text { Time reference from the start of the adiabatic condition, } \mathrm{s} \\ \mathrm{TFL} & \text { Thermal Fluids Lab } \\ \mathrm{T}_{\text {bed }} & \text { Bed fluid temperature at specified axial location, }{ }^{\circ} \mathrm{C} \\ \hat{\mathrm{T}}_{\text {bed }} & \text { Average bed fluid temperature, }{ }^{\circ} \mathrm{C} \\ \mathrm{T}_{\mathrm{c}} & \text { Centerline temperature of particle, }{ }^{\circ} \mathrm{C} \\ \mathrm{T}_{\text {in }} & \text { Inlet temperature to resin bed, }{ }^{\circ} \mathrm{C} \\ \mathrm{T}_{\text {out }} & \text { Exit temperature from resin bed, }{ }^{\circ} \mathrm{C} \\ \mathrm{T}_{\mathrm{s}} & \text { Surface temperature of particle, }{ }^{\circ} \mathrm{C} \\ \mathrm{U} & \text { Superficial velocity within packed bed, } \mathrm{m} / \mathrm{s} \\ \mathrm{V}_{\text {bed }} & \text { Total volume of bed (including porosity), } \mathrm{m}^{3} \\ \text { VERSE-LC } & \text { VErsatile Reaction-SEperation model for Liquid Chromatography } \\ \text { WGI } & \text { Washington Group International } \\ \text { WSRC } & \text { Westinghouse Savannah River Company } \\ \text { WTP } & \text { Waste Treatment Plant }\end{array}$

\section{Greek}

$\beta$

$\Delta \mathrm{p}$

$\Delta \mathrm{T}_{\text {bed }}$

$\Delta \mathrm{T}_{\text {cond }}$

$\Delta \mathrm{T}_{\text {film }}$

$\Delta \mathrm{T}_{\text {part }}$

$\varepsilon_{\mathrm{b}}$

$\varepsilon_{\mathrm{p}}$

$\eta_{137}$

$\mu$

$\rho$

$\rho_{\text {bed }}$

$\rho_{\mathrm{f}}$

$\rho \mathrm{C}_{\mathrm{v}}$

$\rho \mathrm{C}_{\mathrm{vf}}$

$\rho C_{\text {Vpart }}$
Isotherm parameter

Piezometric pressure drop, $\mathrm{N} / \mathrm{m}^{2}$

Temperature rise across entire resin bed, ${ }^{\circ} \mathrm{C}$

Temperature rise through particle due to thermal conduction, ${ }^{\circ} \mathrm{C}$

Temperature rise across stagnant film surrounding particle, ${ }^{\circ} \mathrm{C}$

Temperature rise across particle at specified axial location, ${ }^{\circ} \mathrm{C}$

Bed porosity assumed to be uniform throughout the bed

Particle porosity assumed to be uniform within particles

Isotopic fraction of ${ }^{137} \mathrm{Cs}$ to total $\mathrm{Cs}$

Fluid viscosity, $\mathrm{cP}$

Fluid density, $\mathrm{g} / \mathrm{ml}$

Bed density of lead column, $\mathrm{g} / \mathrm{ml}$ (dry resin mass per bed volume)

Density of inlet fluid, $\mathrm{g} / \mathrm{ml}$

Composite heat capacity of the entire bed (fluid plus resin materials), $\mathrm{J} / \mathrm{m}^{3}-{ }^{\circ} \mathrm{C}$

Heat capacity of the inlet feed solution, $\mathrm{J} / \mathrm{m}^{3}-{ }^{\circ} \mathrm{C}$

Heat capacity of the entire particle (fluid plus resin materials), $\mathrm{J} / \mathrm{m}^{3}-{ }^{\circ} \mathrm{C}$ 
$\rho \mathrm{C}_{\mathrm{Vresin}} \quad$ Heat capacity of the solid resin, $\mathrm{J} / \mathrm{m}^{3}-{ }^{\circ} \mathrm{C}$ 


\subsection{Executive Summary}

Historically, it has been assumed that the inlet and outlet LAW plenums would be designed such that a nearly uniform (i.e., axial only) velocity profile would be maintained at every axial crosssection (i.e., providing nearly $100 \%$ utilization of the resin bed). A more recent conceptual design of the WTP IX column is shown in Figure 1-1. The blue structure in the figure represents the LAW outlet distributor. The red structures are the flush liquid inlet and the spent resin outlet. When looking at this proposed design, we see a LAW outlet distributor that results in significant non-axial velocity gradients in the bottom regions of the bed with the potential to reduce the "effectiveness" of the overall resin bed. The magnitude of this efficiency reduction depends upon how far up-gradient of the LAW outlet these non-axial velocities persist and to what extent a "dead-zone" is established beneath the LAW outlet. This can impact loading and elution performance of the ion-exchange facility. Currently, no experimental studies are planned.

\subsection{Objectives}

The details associated with this task are identified within the technical and quality assurance plan for the ion exchange computer model upgrades (Hamm et al., 2002), performed in support of the River Protection Program Waste Treatment Plant ion exchange process. The scope of this task is provided in the Test Specification 24590-PTF-TSP-RT-01-004, Rev 0 (Toth, 2002a). The primary objective of this work was, through modeling, to assess the fluid dynamic impact on "effective" resin volume of the full-scale column based on its normal operation using a recently proposed LAW outlet distributor. The analysis effort was limited to 3-D flow only analyses (i.e., no follow on transport analyses) with 3-D particle tracking to approximate the impact that a nonaxial velocity profile would have on bed "effectiveness". Based on direction provided by WGI personnel, additional analyses were performed to estimate under nominal operating conditions the thermal temperature rise across a loaded resin bed and within its particles. Hydrogen bubble formation is not considered in the heat transfer analysis or in the determination of minimum flowrate. All modeling objectives were met.

\subsection{Conduct of Modeling}

The porous media Flow And $\underline{\text { Contaminant }}$ Transport code (i.e., acronym FACT) (Hamm and Aleman, 2000) was chosen to perform these assessments. Version 2 of FACT was used where for verification purposes several test cases (i.e., see certification package for FACT Version 2 by Aleman, 1999) where checked to ensure its implementation on the stated PC plateform. Further verification was made by running a "Basecase" model whose overall geometry was very similar to the proposed column design (i.e., including only the LAW outlet distributor hardware). This basecase represents a 4-four symmetry within the velocity field that was confirmed during postprocessing, along with several other key variables of interest in the actual case runs. Bounded hydraulic permeabilities, based on measured pilot-scale test results, were used in the simulations. 


\subsection{Simulation Results}

The previous and current approach to WTP IX column transport modeling and experimentation is based on one-dimensional axial flow (plug flow) through each column bed (i.e., 100\% utilization of the resin bed). To approach 1-D axial flow through the resin bed requires that the diameter of the column be significantly larger than the mean particle diameter of the resin along with ideal feed inlet and outlet flow distributors. The proposed LAW outlet flow distributor design, as shown in Figure 1-1, results in a non-axial velocity profile in the vicinity of the LAW outlet distributor. 3-D Darcy flow analyses based on pilot-scale measured and bounded resin permeabilities were performed using the 3-D variably saturated porous media code named FACT (Hamm and Aleman, 2000). The degree and extent of non-axial flow was quantified by computing the magnitude of the horizontal velocity as a function of axial elevation and by normalizing this with respect to the inlet superficial velocity. Particle tracking (streamtraces) computed from the 3-D flow analyses were used to assess and provide guidance on the impact to bed effectiveness. The travel time (or residence time) along each unique 3-D streamtrace provides some measure as to the effectiveness of the resin bed in its lower regions. The major accomplishments and conclusions are:

- The normalized magnitude of the horizontal velocity field as a function of elevation is an acceptable indicator of non-plug flow conditions (i.e., normalization was performed using the magnitude of the inlet liquid superficial velocity). Figure 1-2 is a plot of the average and maximum normalized magnitude of the horizontal velocity as a function of resin bed elevation. The LAW outlet distributor is located at a resin bed elevation of 16 ". The other obstructions are labeled as well in the plot. In semilog scale, the results shown in Figure 1-2 are re-plotted in Figure 1-3. The average of the normalized magnitude of the horizontal velocity is greater than $10 \%$ of the inlet superficial velocity within 4 inches of the LAW outlet distributor. The maximum value is greater than $10 \%$ of the inlet superficial velocity 12 inches below and 8 inches above the LAW outlet distributor (see Figure 1-3).

- As shown in Figure 1-2, the presence of internal structures (i.e., obstacles) within the resin bed also distorts the local velocity profile away from an ideal plug flow situation. Their impact is substantially less than the impact of outflow boundaries (i.e., the $1 / 2$ " holes in the LAW outlet piping). These results are independent of resin type or inlet flowrate.

- The travel time (or residence time) of feed within the resin bed is an important measure of resin bed utilization. 3-D streamtraces were generated starting from points distributed at the inlet of the resin bed. Forward particle tracking continued until their termination points were reached either at the $1 / 2$ " holes of the 1 " LAW collection pipes or at an obstruction. The arc length and travel time (residence time) of each streamtrace was also computed and then compared to an ideal resin bed operating under similar, but plug flow, conditions.

- Under ideal conditions, IX columns are designed to operate under plug flow conditions where the inlet and outlet feed distributors are located outside the resin bed. The proposed design of the WTP IX column has the LAW outlet distributor embedded within the resin bed at the bottom of the cylindrical section of the vessel, as shown in Figure 1-1 and redrawn in Figure 1-4. The position of the LAW outlet distributor is 16 inches above the oblate hemispherical bottom (i.e., $23 \%$ of the resin bed resides beneath the outlet distributor), that 
potentially (i.e., due to "dead-zones") reduces the effective length of the resin bed from 55 inches to some value approaching 39 inches. The streamtraces shown in Figure 1-4 demonstrate that the upper portion of the bed (i.e., $\sim 30$ inches) is operating in nearly a plug flow state, while the lower portion of the bed (i.e., $\sim 10$ inches) is operating more like a "dead-zone". The recommendation based on this model is to remove the outlet distributor from the resin bed and place it below the resin bed.

During the loading step of lead columns packed with SuperLig ${ }^{\circledR} 644$ resin, ${ }^{\text {total }} \mathrm{Cs}$ is loaded onto ion-exchange sites distributed throughout the resin particles. The deposited ${ }^{137} \mathrm{Cs}$ produces a thermal heat load on the bed and the individual resin particles. The potential for non-isothermal column operation exists and thermal analyses provided within this report were performed to help establish inlet conditions that result in near isothermal column operation. The following conclusions are based on the thermal analyses of SuperLig ${ }^{\circledR} 644$ resin beds, as presented in Appendix A:

- For Envelope B LAW feeds, a limited operating range on flowrate may exist due to potentially unacceptable temperature rise across the bed and within the particles for flowrates less than $\sim 0.6 \mathrm{BV} / \mathrm{hr}$. For flowrates greater than $0.6 \mathrm{BV} / \mathrm{hr}$ temperature increases above the inlet value are estimated to be within $\sim 3{ }^{\circ} \mathrm{C}$. Higher temperatures reduce SuperLig ${ }^{\circledR} 644$ resin capacity since the $\mathrm{Cs}^{+}$to $\mathrm{Na}^{+}$ion-exchange reaction is exothermic.

- For Envelope A and C LAW feeds, where inlet cesium concentrations are close to an order of magnitude less than for Envelope B feeds, no practical flowrate limitation exists.

- An $\sim 2{ }^{\circ} \mathrm{C} / \mathrm{hr}$ upper bound estimate for adiabatic heatup of the resin bed was conservatively computed. Potential heat losses through the vessel walls and through the top and bottom surfaces of the resin bed were conservatively neglected.

- During normal column operation, feed flowrates are high enough such that isothermal column operation can be assumed.

\subsection{Quality Requirements}

This work was conducted in accordance with the RPP-WTP QA requirements specified for work conducted by SRTC as identified in DOE IWO MOSRLE60. SRTC has provided matrices to WTP demonstrating compliance of the SRTC QA program with the requirements specified by WTP. Specific information regarding the compliance of the SRTC QA program with RW0333P, Revision 10, NQA-1 1989, Part 1, Basic and Supplementary Requirements and NQA-2a 1990, Subpart 2.7 is contained in these matrices. This Task was conducted under the Task Plan for the ion exchange computer model upgrades (Hamm et al., 2002). The software used was FACT, Version 2 (see certification package by Aleman, 1999). The results of this work are not to be used directly in the design, analysis or operation of the components in the WTP. The testing and model do not comply with Q-03.2 of the Quality Assurance Manual. This additional compliance is outside the scope of the task. 


\subsection{Issues}

In the process of performing this work, three issues were observed. Briefly stated, they are:

- The currently proposed WTP IX column design places the LAW outlet distributor such that $\sim 23 \%$ of the resin bed resides beneath it in the resin's fully swollen state. This can potentially create a "dead-zone" of resin beneath the distributor. 3-D flow analyses indicate that this dead-zone may be as large as $\sim 19 \%$ of the resin bed. The transport of contaminants (e.g., $\mathrm{Cs}^{+}$and $\mathrm{TcO}_{4}{ }^{-}$) into and out of this dead-zone (i.e., during the loading and elution steps, respectively) is limited to transverse dispersion and molecular diffusion. Both of these mass transfer mechanisms are inefficient. For example, under elution conditions elongated elution profiles (i.e., tails) may result. Remaining with this design would warrant further studies.

- Due to the high levels of inlet cesium concentrations contained within the Envelope B LAW feeds, the currently proposed low processing flowrates for Envelope B feeds need to be carefully reconsidered. It is recommended that design constraints on temperature rise under normal operating conditions be clearly established.

- The dead zone in the column below the distributor may not fully elute each cycle, causing a buildup of Cs over time. This stagnant area would also have poor heat transfer, creating the potential for hot spots. If elution of this region is incomplete each cycle, spent resin may not meet disposal limits.

No other issues were observed. 


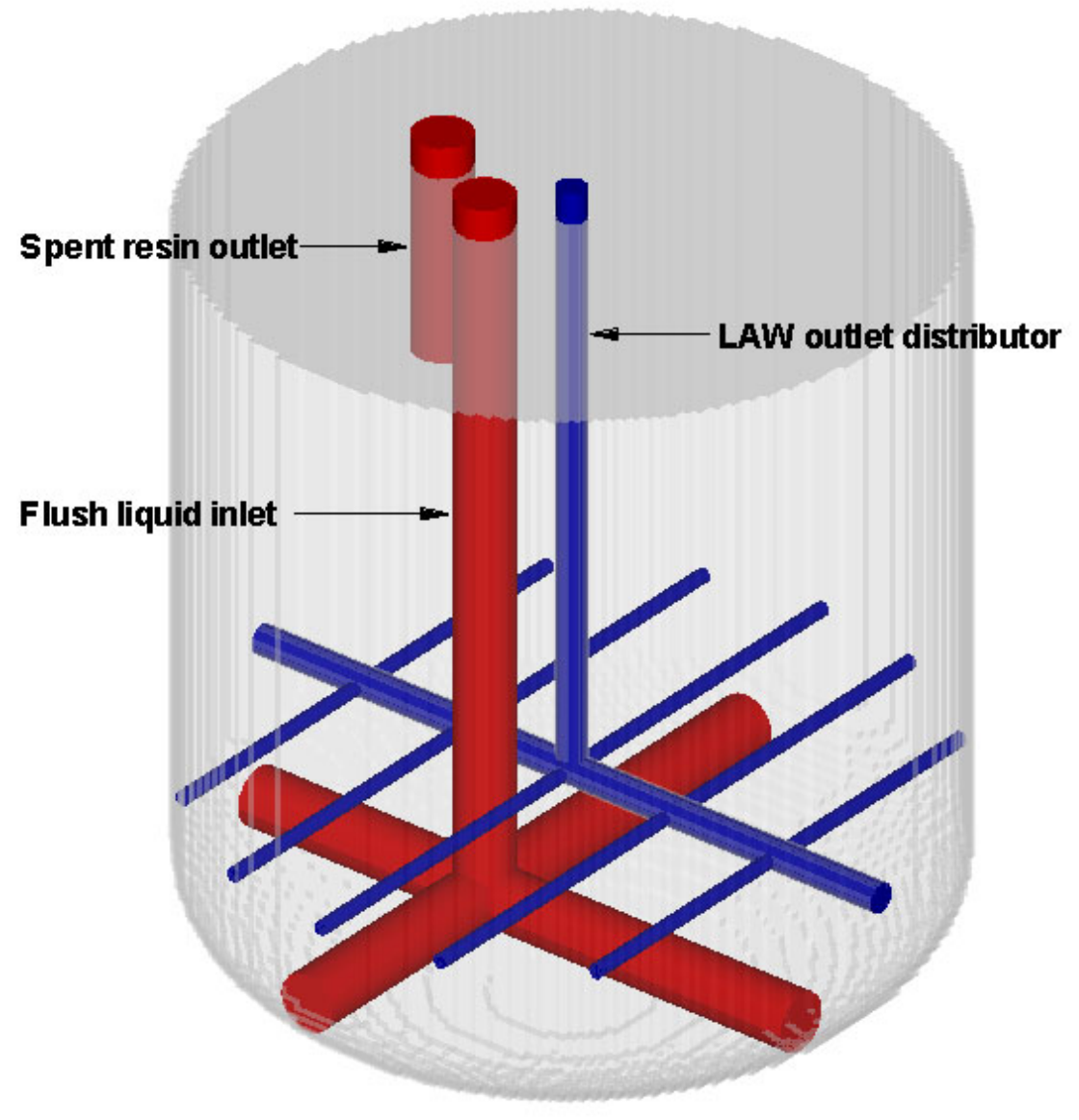

Figure 1-1. The conceptual design of the proposed WTP IX column showing internal hardware. The LAW outlet distributor is shown in blue. The flush liquid inlet and spent resin outlet are shown in red. The inner wall of the vessel shell is highlighted in transparent green, where the components above the top of the resin bed are not being shown. 


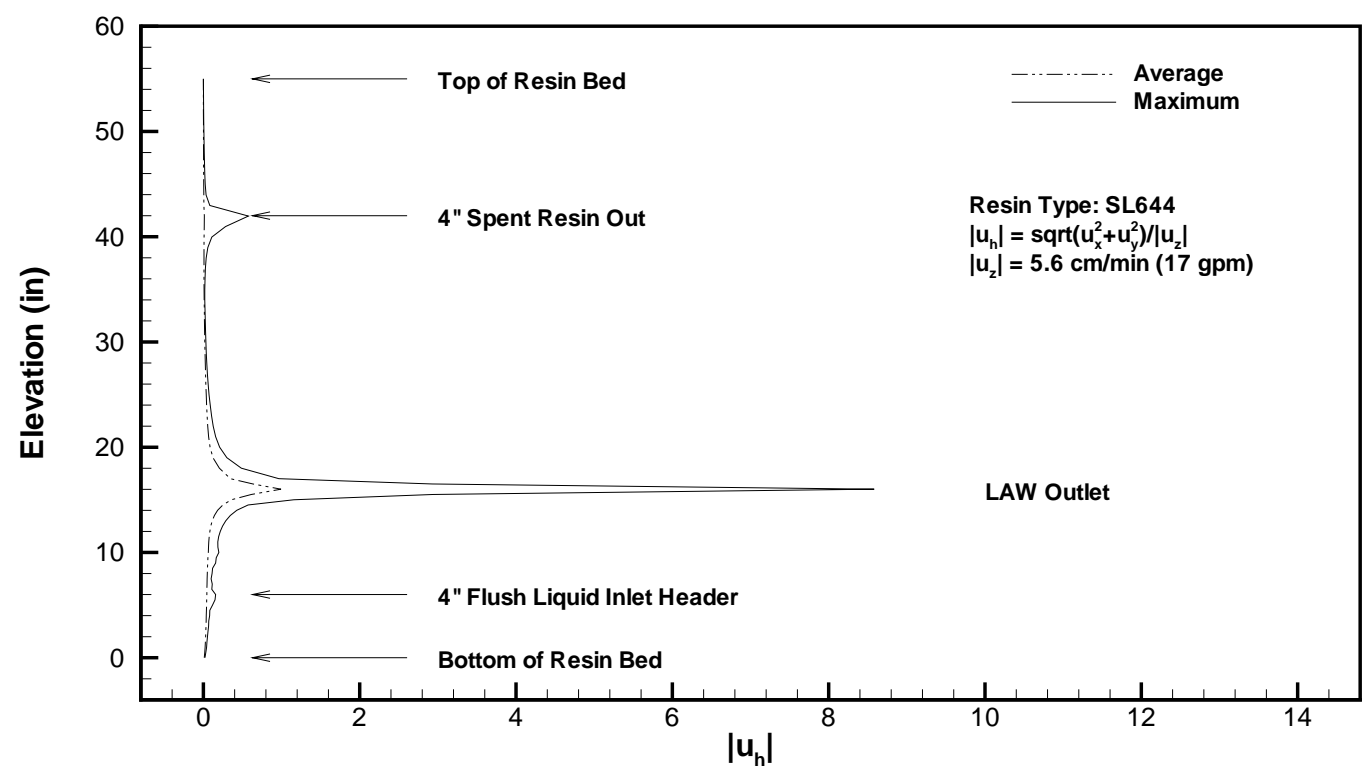

Figure 1-2. Normalized magnitude of the horizontal velocity as a function of resin bed elevation. The level of disturbance due to internal structural components and outflow boundaries is seen as peaks in local horizontal velocity.

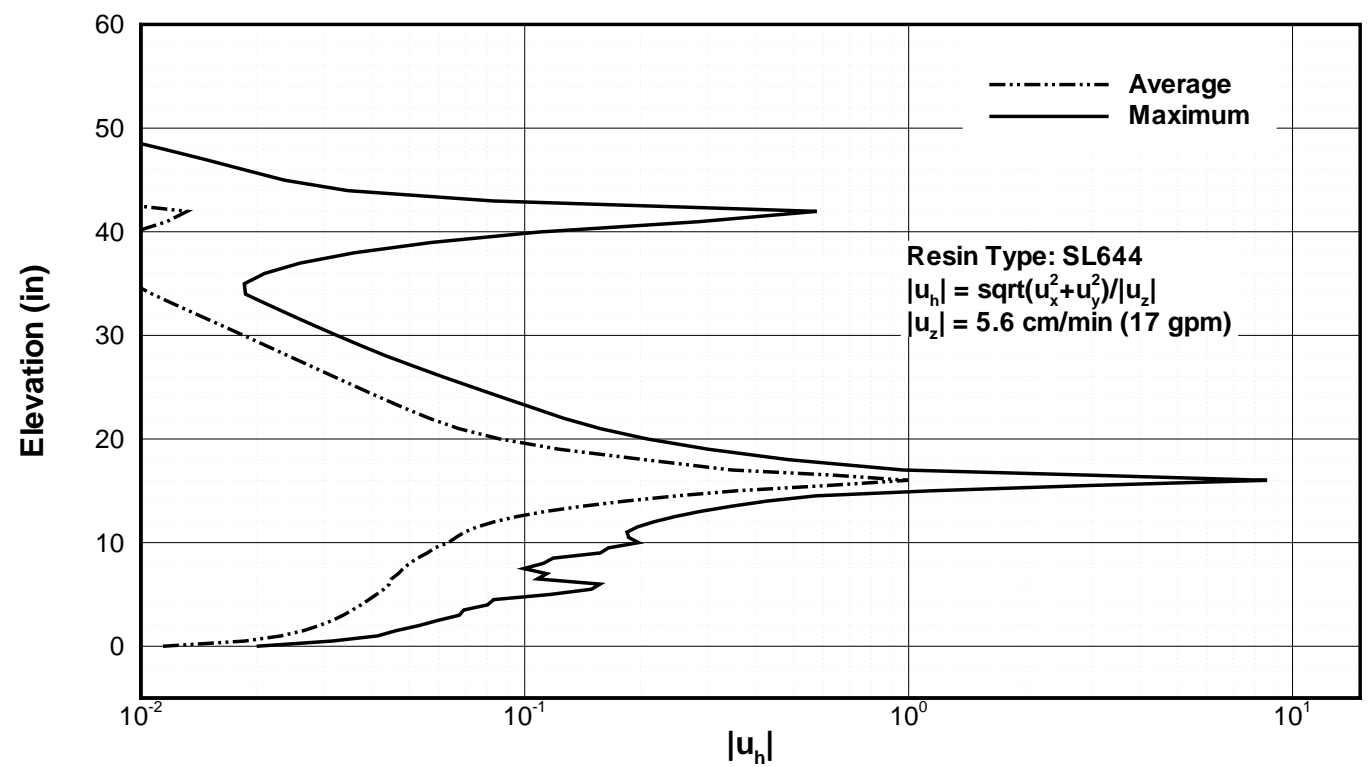

Figure 1-3. The normalized magnitude of the horizontal velocity as a function of resin bed elevation using a semilog scale. Axial average and maximum values are plotted illustrating how local the disturbances are within a horizontal plane. 


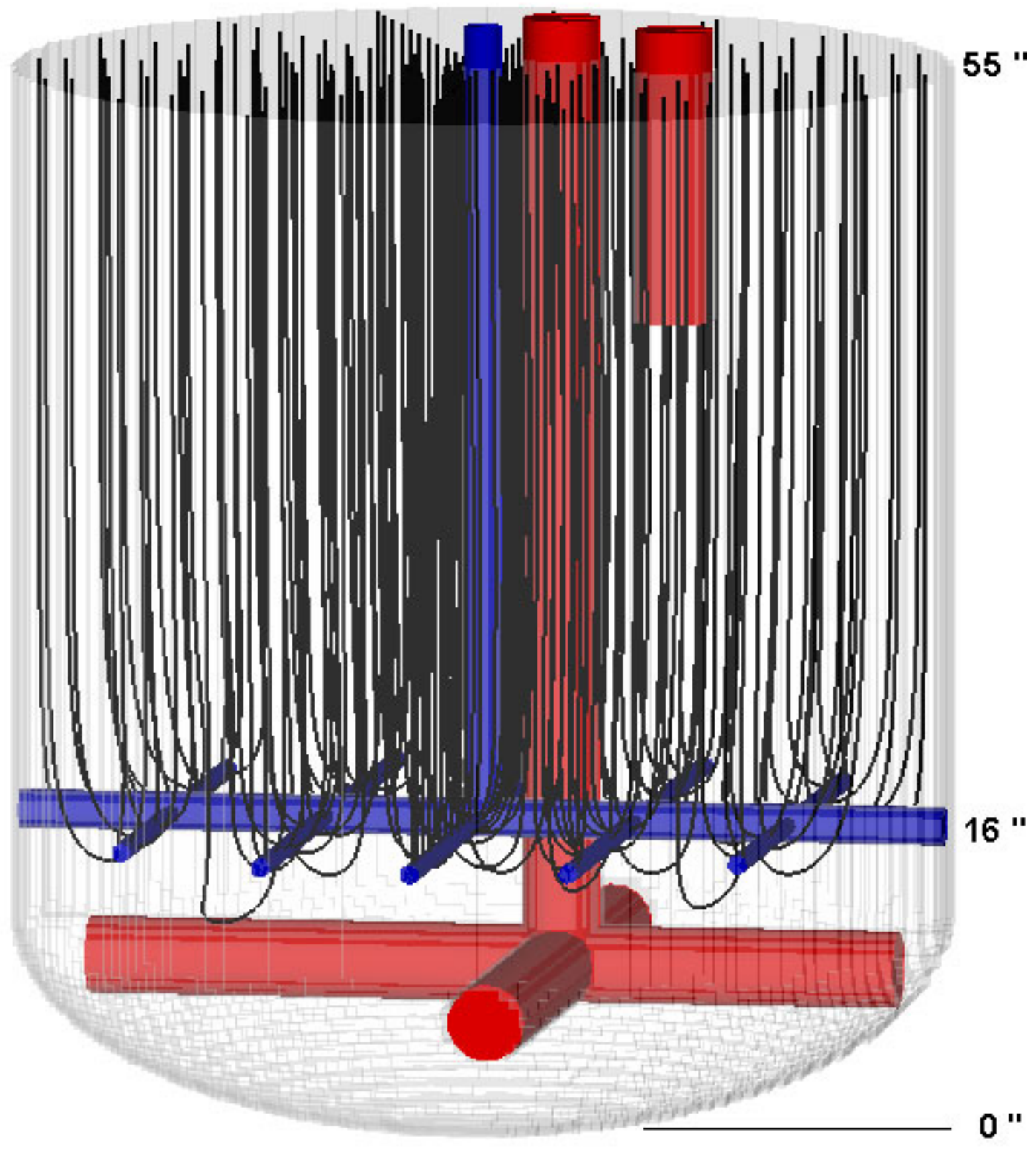

Figure 1-4. 3-D streamtraces for a bed packed with SuperLig ${ }^{\circledR} 644$ resin. The inlet liquid feed flow is $17 \mathrm{gpm}(2.6 \mathrm{BV} / \mathrm{hr}$ or $5.6 \mathrm{~cm} / \mathrm{min}$ superficial velocity). The LAW outlet distributor is shown in blue. The flush liquid inlet and spent resin outlet are shown in red. The inner wall of the vessel shell is highlighted in transparent green. The 3-D streamtraces are shown (black) starting at the top of the resin bed. 


\subsection{Introduction and Background}

The primary IX modeling tool, VERSE-LC (Berninger et al., 1991; Whitley and Wang, 1998) applies to 1-dimensional (1-D) flow in uniformly packed columns. Previous column transport modeling, as well as the column transport modeling currently planned, is based on onedimensional axial flow through each column bed. To approach 1-D axial flow through a resin bed requires that the diameter of the columns be significantly larger than the mean particle diameter of the resin along with ideal feed inlet and outlet distributors. A proposed LAW outlet distributor design (Figure 2-1) results in a non-axial velocity profile in the vicinity of the LAW outlet distributor [The original transmitted drawing (Toth, 2002b) of the LAW outlet (see Figure B-2 in Appendix B) shows a dimension of 36 inches wide. Murray Thorson of Washington Group International in a personal communication said that the LAW outlet should coincide with the diameter of the current column design of 48 inches.]

In the past it had been assumed that the inlet and outlet feed distributors would be designed such that a uniform (i.e., axial only) velocity profile would be maintained at every axial cross-section. Based on this the VERSE-LC code was chosen as the main column transport model for column performance analyses. However, when looking at this recently proposed design (i.e., Figures B1 and B-2 of Appendix B) we see an outlet distributor embedded in the resin bed that results in potentially significant non-axial velocity gradients in the bottom regions of the bed. There is potential to reduce the effectiveness of the overall resin bed. The magnitude of this efficiency reduction will depend upon how far up-gradient of the outlet these non-axial velocities persist and the degree of dead-zone existing beneath the outlet. A non-axial flow field within the resin bed has the potential to reduce the loading capacity of the lead column during the carousel operation (i.e., carousel to occur once the cesium exit concentration is reached). In addition, the number of elution volumes required to adequately refresh a loaded lead column could potentially increase significantly.

To address these concerns, 3-D Darcy flow analyses based on pilot-scale measured and bounded resin permeabilities (Steimke, 2002) were performed using the 3-D variably saturated porous media code named FACT (Hamm and Aleman, 2000). The degree and extent of non-axial flow was quantified by computing the magnitude of the horizontal velocity at each axial elevation and normalizing it with respect to the inlet superficial velocity. Particle tracking (streamtraces) computed from the 3-D flow only analyses were used to assess and provide guidance on the impact on bed effectiveness. The travel time or residence time along each unique 3-D streamtrace provides some measure as to the effectiveness of the resin bed in its lower regions. Particle tracking does not account for longitudinal and transverse dispersion nor particle adsorption, 3-D transport analyses would be required to account for these mass transfer mechanisms.

To fully assess the impact that the 1-inch screened outlet distributor will have on bed performance under loading and elution conditions, 3-D flow and transport analyses are required. In this modeling task we are performing 3-D flow analyses only (i.e., 3-D Darcy flow based on a saturated porous media model) of the resin bed domain to assess the hydraulic impact. Given the 
results from this effort, we may then want to perform subsequent 3-D transport runs if necessary, but these 3-D transport activities would require an upgrade of FACT to incorporate several of the features currently being employed during VERSE-LC transport modeling.

The groundwater code FACT (Hamm and Aleman, 2000) was used to perform these flow assessments. If the 3-D flow analyses indicate that significant impact is likely, subsequent 3-D transport analyses can be performed using the FACT code (note that only 3-D flow analyses pertain to this activity and reported within this document).

The basic hydraulic data (i.e., intrinsic permeabilities) for both the SuperLig ${ }^{\circledR} 639$ and SuperLig ${ }^{\circledR} 644$ resins that are required to perform these simulations are available based on earlier TFL pilot-scale hydraulic testing. Based on this data a fixed hydraulic permeability for SuperLig $^{\circledR} 639$ is acceptable. The hydraulic permeability of SuperLig ${ }^{\circledR} 644$ appears to be strongly ionic strength dependent (i.e., due in part to its swelling/shrinking characteristics) and may also be history dependent due to dynamic compaction effects associated with osmotic and mechanical stresses). For these scoping analyses we limit our assessment to the ionic strength effect only. For both resin types we further assumed that the columns are uniformly packed, with randomly oriented particles, such that the intrinsic permeabilities can be assumed to be spatially and directionally invariant (i.e., the second order permeability tensor can be approximated by a single scalar permeability value). Based on thermal analyses presented within Appendix A, it is also assumed that the bed temperature is nearly isothermal. Given these assumptions, single (i.e., scalar) hydraulic conductivity values for each bed can be computed and used.

The results from these flow analyses will provide insights into how prototypic the 1-D columns are versus the proposed facility. These analyses also provide designers/researchers with information that can help determine if the proposed design is acceptable and if so what changes, if any, would be advisable for testing.

For SuperLig ${ }^{\circledR} 644$ resin beds it has been experimentally observed that significant swelling/shrinking can occur due to ion-strength changes within the fluid (e.g., as high as $150 \%$ volume change has been measured for one batch when converting from the H-form to the Naform of this resin). Generally, the degree of swelling and shrinking of a resin bed is important for design, especially for locating distributors used to disperse incoming feed and collection of outgoing fluid. Once placed, these distributors are typically not adjustable. Design guidance provided by Ruthven (1997, see "Ion Exchange" chapter by Charles Dickert) suggests that the upper distributor should be above (the lower one below) the resin bed, even in the bed's most swollen form.

\subsection{FACT Code Description}

The FACT code can perform three-dimensional finite element simulations of water flow and solute (contaminant) transport in variably saturated and fully saturated porous media. The code employs state-of-the-art numerical technology to provide efficient steady-state and transient solutions of practical problems encountered in the assessment, mitigation, and remediation of soil and groundwater contamination due to the disposal or accidental releases of chemicals 
and/or nuclear wastes. Due to the level of implicitness employed in solving these equations, steady-state analyses can be performed by disregarding all storage terms of the governing equations, thus avoiding the necessity of time marching. Transient analyses are performed by marching in time until the prescribed number of time steps is reached. For water flow simulations, FACT can handle a variety of boundary conditions including well pumping or injection, groundwater recharge, leakage from seepage faces, homogeneous/heterogeneous aquifer and aquitard units, and a variety of source bed types. For solute transport simulations, FACT accounts for advection, hydrodynamic dispersion, equilibrium linear adsorption, mobile/immobile first-order mass transfer, first-order reaction rates and radioactive decay. Single component transport of conservative and non-conservative solutes can be treated.

FACT employs a right-handed Cartesian coordinate system $(\mathrm{x}, \mathrm{y}, \mathrm{z})$ to generate a threedimensional rectangular grid for finite element analysis. The grid is oriented such that the $\mathrm{z}$-axis points in the vertical upward direction. In the areal extent the grid is orthogonal, while in the vertical direction distorted elements are handled. Based upon the formulation chosen and accuracy considerations, the level of vertical elemental distortion from a rectangular shape should be kept to a minimum. As a general rule of thumb, the majority of elements within the domain should maintain their vertical angles within the range $90^{\circ} \pm 10^{\circ}$. In the majority of practical situations, this limitation on mesh distortion will not be reached.

The certification package for FACT Version 2.0 was written in November 1999 (Aleman, 1999). The purpose of that report was to document the implementation of the software management requirements and responsibilities provided in (1) Procedure QAP 20-1 Rev. 5 "Software Quality Assurance", Procedure L1 8.20 Rev. 0 and to also reference associated reports pertinent to the needs of the E7 manual. FACT Version 2.0 was used for all of the analyses presented within this report. The FACT runs were executed on a PC with dual Intel Xeon $1.7 \mathrm{GHz}$ processors running Windows 2000. The verification and validation $(\mathrm{V} \& \mathrm{~V})$ cases documented in the FACT user's manual (Hamm and Aleman, 2000) were executed to ensure proper installation and functionality of FACT.

The FACT code has been used extensively at the Savannah River Site for groundwater resource evaluation, assessment of well performance and pumping test analysis, groundwater contaminant investigations, hazardous waste subsurface disposal and regional aquifer studies. Version 2.1 of the FACT code is being incorporated into the Department of Defense (DOD) Groundwater Modeling System (GMS) in Release 4.

\subsection{Modeling Assumptions}

In order to hydraulically model the proposed column design, several modeling assumptions were made. The key modeling assumptions chosen are:

- The hydraulic head is constant at the top of the resin bed. There is sufficient head-space between the feed distributor and the top of the resin bed, such that a nearly uniform pressure will exist just above the resin bed 
- Steady-state Darcy flow in a saturated isothermal porous media formulation. Figure 2-2 is a plot of dimensionless pressure drop across a bed versus Reynolds number for TFL and IBC SuperLig ${ }^{\circledR} 639$ data. The solid line represents the standard Ergun equation for packed columns (see Bird et al., 1960). The experimental data is below a Reynolds number of 10 (the Blake-Kozeny portion of the Ergun equation, see Figure 6.4-1 in Bird et al., 1960) and indicates laminar (or Darcian) flow through the packed column.

- The near-field velocities in the vicinity of the $1 / 2$ " holes in the LAW outlet distributor may violate the Darcian flow assumption. The existence of non-Darcian flow near point sinks and sources is typically ignored in the groundwater modeling community. This is generally a good approximation for the flow field throughout the bed, excluding the regions very close to the outlet holes.

- Uniform and constant hydraulic conductivity throughout the resin bed domain (i.e., isotropic resin permeability and isothermal fluid properties).

- Bed porosity values are set to current best estimate values, where the columns are assumed to be uniformly packed.

- Bed densities based on current best estimate values.

- The LAW outlet distributor is modeled as a series of point sinks with uniform sink strength. The resin porous media and the LAW outlet distributor manifold are not explicitly coupled to allow a pressure and flow variation within the manifold. There is no form loss across the collection pipe holes in this formulation.

\subsection{Data Needs}

To perform the flow analyses the following input data needs were required:

- Current geometric shape of the column vessel and important internal structures. The geometric data were provided by WGI personnel and are reproduced in Appendix B.

- The expected total amount of resin to be contained within the operating column. WGI personnel indicated that the bed height should be set to $\sim 55$ inches which corresponds to a bed volume of 400.7 gallons for the SuperLig ${ }^{\circledR} 639$ run and 392.5 gallons for the SuperLig ${ }^{\circledR}$ 644 runs within the FACT model developed.

- SRTC/TFL hydraulic test data on pilot-scale SuperLig ${ }^{\circledR} 639$ and SuperLig ${ }^{\circledR} 644$ packed columns. The permeability of the SuperLig ${ }^{\circledR} 639$ resin and fluid properties are documented by Steimke et al. (2000) for the AN-105 LAW simulant. The bounding values of SuperLig ${ }^{\circledR}$ 644 resin permeabilities from the TFL tests are provided by Steimke et al. (2002) and are plotted in Figure 2-3. WGI personnel set the lower and upper bounds shown in Figure 2-3. 


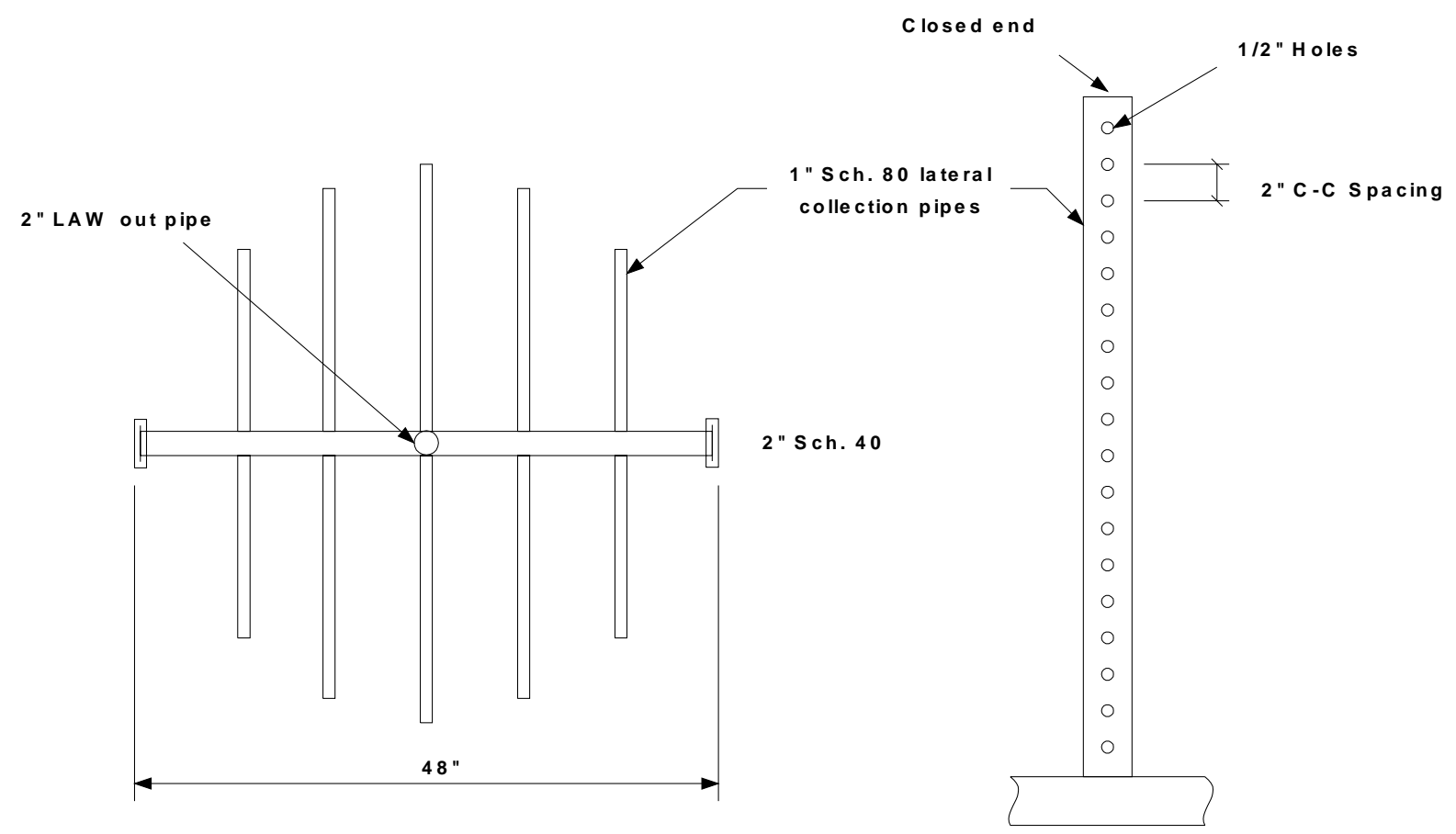

Figure 2-1. Proposed design for the LAW Outlet Distributor.

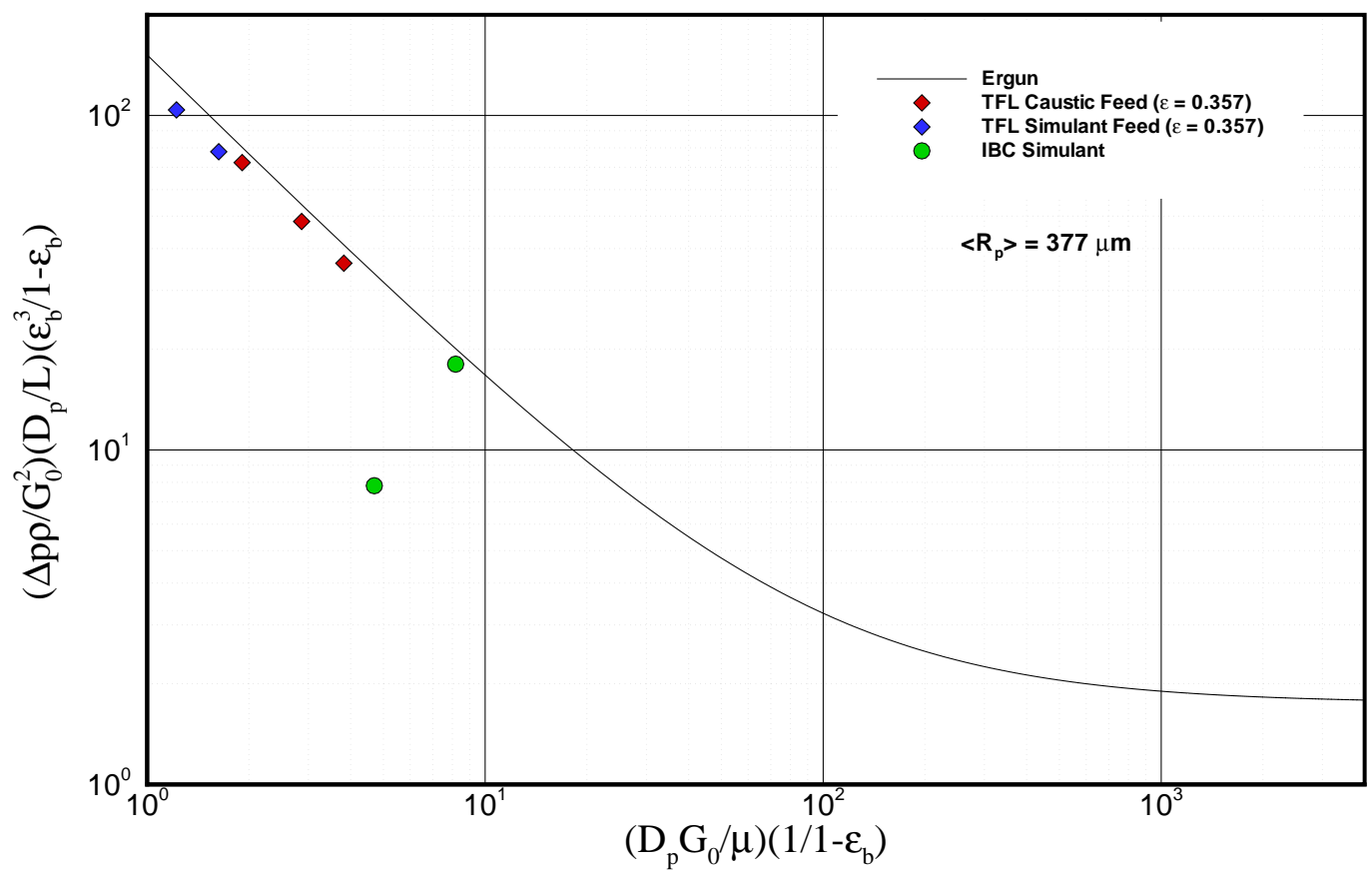

Figure 2-2. Comparison of the standard Ergun equation to available SuperLig ${ }^{\circledR} 639$ hydraulic data for lab-scale and pilot-scale columns. 


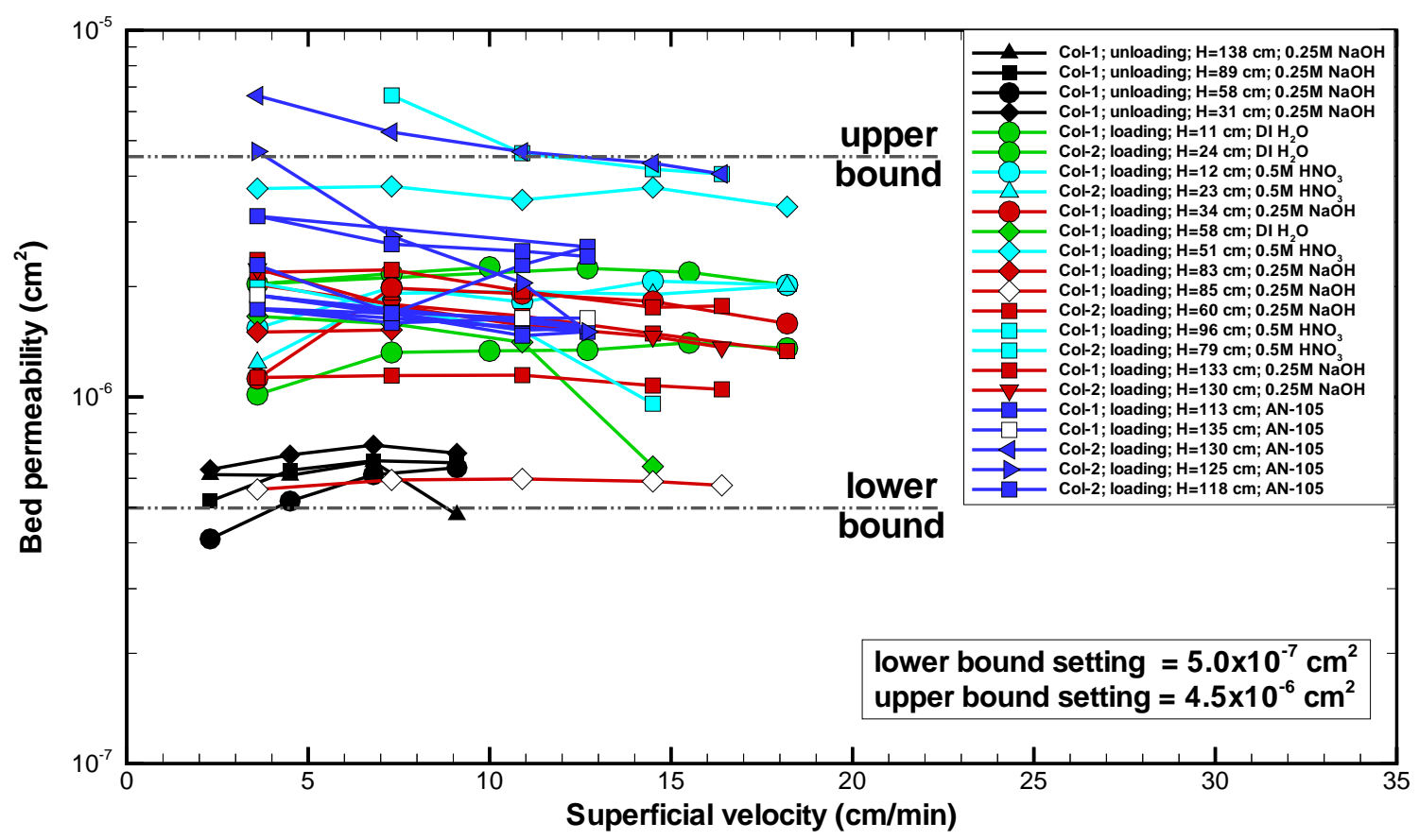

Figure 2-3. $\quad$ SuperLig $^{\circledR} 644$ bed permeability under nearly steady-state conditions for a variety of fluid compositions and bed heights recently measured by Steimke (2002) at 20$25^{\circ} \mathrm{C}$. Due to bed compaction, resulting primarily from osmotic feed changes, a broad range of bed permeabilities were observed. Over night soaking of beds prior to testing minimized dynamic compaction effects. 


\subsection{3-Dimensional Flow Model of WTP IX Column}

The construction of the FACT finite element flow model of the WTP IX column involves several steps that are automated by the FACT preprocessor PreFACT. The PreFACT preprocessor executes a series of UNIX Makefiles that execute Fortran and C programs that build the 12 groups of a FACT input deck.

Four different scenarios characterize the performance of the WTP IX column and are listed in Table 3-1. For SuperLig ${ }^{\circledR} 639$ columns a single case (Basecase) was considered. For SuperLig ${ }^{\circledR}$ 644 columns three case runs were considered. Here, due to the large variations in permeabilities observed in the pilot-scale facility, upper (Run-2) and lower (Run-3) permeability values were considered under loading conditions. The impact of fluid properties was addressed by the third case (Run-1) where properties under elution conditions were used.

The main input groups include mesh specification, material properties, and boundary conditions. The following sections describe in detail each group of the FACT input decks for the four cases described above.

\subsection{Problem Description (Group 1)}

\section{- Basecase}

TXP IX Column, 4 foot Diameter, SL-639

Run 1: Viscosity $=2.94 \mathrm{cp}$ (Simulant), density $=1.225 \mathrm{~g} / \mathrm{ml}$, permeability $=5.2 \mathrm{e}-6 \mathrm{~cm} 2$ (TFL Simulant Feed)

- Run-1

CXP IX Column, 4 foot Diameter, SL-644

Run 1: Viscosity $=1 . \mathrm{cp}(0.5 \mathrm{M}$ HNO3), density $=1.017 \mathrm{~g} / \mathrm{ml}$, permeability $=4.5 \mathrm{e}-6 \mathrm{~cm} 2$ (elution with low packing)

- Run-2

CXP IX Column, 4 foot Diameter, SL-644

Run 2: Viscosity $=3.06 \mathrm{cp}(\mathrm{AZ}-102)$, density $=1.227 \mathrm{~g} / \mathrm{ml}$, permeability $=5.0 \mathrm{e}-7 \mathrm{~cm} 2$ (loading with high packing)

- Run-3

CXP IX Column, 4 foot Diameter, SL-644

Run 2: Viscosity $=3.06 \mathrm{cp}(\mathrm{AZ}-102)$, density $=1.227 \mathrm{~g} / \mathrm{ml}$, permeability $=4.5 \mathrm{e}-6 \mathrm{~cm} 2$ (loading with low packing)

\subsection{Simulation Options (Group 2)}

- Steady-state, flow simulation only

- $\quad$ Saturated modeling

- Influence matrix formulation for flow equation 


\subsection{Upstream Weighting (Group 3)}

- Irrelevant to saturated modeling

\subsection{Iteration Control Parameters (Group 4)}

- Head tolerance set to $1 . \mathrm{e}-6 \mathrm{~cm}$

\subsection{Time Control Parameters (Group 5)}

- Not applicable for steady-state simulation

\subsection{Output Control Parameters (Group 6)}

- Save hydraulic heads, nodal velocities and elemental velocities to restart files and Tecplot post-processing files

\subsection{Mesh Specification (Group 7)}

- $\quad$ Number of nodes in the $\mathrm{x}$-direction $=97$

- $\quad$ Number of nodes in the $y$-direction $=97$

- $\quad$ Number of nodes in the $\mathrm{z}$-direction $=73$

The $\mathrm{x}-\mathrm{y}$ mesh is centered at $(0,0)$. The gridline $\mathrm{x}$ and $\mathrm{y}$ coordinates extend from $-60.96 \mathrm{~cm}(-24$ in) to $60.96 \mathrm{~cm}(24 \mathrm{in})$ with a mesh spacing of $1.27 \mathrm{~cm}(0.5 \mathrm{in})$. Figure $3-1$ is a xy crosssectional view of the FACT mesh. The circle represents the 4-ft diameter of the IX column. In Group 9 of the FACT input, Material Properties, all elements whose x-y centroid extends beyond $4 \mathrm{ft}$ will be inactivated (i.e., the elemental contribution to the global matrix of the flow equation is ignored).

The bottom of the resin bed represents the $\mathrm{z}$ datum and is assigned an elevation of $0 \mathrm{~cm}(0 \mathrm{in})$. The top of the resin bed is at $139.7 \mathrm{~cm}$ (55 in) and is the top surface of the mesh (corresponding to the top of the resin bed as well). A resin height of 55 inches is a nominal value during the loading phase of the IX column. The key surfaces of the mesh in the z-direction are given in Table 3-2.

Once the key surfaces are defined, the layers formed by these surfaces are discretized as shown in Table 3-3. The vertical mesh spacing is $1 / 2$ inch for 34 elements from the bottom of the IX column to the top of the LAW outlet header. The remaining 38 elements have a vertical mesh spacing of 1 inch to the top of the resin bed. Within the region surrounding the outlet distributor $1 / 2$ inch holes, the vertical and horizontal elements are also $1 / 2$ inch cubes. This choice of mesh spacing allowed the point sinks to be set directly on element nodes. 
The 3-dimensional FACT mesh of the IX column is shown in Figure 3-2 with a 90-degree chair cut revealing the internal structures. Those finite elements contained within the structures shown are inactive elements representing solid obstacles (i.e., zero flow regions).

\subsection{Initial Conditions and Flow Solution (Group 8)}

- The initial condition for hydraulic head is set to $304.8 \mathrm{~cm}$ or $10 \mathrm{ft}$ of head.

\subsection{Material Properties (Group 9)}

This section of the FACT input specifies the active and inactive elements in the finite element mesh, saturated hydraulic properties of the porous media (resin), variably saturated properties of the resin, and resin-solute transport parameters. This model of the IX column only deals with the saturated flow of liquid through the resin (no resin-solute transport), therefore the saturated hydraulic conductivity tensor must be specified for each resin bed type and liquid feed solution.

The internal structures within the IX column are modeled as inactive elements (i.e. the hydraulic head is not computed for nodes only associated with inactive elements). Since the FACT code uses Cartesian coordinates ( $\mathrm{x}, \mathrm{y}$ and $\mathrm{z}$ ) and the IX column is cylindrical, all elements whose $\mathrm{x}-\mathrm{y}$ centroidal coordinates extend beyond a radius of 4 feet are inactive. Furthermore, the bottomdished head of the column is an oblate hemisphere and elements whose $x-y$ centroidal coordinates extend beyond the circular cross section of the bottom-dished head are inactive.

The saturated hydraulic conductivity of the resin is a function of resin permeability, liquid density, and liquid viscosity. It is computed as

$$
\mathrm{K}=\rho \mathrm{gk} / \mu
$$

where

$$
\begin{array}{ll}
\mathrm{K} & \text { saturated hydraulic conductivity of porous media (resin), } \mathrm{cm} / \mathrm{min} \\
\rho & \text { liquid density, } \mathrm{g} / \mathrm{ml} \\
\mathrm{g} & \text { acceleration due to gravity, } 980.665 \mathrm{~cm} / \mathrm{s}^{2} \\
\mathrm{k} & \text { intrinsic permeability of porous media, } \mathrm{cm}^{2} \\
\mu & \text { liquid viscosity, } \mathrm{cP}
\end{array}
$$

The hydraulic conductivities of the WTP IX column scenarios are tabulated in Table 3-4, where the fluid properties used were measured simulant values provided by Steimke et al. (2000) and Steimke and Steeper (2002) for SuperLig ${ }^{\circledR} 639$ and SuperLig ${ }^{\circledR} 644$ packed columns, respectively. As stated earlier, the beds were assumed to be isotropic so that the conductivity tensor reduces to a scalar quantity. 


\subsection{Boundary Conditions (Group 10)}

- Specified head nodes (Dirchlet boundary conditions) at the top of the active resin bed are set to $304.8 \mathrm{~cm}$ or $10 \mathrm{ft}$ of head. This represents the pressure due to the head-space above the resin bed. This boundary condition sets a hydraulic reference pressure and its value is really not of importance (i.e., pressure difference is the parameter of interest). Specifically, the piezometric pressure drop is of importance to the design team.

- Specified mass flow node boundary conditions are assigned to the ninety-four $1 / 2$ inch diameter holes in the five collection pipes that connect to the LAW outlet distributor header. The collection holes are spaced 2 inches center-to-center along each arm of the collection pipe. The LAW outlet distributor and collection pipe hole pattern is shown in Figure 3-3. The volumetric flow rate of each $1 / 2$ inch diameter hole is assigned the same value such that the inlet volumetric flow of feed into the column is $17 \mathrm{gpm}$. At this volumetric flowrate, the average velocity through each $1 / 2$ inch hole becomes $\sim 17.7 \mathrm{ft} / \mathrm{min}(9 \mathrm{~cm} / \mathrm{s})$. The $17 \mathrm{gpm}$ flowrate was provided by WGI personnel based on the work of Eager (2001, largest flowrate given in this report). The latest published versions of the system descriptions (Rev B) indicate normal and maximum flowrates of $15 \mathrm{gpm}$ and $22 \mathrm{gpm}$ for the Cs system (Olson and Stewart, 2002a), and $16 \mathrm{gpm}$ and $24 \mathrm{gpm}$ for the Tc system (Olson and Stewart, 2002b).

\subsection{Special Features (Group 11)}

- Specify flow equation mass balance calculation.

\subsection{Spine Profile Data (Group 12)}

- Specify a linear spline of constant value 1.0. This value is a multiplier on the boundary conditions specified in 3.10 .

Table 3-1. WTP IX column scenarios.

\begin{tabular}{|c|c|c|c|c|c|c|c|}
\hline Run & $\begin{array}{c}\text { Resin } \\
\text { Type }\end{array}$ & Feed & $\begin{array}{c}\mathbf{k} \\
\text { Permeability } \\
\mathbf{( c m}^{\mathbf{2}} \mathbf{)}\end{array}$ & $\begin{array}{c}\mu \\
\text { Viscosity } \\
(\mathbf{c P})\end{array}$ & $\begin{array}{c}\rho \\
\text { Density } \\
(\mathbf{g} / \mathbf{m l})\end{array}$ & $\begin{array}{c}\text { Column } \\
\text { Operation }\end{array}$ & $\begin{array}{c}\text { Column } \\
\text { Packing }\end{array}$ \\
\hline \hline Basecase & SL-639 & AN-105 Simulant & $5.2 \mathrm{E}-6$ & 2.94 & 1.225 & loading & low \\
\hline Run-1 & SL-644 & $0.5 \mathrm{HNO}_{3}$ & $4.5 \mathrm{E}-6$ & 1.00 & 1.017 & elution & low \\
\hline Run-2 & SL-644 & AZ-102 Simulant & $5.0 \mathrm{E}-7$ & 3.06 & 1.227 & loading & high \\
\hline Run-3 & SL-644 & AZ-102 Simulant & $4.5 \mathrm{E}-6$ & 3.06 & 1.227 & loading & low \\
\hline
\end{tabular}


Table 3-2. Key surfaces of IX column mesh.

\begin{tabular}{|c|c|c|c|c|c|c|}
\hline Component & Surface & Elevation & Model (cm) & Model (in) & Depth (cm) & Depth (in) \\
\hline \hline Resin & 8 & Top & 139.70 & 55.00 & 0. & 0. \\
\hline 4" Spent Resin Out & 7 & Bottom & 106.59 & 41.96 & 33.11 & 13.04 \\
\hline LAW Outlet Header & 6 & Top & 43.21 & 17.01 & 96.49 & 38.00 \\
\hline LAW Outlet Header & 5 & Bottom & 38.13 & 15.01 & 101.57 & 40.00 \\
\hline Cylindrical Section & 4 & Bottom & 27.97 & 11.01 & 111.73 & 44.00 \\
\hline 4" Flush Liquid Inlet & 3 & Top & 25.40 & 10.00 & 114.30 & 45.00 \\
\hline 4" Flush Liquid Inlet & 2 & Bottom & 15.24 & 6.00 & 124.46 & 49.00 \\
\hline Bottom Dished Head & 1 & & 0 & 0 & 139.70 & 55.00 \\
\hline
\end{tabular}

Table 3-3. Vertical mesh discretization.

\begin{tabular}{|c|c|c|c|c|}
\hline Layer & Surfaces & $\begin{array}{c}\text { Number of } \\
\text { Elements }\end{array}$ & $\begin{array}{c}\text { Mesh Spacing } \\
\text { (cm) }\end{array}$ & $\begin{array}{c}\text { Mesh Spacing } \\
\text { (in) }\end{array}$ \\
\hline \hline 1 & $1-2$ & 12 & 1.27 & 0.50 \\
\hline 2 & $2-3$ & 8 & 1.27 & 0.50 \\
\hline 3 & $3-4$ & 2 & 1.29 & 0.51 \\
\hline 4 & $4-5$ & 8 & 1.27 & 0.50 \\
\hline 5 & $5-6$ & 4 & 1.27 & 0.50 \\
\hline 6 & $6-7$ & 25 & 2.54 & 1.00 \\
\hline 7 & $7-8$ & 13 & 2.55 & 1.00 \\
\hline
\end{tabular}

Table 3-4. Hydraulic conductivities of the WTP IX column scenarios.

\begin{tabular}{|c|c|c|c|c|c|c|c|}
\hline Run & $\begin{array}{l}\text { Resin } \\
\text { Type }\end{array}$ & Feed & $\begin{array}{c}\text { k } \\
\text { Permeability } \\
\left(\mathrm{cm}^{2}\right)\end{array}$ & $\begin{array}{c}\mu \\
\text { Viscosity } \\
\text { (cP) }\end{array}$ & $\begin{array}{c}\rho \\
\text { Density } \\
(\mathrm{g} / \mathrm{ml})\end{array}$ & $\begin{array}{c}\text { K } \\
\text { Hydraulic } \\
\text { Conductivity } \\
\text { (cm/min) }\end{array}$ & $\begin{array}{l}\text { Resin Bed } \\
\text { Volume }^{\text {a }} \\
\quad \text { (gal) }\end{array}$ \\
\hline Basecase & $\overline{~ S L-639}$ & $\begin{array}{l}\text { AN-105 } \\
\text { Simulant }\end{array}$ & (5.2E-6 & 2.94 & 1.225 & 12.75 & 400.7 \\
\hline Run-1 & SL-644 & $0.5 \mathrm{HNO}_{3}$ & $4.5 \mathrm{E}-6$ & 1.00 & 1.017 & 26.93 & 392.5 \\
\hline Run-2 & SL-644 & $\begin{array}{c}\text { AZ-102 } \\
\text { Simulant }\end{array}$ & $5.0 \mathrm{E}-7$ & 3.06 & 1.227 & 1.18 & 392.5 \\
\hline Run-3 & SL-644 & $\begin{array}{c}\text { AZ-102 } \\
\text { Simulant }\end{array}$ & $4.5 \mathrm{E}-6$ & 3.06 & 1.227 & 10.62 & 392.5 \\
\hline
\end{tabular}

a Resin bed volume beneath the LAW outlet distributor is 96.3 gal for the Basecase and 91.1 gal for the Run-1, Run-2, and Run-3 cases. 


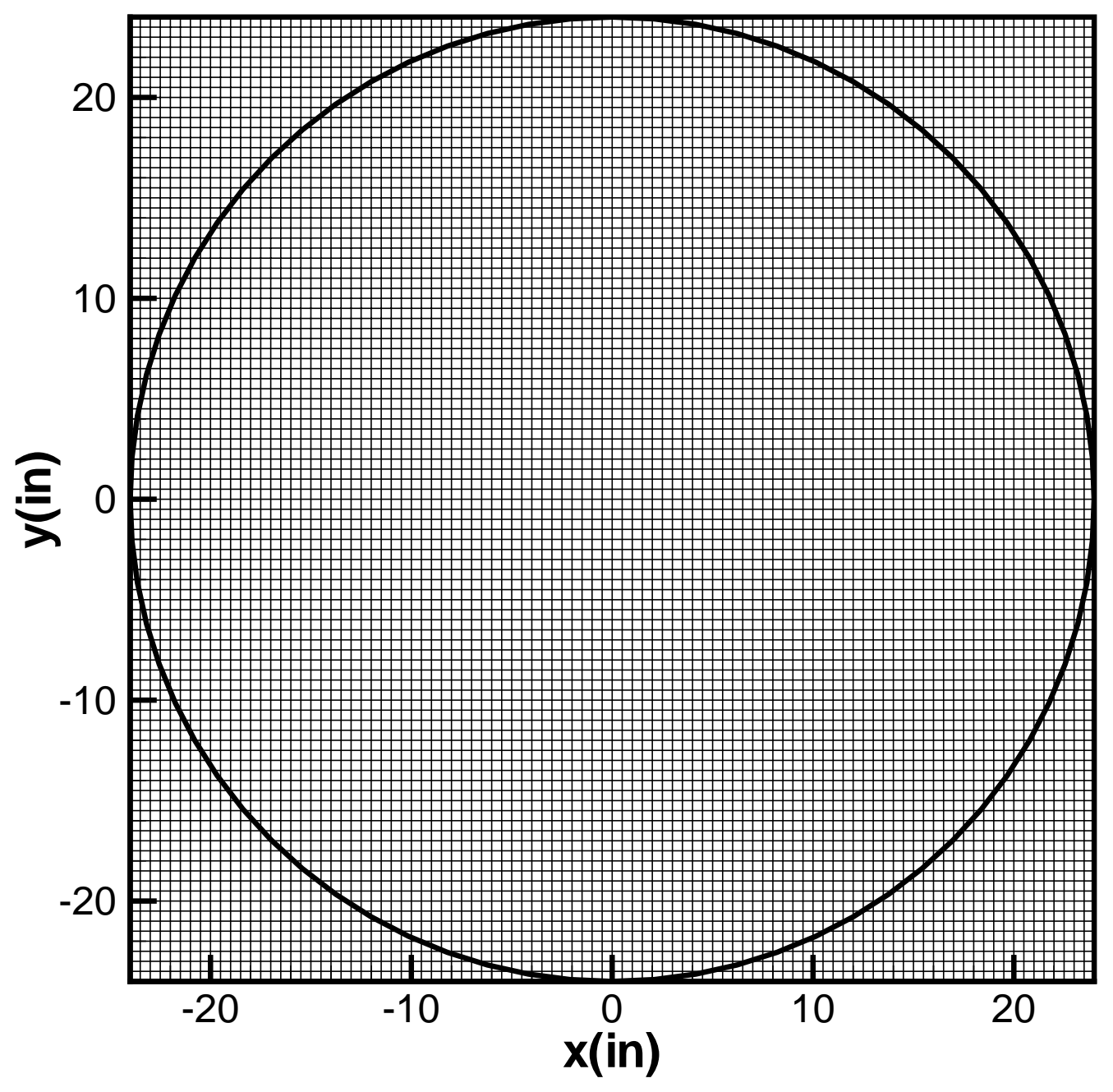

Figure 3-1. XY (horizontal) cross-sectional view of IX column mesh used as input for FACT analyses. The mesh spacing is $1 / 2$ inch by $1 / 2$ inch. 


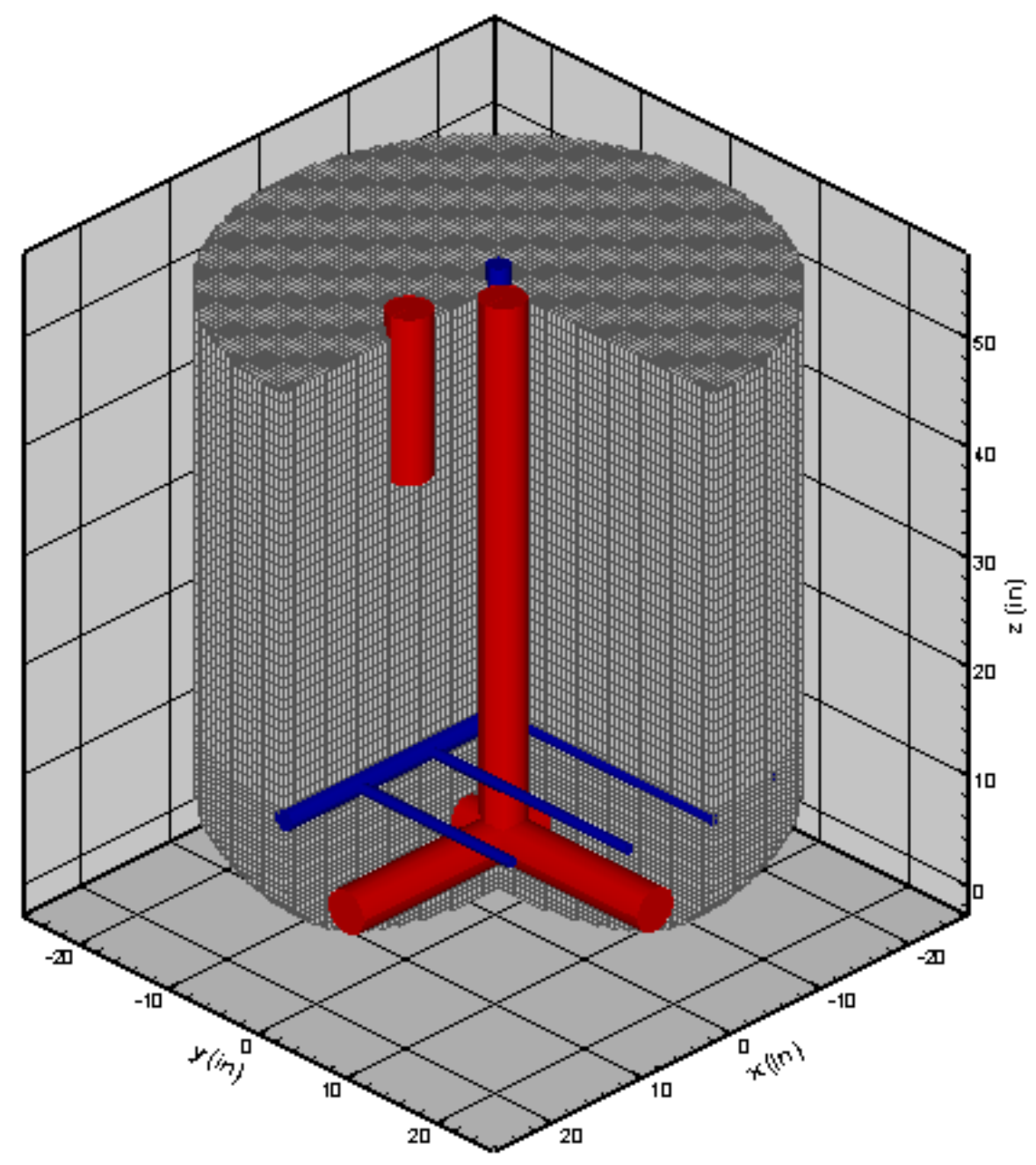

Figure 3-2. 3-D FACT mesh showing internal structures. This 90-degree chair-cut shows the internal structures of the column. The blue structure is the LAW outlet distributor. The structures are the resin inlet and outlet distributors. 


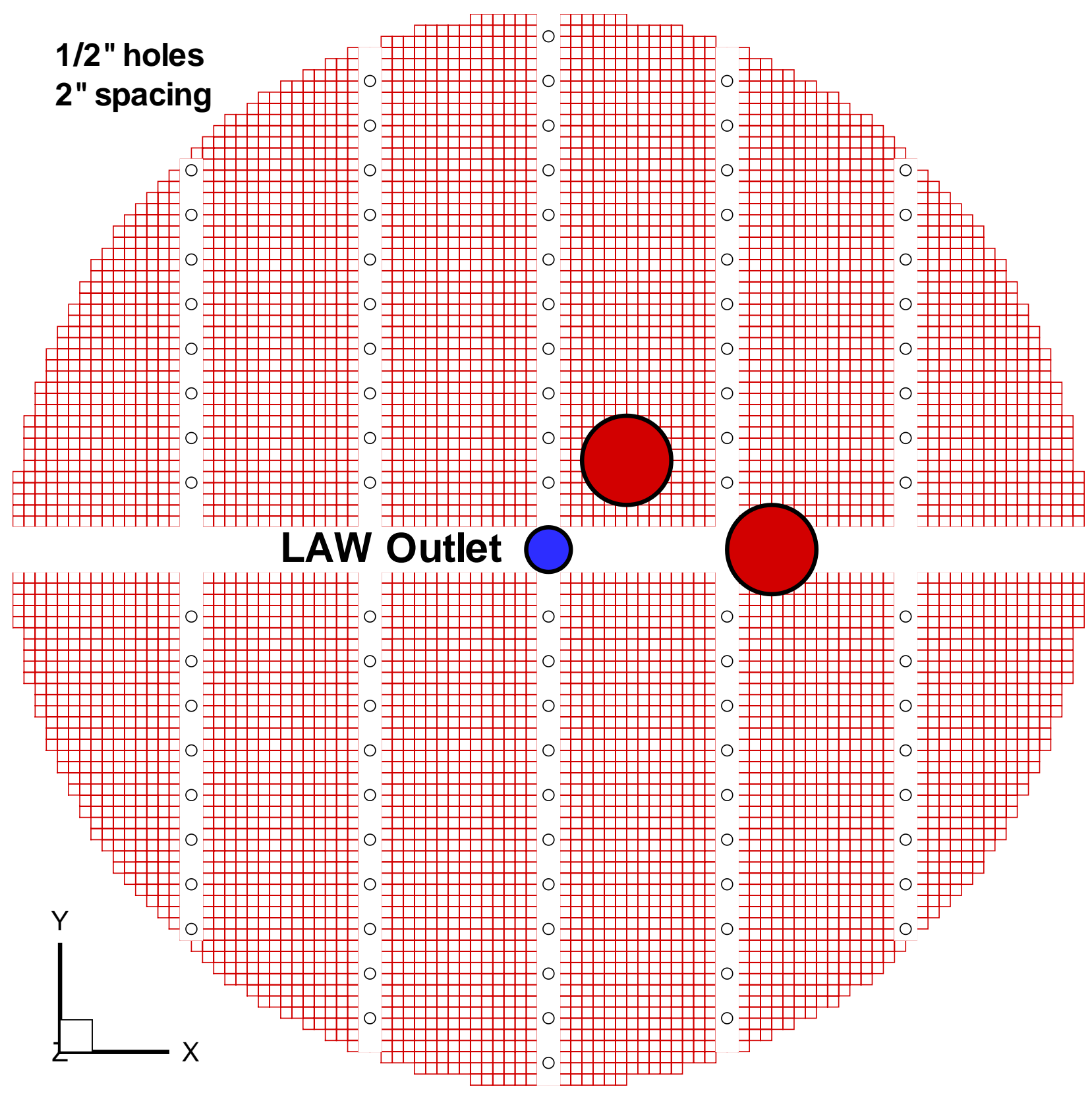

Figure 3-3. LAW outlet distributor with collection pipe hole pattern. Outlet manifold consists of a single 2" main with five 1" cross-pipes containing uniformly distributed outlet holes $1 / 2$ " in diameter. 


\subsection{Column Flow Modeling Results}

A series of FACT simulations were performed to evaluate the hydraulic performance of the IX column during various scenarios (see Table 3-1). A "Basecase" verification run was developed to confirm the proper operation of the FACT code and subsequent post-processing of the code results. Upon successful verification, the IX column piezometric pressure profile, velocity profile, 3-dimensional particle tracking, and residence times of feed in the resin bed were computed for three SuperLig ${ }^{\circledR} 644$ runs (Run-1 to Run-3). The Basecase represents the column packed with SuperLig ${ }^{\circledR} 639$ resin where the only internal structure accounted for is the LAW outlet distributor. Run-1, Run-2, and Run-3 represent the column packed with SuperLig ${ }^{\circledR} 644$ under varying fluid and resin properties, where the internal structures of the LAW outlet distributor and resin distributors are accounted for.

When looking at the results presented within this chapter, it should be noted that isothermal 3-D Darcy flow is being computed for an incompressible fluid and resin bed. The fluid momentum equations become linear in the Darcy flow regime under isothermal conditions. This linearity condition allows us to generalize some of the results to other flow conditions. For example:

- The inlet reference pressure is arbitrary and only pressure differences are meaningful. Piezometric pressure was chosen for presentation of the results since piezometric pressure drops represent the frictional losses within the resin bed. All of the simulations presented were performed at the same volumetric flowrate (i.e., $17 \mathrm{gpm}$ ). For each simulation case the overall bed piezometric pressure drop can be computed for different flowrates by a simple scaling of the results provided.

- The velocity vector field does vary with the volumetric outlet flowrate; however, only the magnitude varies. The velocity vectors retain their geometric directions but the magnitude changes. The streamtraces do not vary with volumetric flowrate. For each simulation case the velocity vector field can be computed for different total flowrates by a simple scaling of the results provided.

- The normalized (i.e., ratio) residence times are a function of the normalized velocity vector fields. Therefore, their values are independent of volumetric flowrate.

The results of the four simulation cases are discussed in the next five subsections where a volumetric flowrate of $17 \mathrm{gpm}$ was chosen.

\subsection{Basecase Verification}

The basecase chosen is an IX column with SuperLig ${ }^{\circledR} 639$ resin containing only the LAW outlet distributor. The feed is AN-105 simulant flowing at $17 \mathrm{gpm}$ with a bed volume of 400.7 gal (i.e., $2.55 \mathrm{BV} / \mathrm{hr}$ ). This geometry exhibits four-fold symmetry about the $\mathrm{X}-\mathrm{Z}$ and $\mathrm{Y}-\mathrm{Z}$ vertical planes sliced through the center of the column. As such, it is easy to verify that the flow (head or 
pressure) solution computed by FACT is correct within the assumptions and boundary conditions applied.

Due to the geometrical symmetry and symmetrical boundary conditions, the FACT solution (i.e., computed pressure and velocity fields) should also have four-fold symmetry. Taking a vertical slice through the center of the middle collection pipe in the LAW outlet distributor $(\mathrm{Y}=0)$, we can inspect the piezometric pressure profile for symmetry. Figure 4-1 is the $\mathrm{X}-\mathrm{Z}$ piezometric pressure profile at $\mathrm{Y}=0$ parallel to the LAW outlet collection pipes. By inspection the pressure profile is symmetric about the centerline (z-axis) as expected. Figure 4-2 is the $\mathrm{Y}-\mathrm{Z}$ piezometric pressure profile at $X=0$ (center of the LAW outlet header) which is perpendicular to the LAW outlet collection pipes. By inspection the pressure profile is again symmetric about the centerline. Figure 4-3 is a 3-D perspective of the column pressure profile with a 90-degree sector removed to expose the center.

Finally, the normalized residence times of feed in the SuperLig ${ }^{\circledR} 639$ resin bed are computed and plotted in Figure 4-4. The detailed discussion on the computation of the normalized residence time is reserved for section 4.5. This $\mathrm{X}-\mathrm{Y}$ cross-sectional view shows symmetry of the normalized residence times about the centerline (i.e., $\mathrm{X}=0$ and $\mathrm{Y}=0$ axes). This is no surprise since the velocity profile, which is computed from the gradient of the head solution, exhibits the same symmetry....again by inspection.

Detailed probing within the Tecplot ${ }^{\circledR}$ graphics package confirms the visually observed symmetry in the FACT results. This test case provides assurance and verification that the methodology being used is algorithmically sound.

\subsection{Column Pressure Profile}

The piezometric (or frictional pressure) drop across an IX column is an important parameter to consider in the design and operation of the column. Too high a pressure drop during any of the stages of the loading and regeneration steps of the column may result in a flow situation where it is not feasible to pump liquid through the column at desired flowrates. This is not desirable and may lead to premature shutdown of the plant. In this study, we present the hydraulic performance of the proposed WTP IX column based on the current state-of-knowledge of the hydraulic properties of SuperLig ${ }^{\circledR} 639$ and SuperLig ${ }^{\circledR} 644$ resins. Table 4-1 shows the minimum, average and maximum piezometric pressure drops across the IX column for the SuperLig ${ }^{\circledR} 639$ and SuperLig ${ }^{\circledR} 644$ cases. The piezometric pressure drop across the column does not include losses in the LAW outlet distributor.

The permeability of the SuperLig ${ }^{\circledR} 639$ resin has been computed from column tests in the TFL by Steimke et al. (2000). This particular resin does not exhibit much swelling or shrinkage (i.e., $1-2 \%$ ) during the various steps of regeneration. Therefore, for this study we address the hydraulic performance of this resin under nominal conditions. The piezometric pressure profile has been shown in Figure 4-3.

The permeability of the SuperLig ${ }^{\circledR} 644$ resin is not quite as attainable through experimentation as that of the SuperLig ${ }^{\circledR} 639$ resin. The production of the SuperLig ${ }^{\circledR} 644$ resin by the vendor has 
yielded batches where the resin has swelled over $100 \%$ in volume during the $0.1 \mathrm{M} \mathrm{NaOH}$ displacement step, to the point where liquid could not be pumped adequately through the column in the TFL tests. The TFL tests used a column with a high Length-to-Diameter ratio, which may play some role in the hydraulic performance of the column during some phases of the column regeneration. Here we try to salvage data from the TFL tests that provide bounding values of the permeability of the resin. The bounding values of SuperLig ${ }^{\circledR} 644$ permeabilities from the TFL tests given in Table 3-1 are converted to hydraulic conductivities, based on liquid properties, to the values listed in Table 3-4. The permeability data shown in Figure 2-3 represents near steadystate hydraulic conditions where dynamic compaction effects have diminished. The dynamic compaction effects associated with osmotic shocks were minimized through overnight soaking in the test solution of interest. During an osmotic shock transient local permeabilities could be significantly lower than the lower bound used in these analyses.

The three simulations with SuperLig ${ }^{\circledR} 644$ resin have included within the model the structural obstacles associated with the resin distributor piping (i.e., resulting in a slightly reduced bed volume of $392.5 \mathrm{gal}$ ). The feed is AZ-102 simulant flowing at $17 \mathrm{gpm}$ (i.e., 2.60 BV/hr). The piezometric pressure profile of the WTP IX column with SuperLig ${ }^{\circledR} 644$ during the elution stage and low column packing is shown in Figure 4-5 (Run-1). The piezometric pressure profile of the WTP IX column with SuperLig ${ }^{\circledR} 644$ during the loading stage and high column packing is shown in Figure 4-6 (Run-2). The piezometric pressure profile of the WTP IX column with SuperLig ${ }^{\circledR} 644$ during the loading stage and low column packing is shown in Figure 4-7 (Run-3).

The average piezometric pressure drop for a range of volumetric flowrates is provided in Figure 4-8. In Figure 4-8 each of the simulation cases discussed earlier are plotted as symbols. The curves shown are linear lines originating at the origin and pass through each of these cases at 17 gpm.

\subsection{Column Velocity Profile}

A good indicator of non-plug flow conditions through the column is to look at the variation of the horizontal $(\mathrm{X}-\mathrm{Y})$ velocity as a function column elevation. The horizontal velocity in an ideal plug flow situation is zero everywhere. The horizontal velocity is normalized by the magnitude of the inlet liquid superficial velocity as

$$
\begin{aligned}
& \left|\mathrm{u}_{\mathrm{h}}\right|=\sqrt{\mathrm{u}_{\mathrm{x}}^{2}+\mathrm{u}_{\mathrm{y}}^{2}} /\left|\mathrm{u}_{\mathrm{z}}\right| \\
& \left|\mathrm{u}_{\mathrm{z}}\right|=5.6 \mathrm{~cm} / \min (17 \mathrm{gpm})
\end{aligned}
$$

where

$$
\begin{aligned}
& u_{x} \quad \text { x-component of the velocity vector } \\
& u_{y} \quad y \text {-component of the velocity vector } \\
& u_{z} \quad \text { z-component of the velocity vector at the column inlet }
\end{aligned}
$$

Figure 4-9 is a plot of the average and maximum normalized magnitude of the horizontal velocity as a function of resin bed elevation. The LAW outlet distributor is located at a resin bed 
elevation of 16 inches. The other obstructions are also labeled in the plot. A semilog plot of Figure 4-9 is shown in Figure 4-10. The average of the normalized magnitude of the horizontal velocity is greater than $10 \%$ of the inlet superficial velocity within 4 inches of the LAW outlet distributor. The maximum of the normalized magnitude of the horizontal velocity is greater than $10 \%$ of the inlet superficial velocity 12 inches below and 8 inches above the LAW outlet distributor. We also can see a small impact resulting from the 4" spent resin outlet pipe. Here the disturbance is fairly local as seen in Figure 4-10 where the average value is much less than its maximum value.

We can also examine the variation of the normalized horizontal velocity within a cross-sectional slice at a given column elevation. A series of contour plots are presented with $u_{\mathrm{h}}$ contour levels at $0,0.5,1.0,1.5,2.0$ and 2.5. A contour plot of the normalized horizontal velocity at the elevation of the LAW outlet distributor is shown in Figure 4-11. There is a strong gradient in horizontal velocity as you approach the holes in the LAW collection pipes. In the vicinity of the $1 / 2$ inch holes the magnitude of the horizontal velocity is greater than 2.5 , which exceeds $45 \%$ of the inlet superficial velocity. As we move away from the LAW outlet collection holes, we see a marked reduction in magnitude of the horizontal velocity. Figure 4-12 is a cross-sectional slice $1 / 2$ inch above the LAW outlet and Figure $4-13$ is 1 inch above the LAW outlet.

A series of contour plots similar to the above mentioned plots were generated by restricting the contour intervals to a single interval with a value of 0.1 . This cutoff contour value represents $10 \%$ of the inlet superficial velocity. The value is somewhat arbitrary; however, Figures 4-9 and 4-10 provide essentially the same information as a function of this quantity. With the single contour interval of 0.1 established, we take cross-sectional slices every 3 inches beginning 9 inches below the LAW outlet and ending 9 inches above the outlet. Figures 4-14 to 4-20 are the contour plots of the normalized magnitude of the horizontal velocity at elevations of $-9,-6,-3,0$. $+3,+6$, and +9 inches relative to the LAW outlet elevation, respectively. The magnitudes of the horizontal velocity field are at maximum values at the LAW outlet (Figure 4-17) and diminish as you move away from the distributor. The magnitudes of the horizontal velocity field are less than 0.1, 9 inches away from the LAW outlet (Figures 4-14 and 4-20).

For completeness, we superimpose the vector plot of the horizontal velocity field at the LAW outlet with the contour plot of the normalized magnitude of the horizontal velocity field in Figure 4-21. The volumetric flow of feed through each of the collection pipe holes is $\sim 0.181$ gpm. The velocity of the liquid feed at each collection pipe hole is $540.4 \mathrm{~cm} / \mathrm{min}$ (or $0.295 \mathrm{ft} / \mathrm{s}$ ).

\subsection{3-Dimensional Particle Tracking (Streamtraces)}

The FACT code computes the velocity components at each active finite element node within the IX column mesh. We can now use particle tracking based upon the results of the finite element flow simulation by FACT to determine feed pathlines (streamtraces) and travel times throughout the IX column resin.

The streamtrace feature in Tecplot ${ }^{\circledR}$ (Amtec, 2001) was used to generate volume streamtraces (i.e. 3-D pathlines) from initial points distributed at the inlet of the resin bed. Table 4-2 shows 
the parameters that were used to generate the Tecplot ${ }^{\circledR}$ streamtrace macros. The starting seed elevation of each streamtrace was 54.96 inches or 0.04 inches below the top of the resin bed. The predictor-corrector integration algorithm sometimes has problems starting at a mesh boundary, so we placed the streamtrace seeds slightly below the top of the resin. The $\mathrm{x}-\mathrm{y}$ starting position of each streamtrace was computed by generating 32 (XY-01 to XY-21) or 64 (XY-22) azimuthal seeds at a fixed radius from the center of the column as shown in Table 4-2. Twenty two radial sets of seeds were generated. Once the $\mathrm{x}, \mathrm{y}$, and $\mathrm{z}$ starting coordinate is known, then forward particle tracking of the velocity field generates a volume streamtrace that terminates at one of the 1 inch collection pipe holes or at an obstruction. A total of 736 forward volume streamtraces were computed for Run-1. The results for Run-2 and Run-3 would be identical since their velocity vector fields are identical.

Figure 4-22 shows 3 rings of volume streamtraces out of the total of 22. The streamtraces have 10-minute timing markers (black circles). As shown, the volume streamstraces all terminate at the LAW outlet collection pipes (blue). From the perspective shown in Figure 4-22, it is difficult to see to what extent does these streamtraces dip down below the LAW outlet distributor. In Figure 4-23, we show an X-Z projection of the volume streamtraces perpendicular to the array of collection pipes at $Y=2$ inches. Between collection pipes, the streamtraces dip below the LAW outlet and curve back toward one of the holes in a collection pipe. Basically, fluid entering at the top of the bed that resides directly over a 1" collection pipe, completely short-circuits the bed that resides beneath the LAW outlet distributor. Fluid entering the bed that resides between two 1" collection pipes, travels partially through the bed beneath the outlet distributor. As shown in Figure 4-23, effectively the LAW outlet distributor creates a "dead-zone" of resin beneath it. $23 \%$ for the SuperLig ${ }^{\circledR} 644$ cases (and $24 \%$ for the SuperLig ${ }^{\circledR} 639$ case) of the resin bed lies beneath the LAW outlet distributor (i.e., 91.3 gal of resin out of the total 392.5 gal bed for the SuperLig ${ }^{\circledR} 644$ cases). Only a small fraction of this resin beneath the LAW outlet distributor can be effectively used during the loading step. The sorption of cesium into the dead-zone would be primarily through transverse dispersion of the bed fluid and molecular diffusion. Upon eluting this column, the potential for elongated tailing of the elution curve would exist.

Once Tecplot ${ }^{\circledR}$ has generated all the volume streamtraces, we can then extract each individual streamtrace into a separate Tecplot ${ }^{\circledR}$ I-ordered zone. Each Tecplot ${ }^{\circledR}$ zone contains the coordinates and velocity components of the streamtrace generated during the predictor-corrector integration algorithm from the start to the termination of the streamtrace. A Tecplot ${ }^{\circledR}$ ASCII datafile containing all 736 streamtrace zones is written out and later post-processed to compute the arc length and travel time along each streamtrace.

\subsection{Residence Times of Feed in Resin Bed}

During the loading and elution steps mass transport through the bed fluid is the result of advection, dispersion, and molecular diffusion. Generally, advection dominates over dispersion, which in term dominates over molecular diffusion. Based on this, looking at the travel time along the various streamtraces can provide us with some insight. 
The travel time or residence time of feed within the resin bed is an important measure of resin bed utilization. Ideally, the IX column is designed to operate under plug flow conditions where the inlet feed and outlet feed distributors are located in liquid plenums outside the resin bed (see Ruthven, 1997), even under it fully swollen state. The proposed design of the WTP IX column has the LAW outlet distributor embedded within the resin bed at the bottom of the cylindrical section of the column. The position of the outlet distributor is 16 inches above the bottom of the oblate hemispherical bottom, which reduces the effective length of the column from 55 inches to 39 inches (i.e., 55-16). Loading and elution performance can be impacted by these potential "dead-zones".

The coordinates and velocity components of each volume streamtrace is computed by Tecplot ${ }^{\circledR}$ and extracted to separate I-ordered zones (Section 4.4). The method to extract the arc length and timing information from a streamtrace is performed using the following procedure:

For each streamtrace zone:

1. Set the time ST(I) and arc length $\mathrm{SL}(\mathrm{I})$ at $\mathrm{I}=1$ to zero. This is the starting point of the streamtrace.

2. Loop from $\mathrm{I}=2$ to $\mathrm{N}$, where $\mathrm{N}$ represents the termination point of the streamtrace.

a) Calculate the arc length of each streamtrace segment dS as

$$
\mathrm{dS}=\sqrt{(\mathrm{X}(\mathrm{I})-\mathrm{X}(\mathrm{I}-1))^{2}+(\mathrm{Y}(\mathrm{I})-\mathrm{Y}(\mathrm{I}-1))^{2}+(\mathrm{Z}(\mathrm{I})-\mathrm{Z}(\mathrm{I}-1))^{2}}
$$

b) Calculate the average velocity magnitude of each streamtrace segment $\mathrm{dV}$ as

$$
\mathrm{dV}=0.5\left(\sqrt{\mathrm{U}(\mathrm{I})^{2}+\mathrm{V}(\mathrm{I})^{2}+\mathrm{W}(\mathrm{I})^{2}}+\sqrt{\mathrm{U}(\mathrm{I}-1)^{2}+\mathrm{V}(\mathrm{I}-1)^{2}+\mathrm{W}(\mathrm{I}-1)^{2}}\right)
$$

c) Calculate the incremental time of each streamtrace segment dt as

$$
\mathrm{dt}=\mathrm{dS} / \mathrm{dV}
$$

d) Set the cumulative time ST(I) of the streamtrace as

$$
\mathrm{ST}(\mathrm{I})=\mathrm{ST}(\mathrm{I}-1)+\mathrm{dt}
$$

e) Set the cumulative arc length SL(I) of the streamtrace as

$$
\mathrm{SL}(\mathrm{I})=\mathrm{SL}(\mathrm{I}-1)+\mathrm{dS}
$$

Equation (4-5) represents the cumulative time or residence time of the feed in the IX column resin bed. The advection term in the transport equation generally represents the dominant term for mass transport through the column bed. By neglecting the other mass transfer mechanisms, the transport times along the various streamtraces provide some measure of bed performance 
(i.e., longer residence times indicate more resin utilization). Given this, we now attempt to quantify the effectiveness of the resin bed in terms of the advective component of transport in terms of residence time. To evaluate the effectiveness of the resin bed, we normalize the residence times of the proposed WTP IX column with a residence time computed for an ideal IX column that contains the same volume of resin, inlet cross-sectional flow area, and inlet superficial liquid velocity. The ideal column represents a cylindrical shaped bed with the same diameter as the actual column. Under plug flow conditions this ideal column makes use of its resin. For our situation the ideal residence time, $t_{i d e a l}$, is computed as $23.1 \mathrm{~min}$ for total utilization of the resin bed under plug flow conditions. The normalized residence time in the resin bed is computed as (i.e., a tau factor)

$$
\tau=\mathrm{t}_{\text {resin }} / \mathrm{t}_{\text {ideal }}
$$

Figure 4-24 demonstrates the normalized residence times in the SuperLig ${ }^{\circledR} 644$ resin cases with an inlet liquid feed flowrate of $17 \mathrm{gpm}$ (or $5.6 \mathrm{~cm} / \mathrm{min}$ superficial inlet liquid velocity). Due to the short-circuiting discussed above in Section 4.4, the majority of the normalized residence times is below unity, which is the value for ideal or plug flow conditions. The only normalized residence times that are above the ideal condition (i.e., tau greater than one) are those streamtraces which originate between collection pipes and near the wall of the column, which then loop back toward the collection pipe holes from below the LAW outlet (see Figure 4-23). This pattern can be seen in Figure 4-24 where the tau values drop in between the regions between the 1" outlet pipes and near the outer vessel wall.

A histogram of the frequency versus residence time provides insight into the level of resin utilization loss. Figure 4-25 is a plot of such a histogram. The histogram appears to have a shifted lognormal distribution. The median value of the residence time is 18.7 minutes, which corresponds to a normalized residence time of 0.81 . Half of the streamtraces have residence times which are below $81 \%$ of the ideal residence time for ideal plug flow. The average normalized residence time is 20.8 minutes or a normalized residence time of 0.90 .

As mentioned in Section 4.4, for the SuperLig ${ }^{\circledR} 644$ cases $\sim 77 \%$ of the resin resides above the LAW outlet distributors. If none of the streamtraces would dip below the outlet distributor, then the corresponding tau factor would be $\sim 77 \%$ also. However, as indicated in Figure $4-23$ some portion of the resin below the outlet distributor, $\sim 4 \%$, is participating. The remainder, $\sim 19 \%$, is contained in a "dead-zone". Within this "dead-zone" cesium loading and eluting can only occur as the result of bed dispersion and molecular diffusion. Both of these mass transfer mechanisms have diminished capability. 
Table 4-1. Piezometric pressure drop across WTP IX column.

\begin{tabular}{|c|c|c|c|c|c|}
\hline Run & $\begin{array}{c}\text { Resin } \\
\text { Type }\end{array}$ & $\begin{array}{c}\text { Hydraulic } \\
\text { Conductivity } \\
\text { (cm/min) }\end{array}$ & $\begin{array}{c}\text { Minimum } \\
\text { Pressure } \\
\text { Drop (psid) }\end{array}$ & $\begin{array}{c}\text { Average } \\
\text { Pressure } \\
\text { Drop (psid) }\end{array}$ & $\begin{array}{c}\text { Maximum } \\
\text { Pressure } \\
\text { Drop (psid) }\end{array}$ \\
\hline \hline Basecase & SuperLig $^{\circledR} 639$ & 12.75 & 1.03 & 1.06 & 1.09 \\
\hline Run-1 & SuperLig $^{\circledR} 644$ & 26.93 & 0.41 & 0.42 & 0.43 \\
\hline Run-2 & SuperLig $^{\circledR} 644$ & 1.18 & 11.24 & 11.58 & 11.85 \\
\hline Run-3 & SuperLig $^{\circledR} 644$ & 10.62 & 1.25 & 1.29 & 1.32 \\
\hline
\end{tabular}

Table 4-2. Parameters for generation of Tecplot ${ }^{\circledR}$ streamtrace macros.

\begin{tabular}{|c|c|c|c|c|c|}
\hline $\begin{array}{l}\text { Streamtrace } \\
\text { Macro } \\
\text { Name }\end{array}$ & $\begin{array}{l}\text { Starting } \\
\text { Seed } \\
\text { Elevation } \\
(\mathrm{cm})\end{array}$ & $\begin{array}{l}\text { Starting } \\
\text { Seed } \\
\text { Elevation } \\
\text { (in) }\end{array}$ & $\begin{array}{l}\text { Radius of } \\
\text { Streamtrace } \\
\text { Seed (cm) }\end{array}$ & $\begin{array}{l}\text { Radius of } \\
\text { Streamtrace } \\
\text { Seed (in) }\end{array}$ & $\begin{array}{c}\text { Number of } \\
\text { Azimuthal } \\
\text { Seeds }\end{array}$ \\
\hline XY-01 & 139.6 & 54.96 & 5.0 & 1.968 & 32 \\
\hline XY-02 & 139.6 & 54.96 & 7.5 & 2.953 & 32 \\
\hline XY-03 & 139.6 & 54.96 & 10.0 & 3.937 & 32 \\
\hline XY-04 & 139.6 & 54.96 & 12.5 & 4.921 & 32 \\
\hline$X Y-05$ & 139.6 & 54.96 & 15.0 & 5.905 & 32 \\
\hline XY-06 & 139.6 & 54.96 & 17.5 & 6.890 & 32 \\
\hline XY-07 & 139.6 & 54.96 & 20.0 & 7.874 & 32 \\
\hline XY-08 & 139.6 & 54.96 & 22.5 & 8.858 & 32 \\
\hline XY-09 & 139.6 & 54.96 & 25.0 & 9.842 & 32 \\
\hline $\mathrm{XY}-10$ & 139.6 & 54.96 & 27.5 & 10.827 & 32 \\
\hline$X Y-11$ & 139.6 & 54.96 & 30.0 & 11.811 & 32 \\
\hline XY-12 & 139.6 & 54.96 & 32.5 & 12.795 & 32 \\
\hline XY-13 & 139.6 & 54.96 & 35.0 & 13.779 & 32 \\
\hline XY-14 & 139.6 & 54.96 & 37.5 & 14.764 & 32 \\
\hline $\mathrm{XY}-15$ & 139.6 & 54.96 & 40.0 & 15.748 & 32 \\
\hline XY-16 & 139.6 & 54.96 & 42.5 & 16.732 & 32 \\
\hline $\mathrm{XY}-17$ & 139.6 & 54.96 & 45.0 & 17.716 & 32 \\
\hline XY-18 & 139.6 & 54.96 & 47.5 & 18.701 & 32 \\
\hline XY-19 & 139.6 & 54.96 & 50.0 & 19.685 & 32 \\
\hline$X Y-20$ & 139.6 & 54.96 & 52.5 & 20.669 & 32 \\
\hline XY-21 & 139.6 & 54.96 & 55.0 & 21.653 & 32 \\
\hline$X Y-22$ & 139.6 & 54.96 & 58.5 & 23.031 & 64 \\
\hline
\end{tabular}




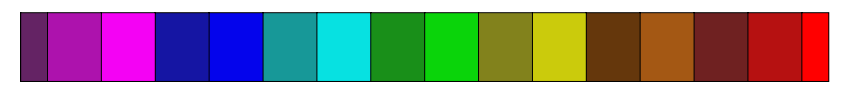

psi: 19.319 .419 .519 .619 .719 .819 .920
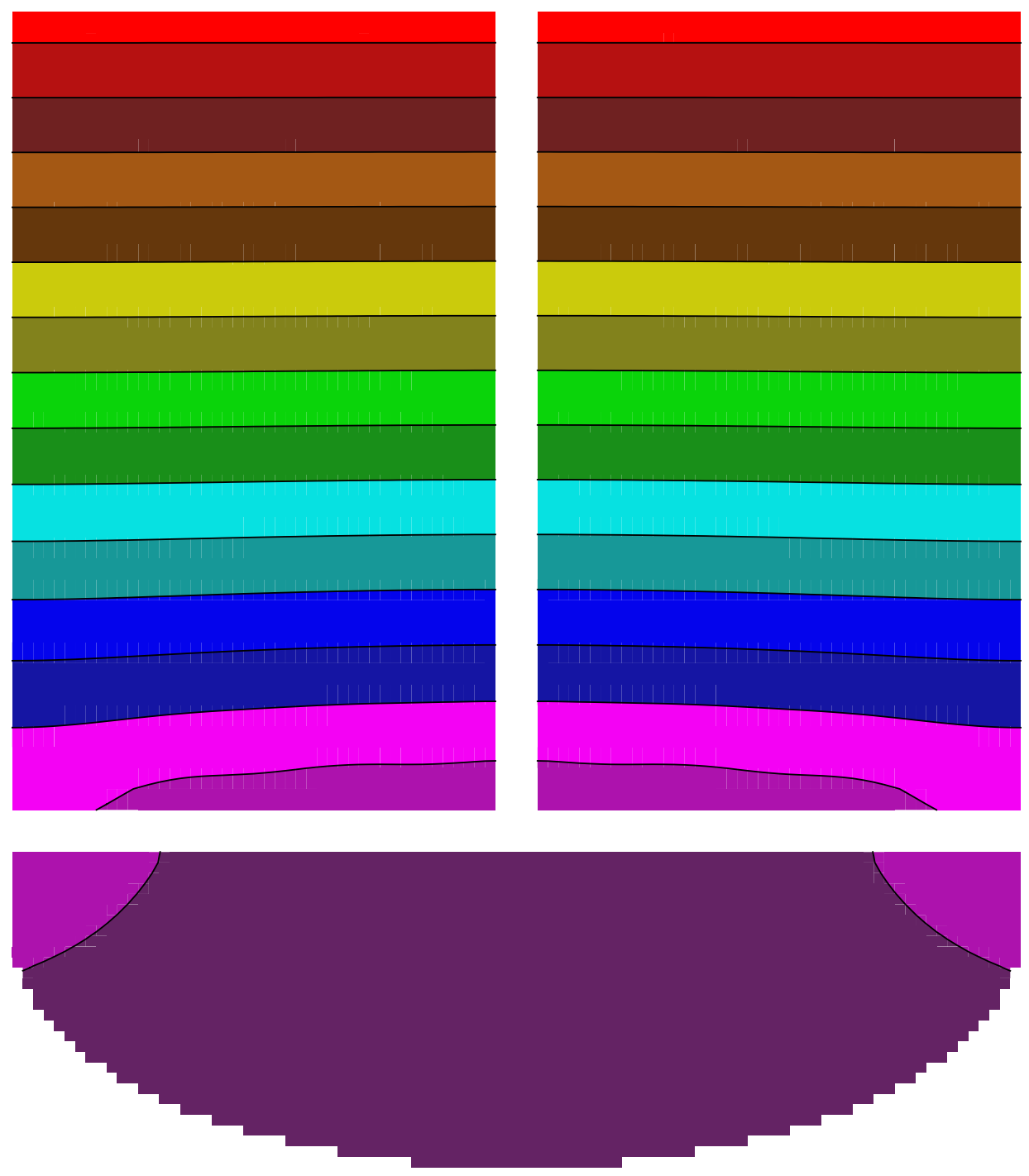

Figure 4-1. Basecase: $\mathrm{X}-\mathrm{Z}$ piezometric pressure profile slice $(\mathrm{Y}=0)$ of WTP IX column containing SuperLig ${ }^{\circledR} 639$ during loading stage with low resin packing. The feed is $\mathrm{AN}-105$ simulant flowing at $17 \mathrm{gpm}(2.6 \mathrm{BV} / \mathrm{hr})$. 


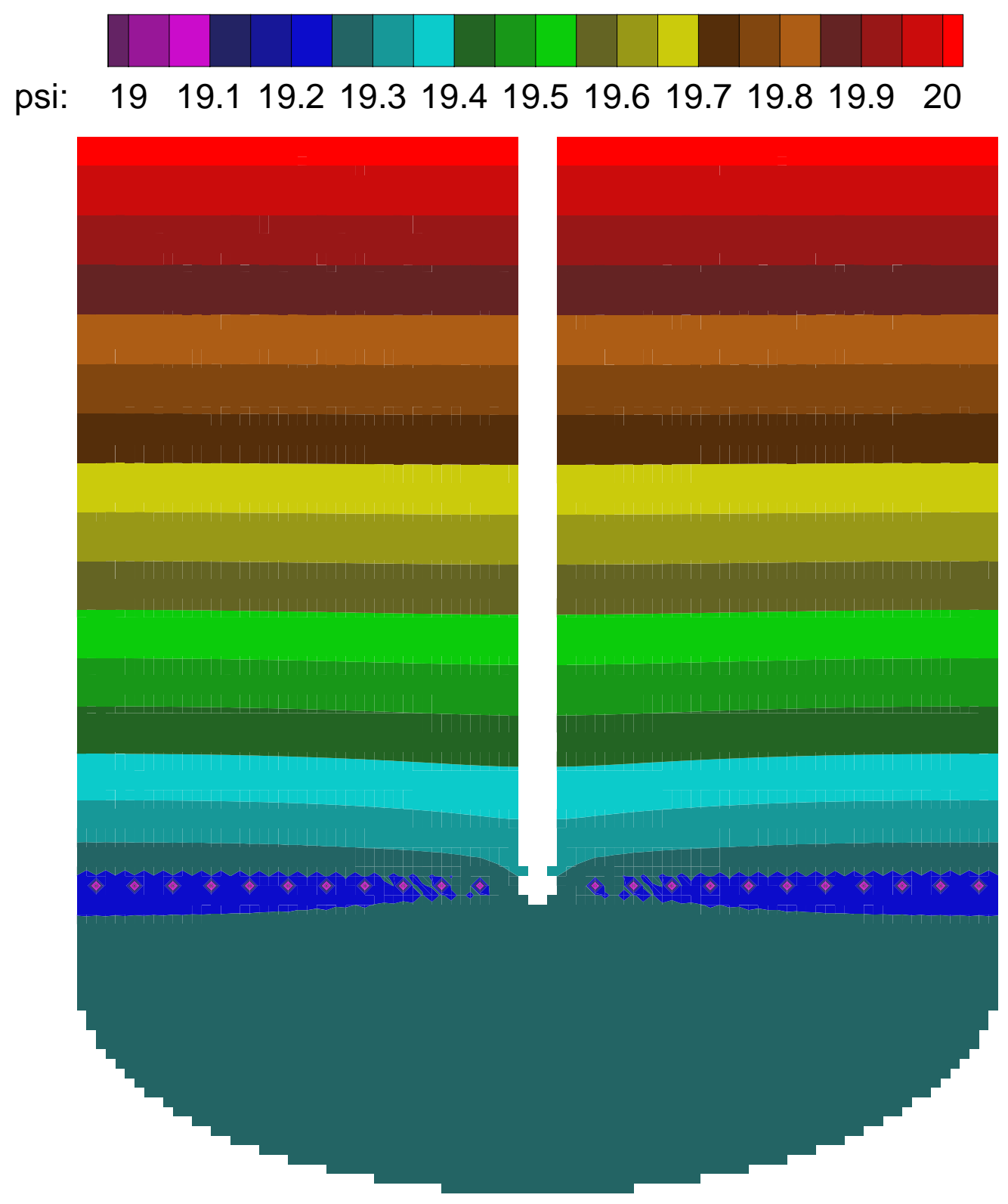

Figure 4-2. Basecase: Y-Z piezometric pressure profile slice $(\mathrm{x}=0)$ of WTP IX column containing SuperLig ${ }^{\circledR} 639$ during loading stage with low resin packing. The feed is $\mathrm{AN}-105$ simulant flowing at $17 \mathrm{gpm}(2.6 \mathrm{BV} / \mathrm{hr})$. 


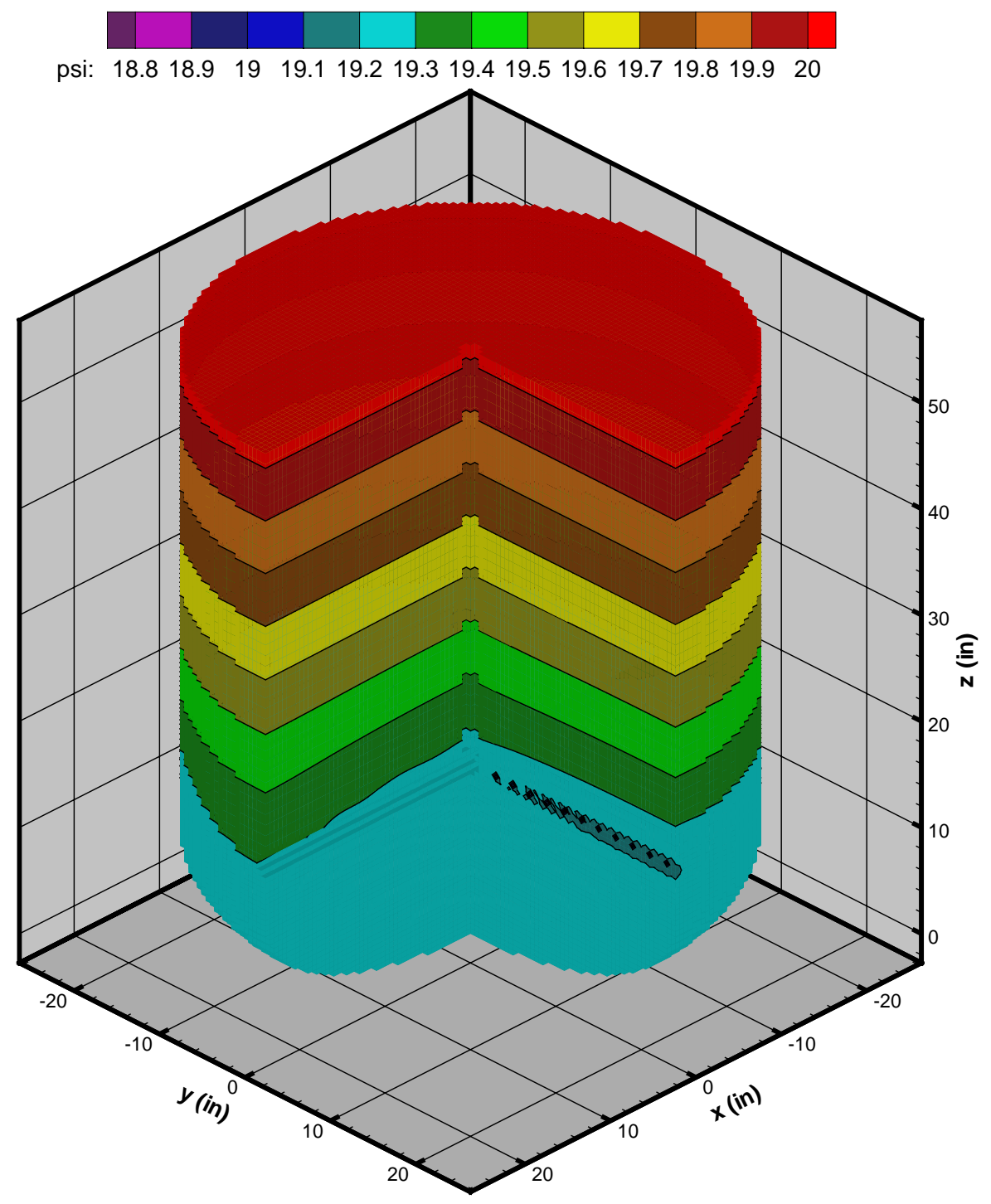

Figure 4-3. Basecase: Piezometric pressure profile of WTP IX column containing SuperLig ${ }^{\circledR}$ 639 during loading stage with low resin packing. The feed is AN-105 simulant flowing at $17 \mathrm{gpm}(2.6 \mathrm{BV} / \mathrm{hr})$. The average pressure drop across the bed is 1.06 psid. 


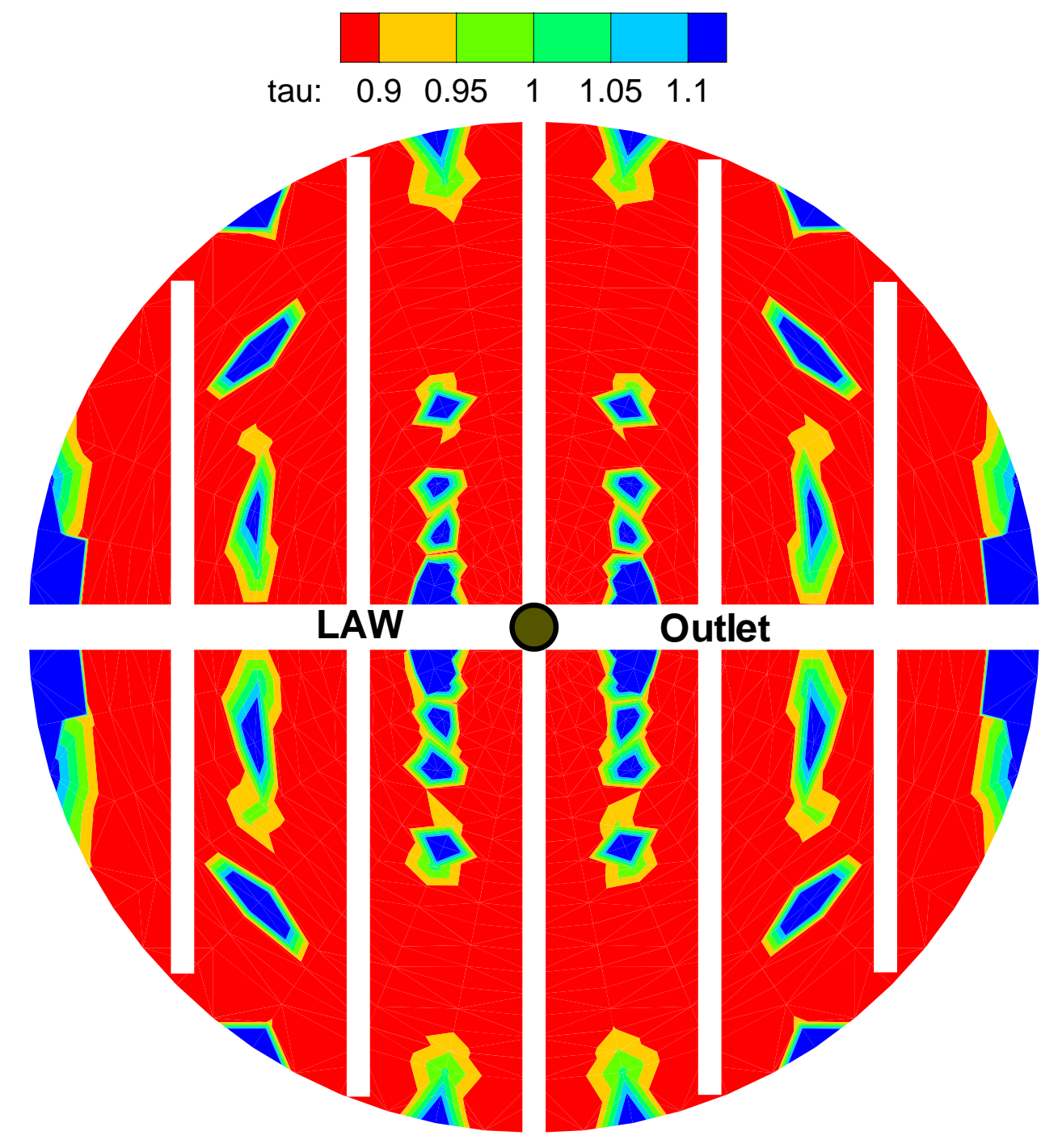

Figure 4-4. Basecase: Cross-sectional view of normalized residence times in SuperLig ${ }^{\circledR} 639$ resin bed. The feed is AN-105 simulant flowing at $17 \mathrm{gpm}(2.6 \mathrm{BV} / \mathrm{hr})$. 


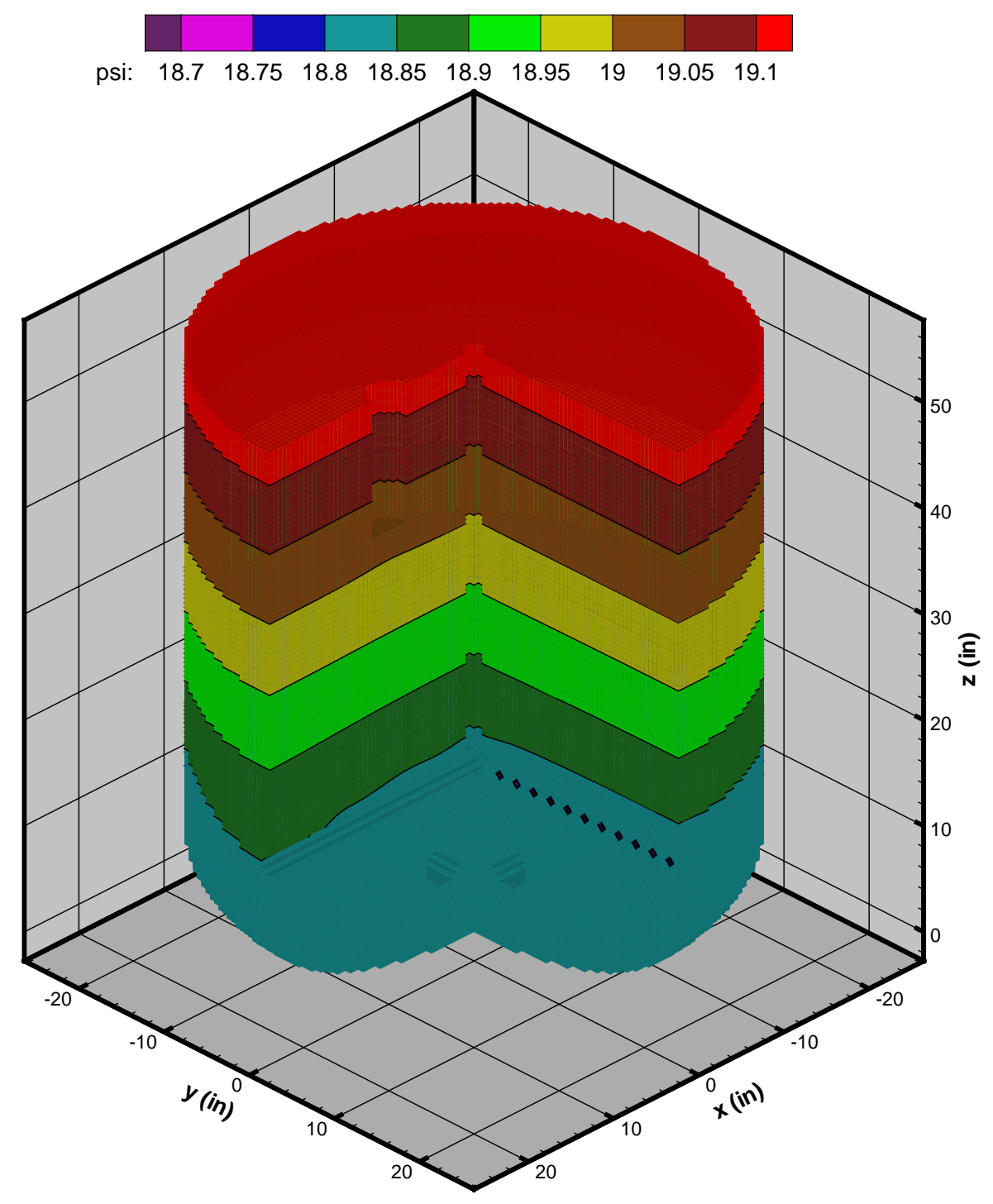

Figure 4-5. Run-1: Piezometric pressure profile of WTP IX column containing SuperLig ${ }^{\circledR}$ 644 during the elution stage and low column packing. The feed is $0.5 \mathrm{M} \mathrm{HNO}_{3}$ flowing at $17 \mathrm{gpm}(2.6 \mathrm{BV} / \mathrm{hr})$. The average pressure drop across the bed is 0.42 psid. 


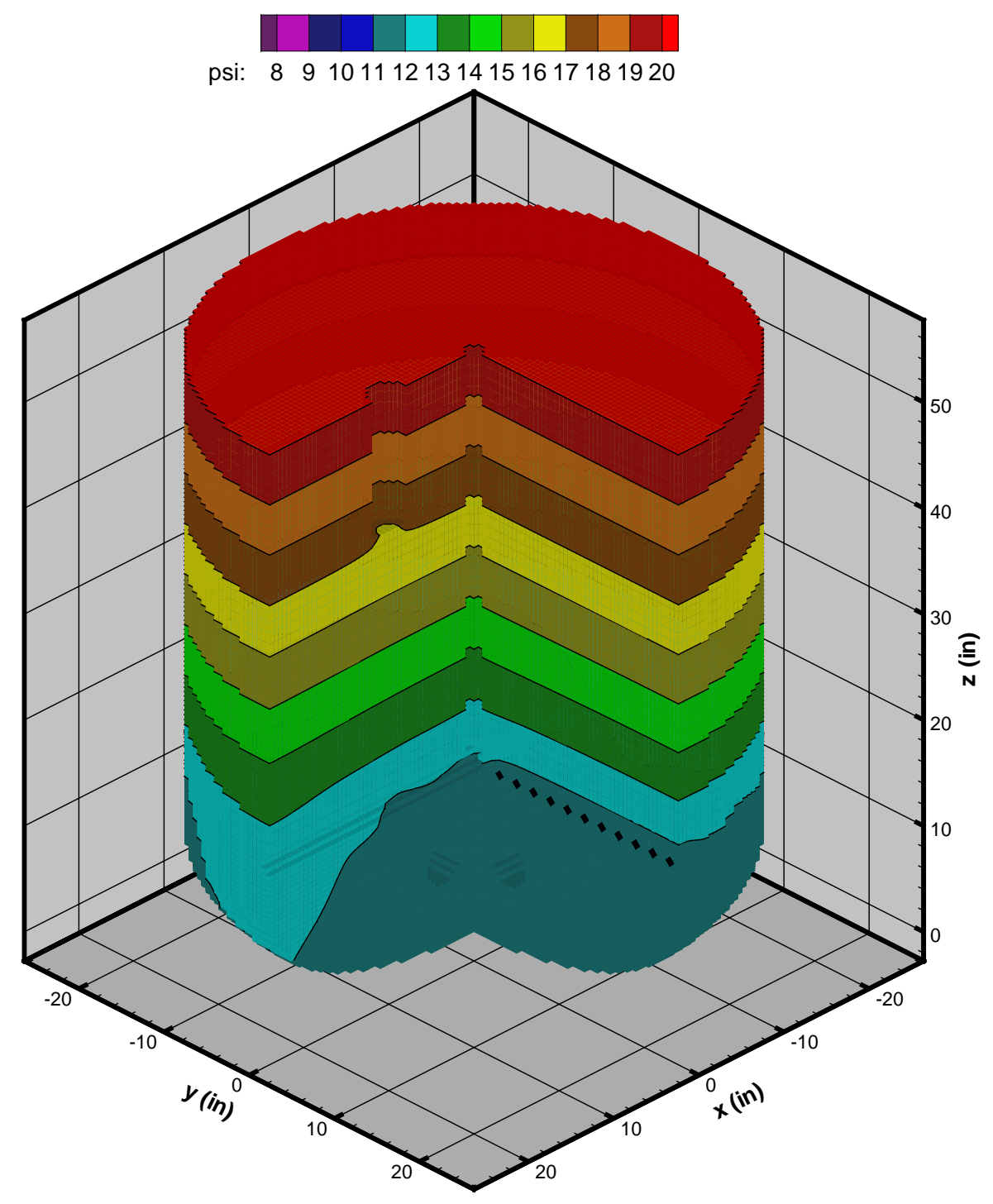

Figure 4-6. Run-2: Piezometric pressure profile of WTP IX column containing SuperLig ${ }^{\circledR}$ 644 during the loading stage and high column packing. The feed is AZ-102 (Envelope B) simulant flowing at $17 \mathrm{gpm}$. The average pressure drop across the bed is 11.58 psid. 


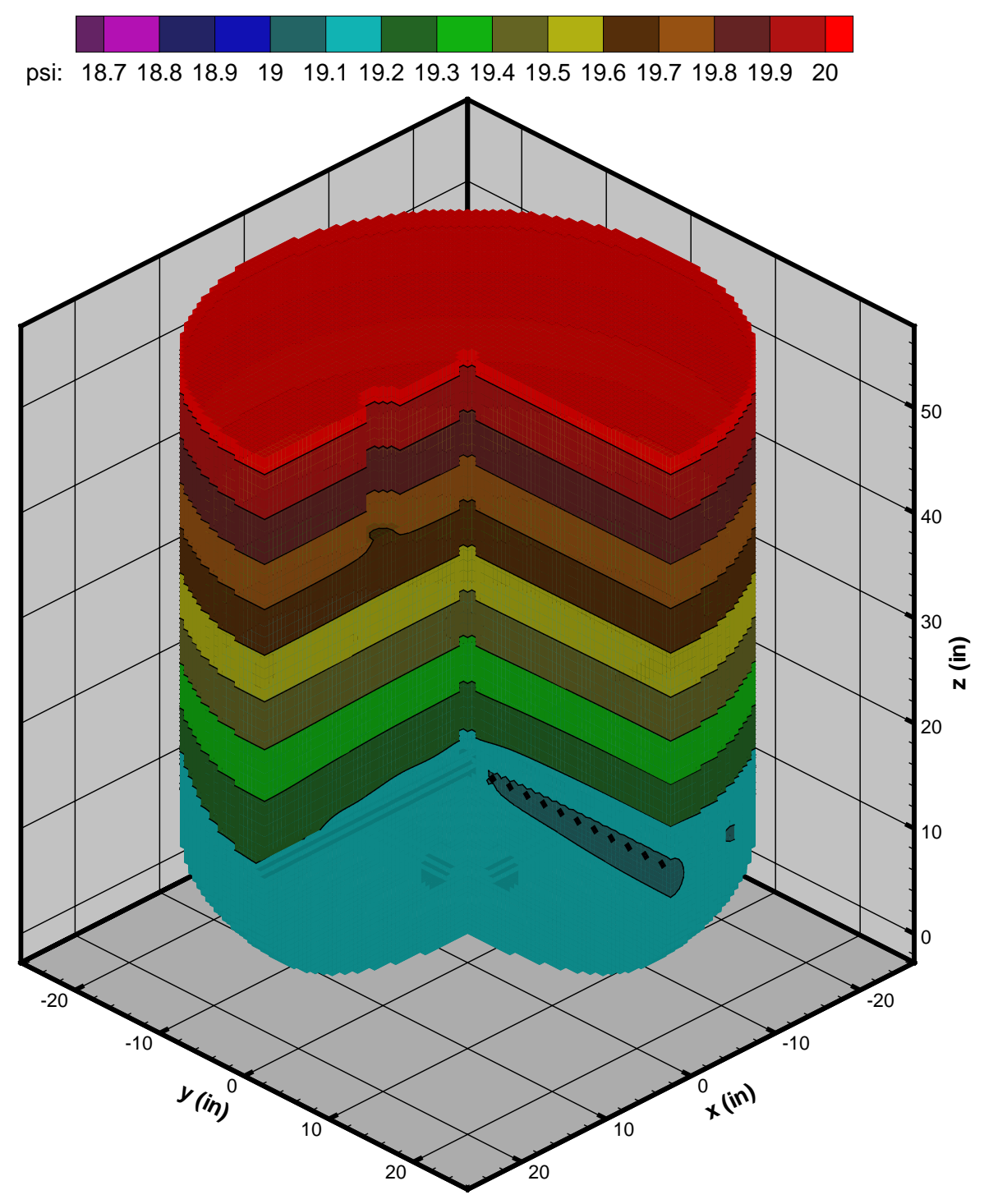

Figure 4-7. Run-3: Piezometric pressure profile of WTP IX column containing SuperLig ${ }^{\circledR}$ 644 during the loading stage and low column packing. The feed is AZ-102 (Envelope B) simulant flowing at $17 \mathrm{gpm}(2.6 \mathrm{BV} / \mathrm{hr})$. The average pressure drop across the bed is 1.29 psid. 


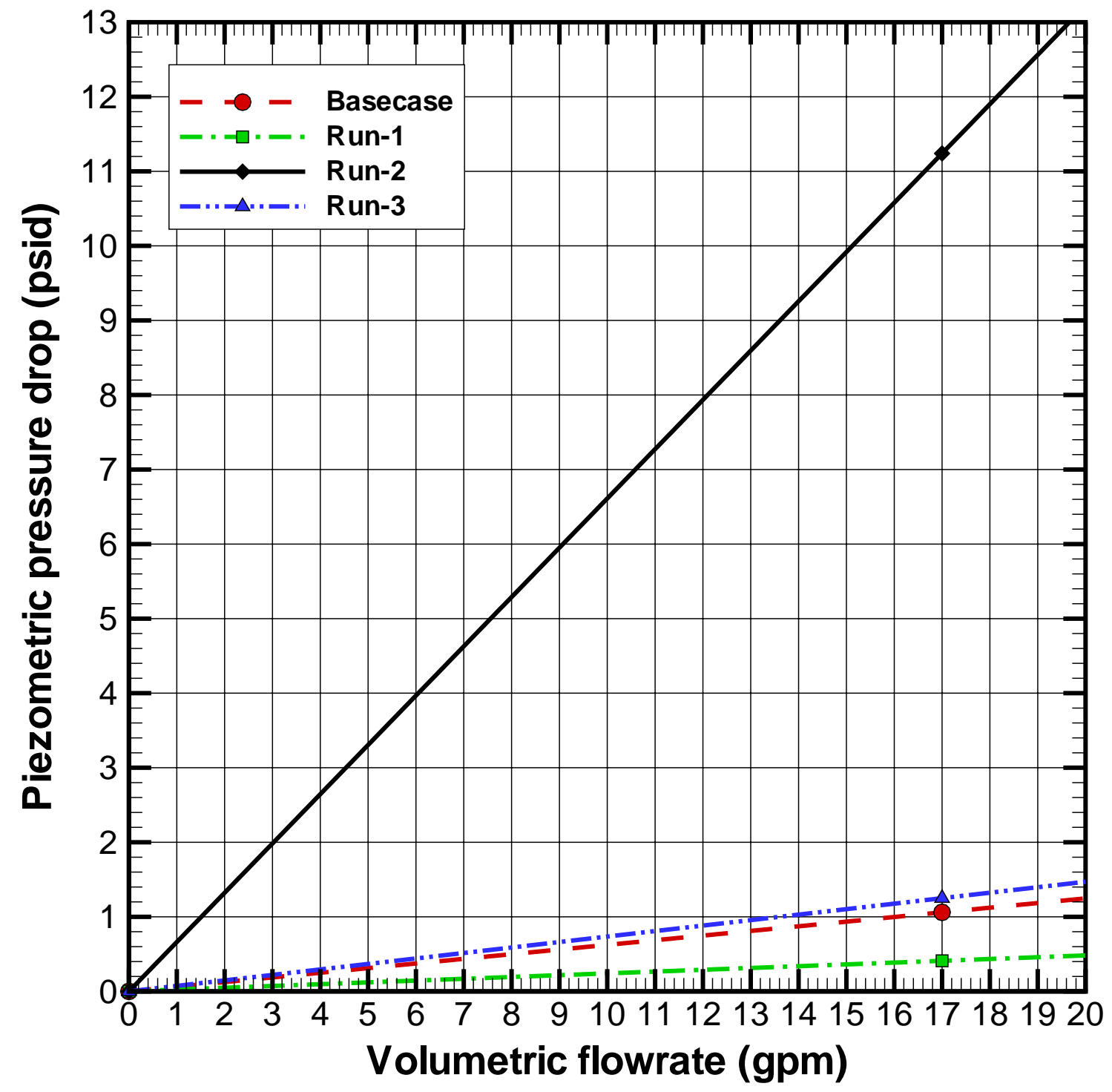

Figure 4-8. Average piezometric pressure drop across resin bed for the four case studies considered (symbols). The lines represent estimates of the pressure drop at other flowrates where the linearity of the model is employed. 


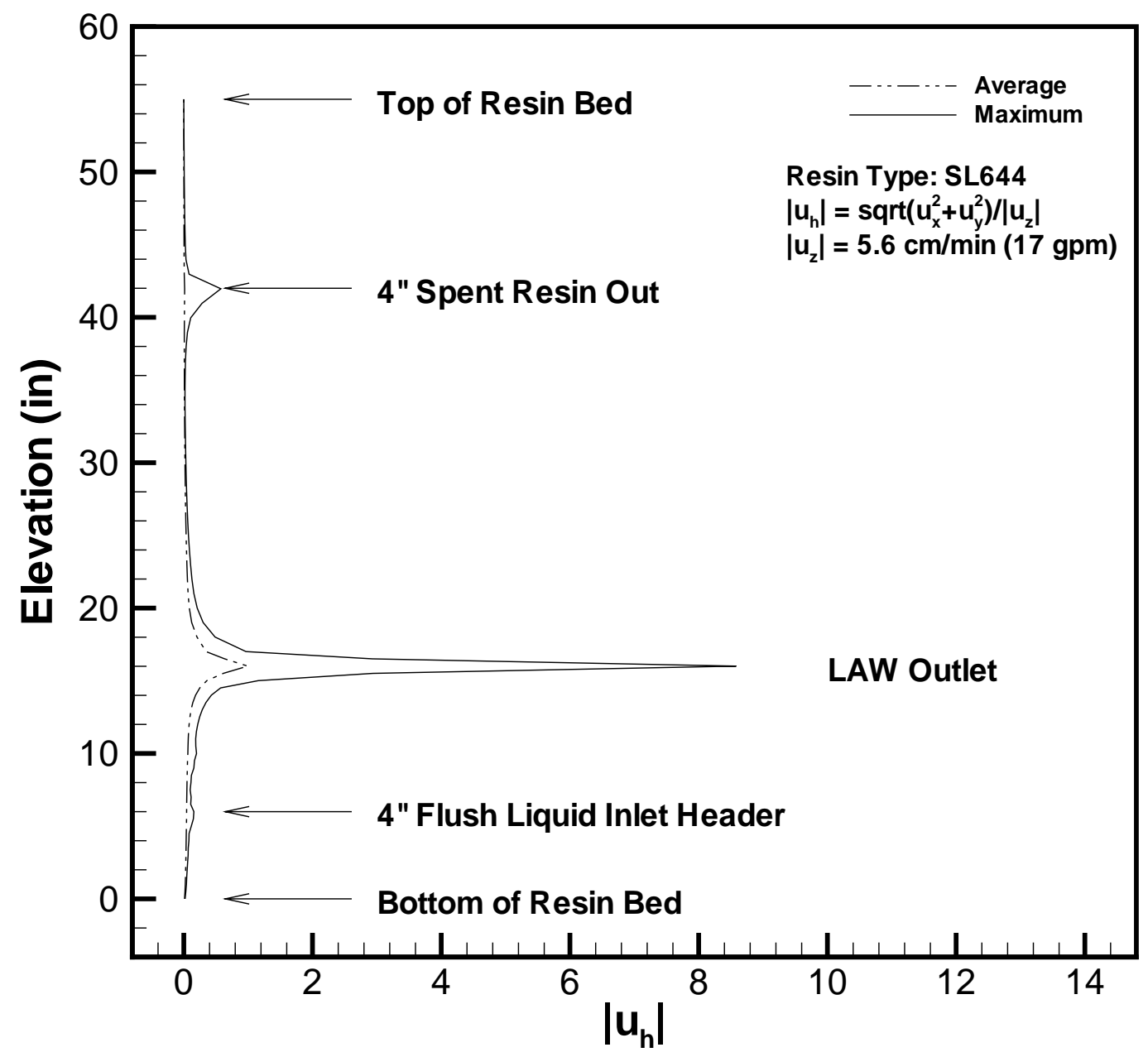

Figure 4-9. $\quad$ Normalized magnitude of horizontal velocity versus bed elevation in a SuperLig ${ }^{\circledR}$ 644 packed column. The levels of disturbance due to structural components and outflow boundaries are seen as peaks in local horizontal velocity. 


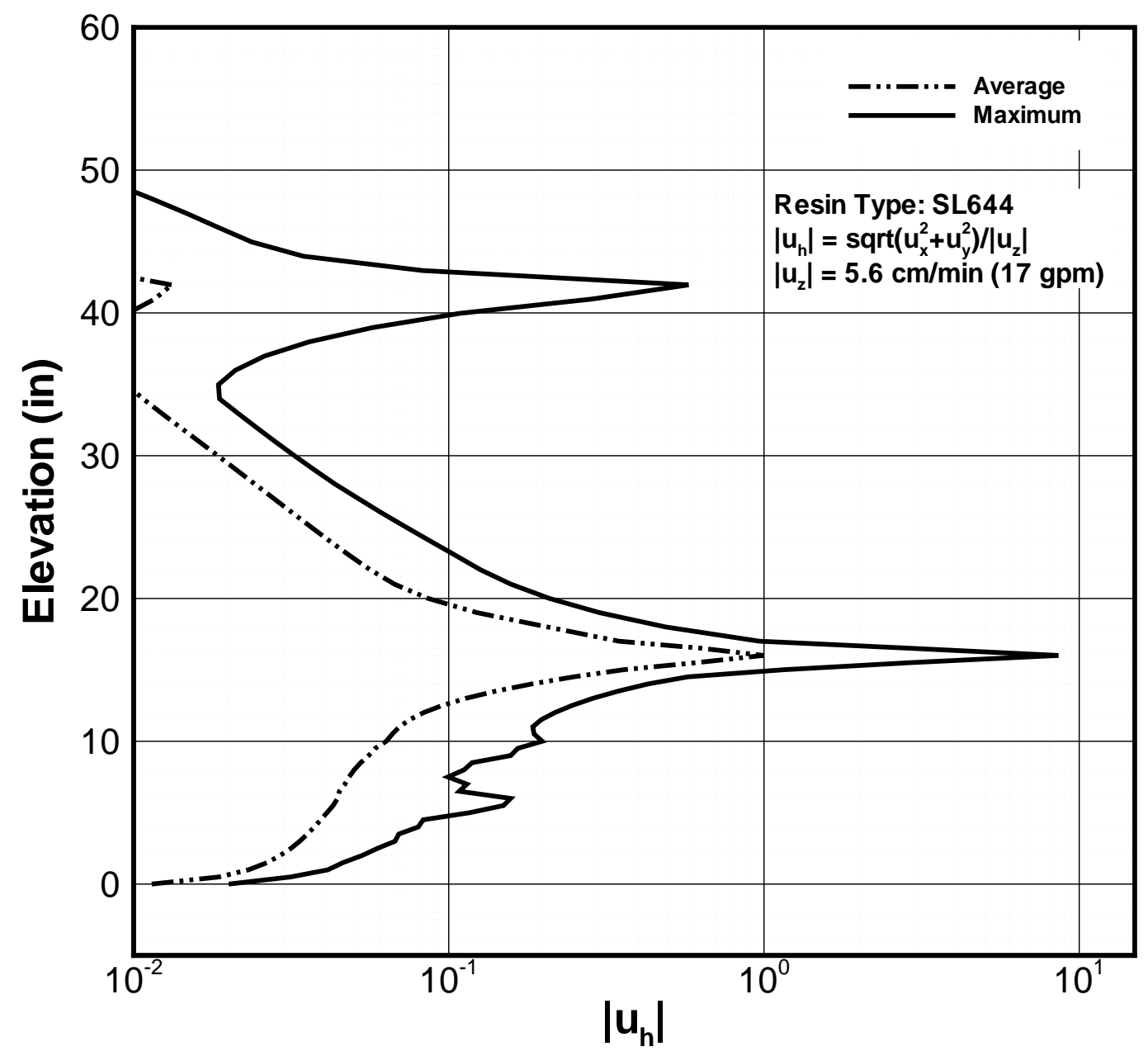

Figure 4-10. Normalized magnitude of horizontal velocity versus bed elevation in a SuperLiq ${ }^{\circledR}$ 644 packed column (Semilog scale). Axial average and maximum values are plotted illustrating how local the disturbances are within a horizontal plane. 


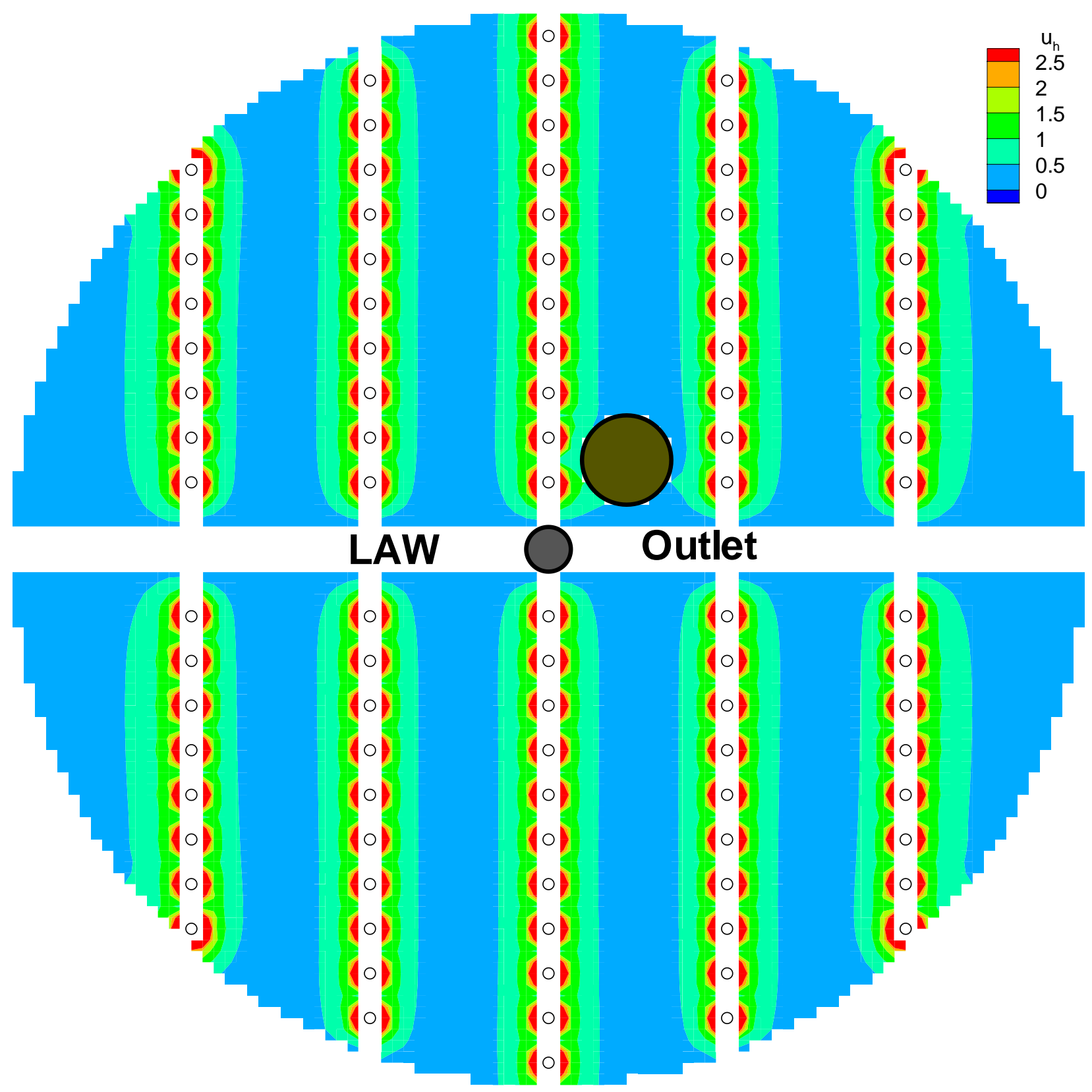

Figure 4-11. Contour plot of normalized horizontal velocity at the elevation of the LAW outlet distributor. The inlet liquid feed flow is $17 \mathrm{gpm}(2.6 \mathrm{BV} / \mathrm{hr})$ or $5.6 \mathrm{~cm} / \mathrm{min}$ superficial velocity. 


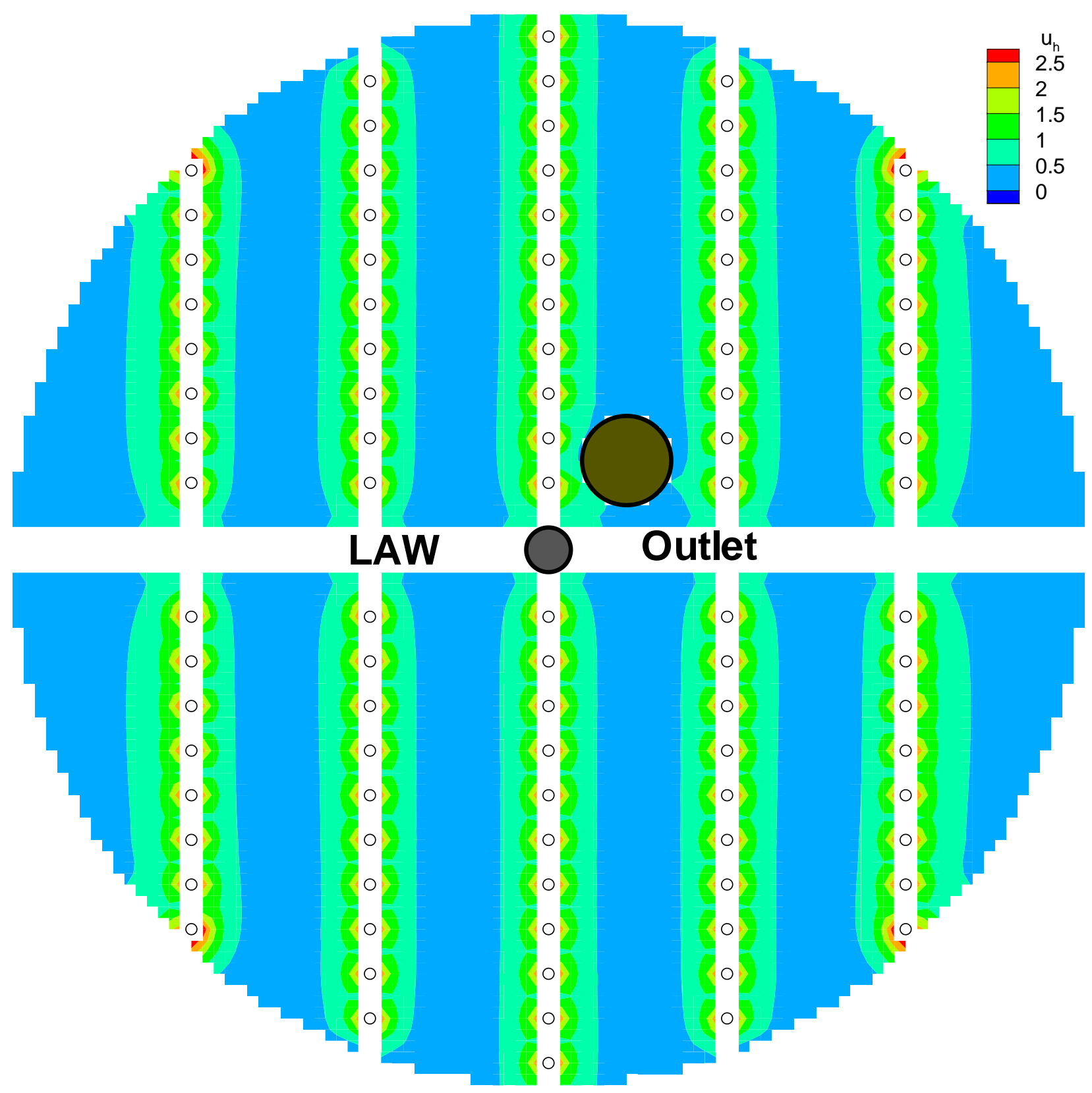

Figure 4-12. Contour plot of normalized horizontal velocity $1 / 2$ inch above the elevation of the LAW outlet distributor. The inlet liquid feed flow is $17 \mathrm{gpm}(2.6 \mathrm{BV} / \mathrm{hr})$ or 5.6 $\mathrm{cm} /$ min superficial velocity. 


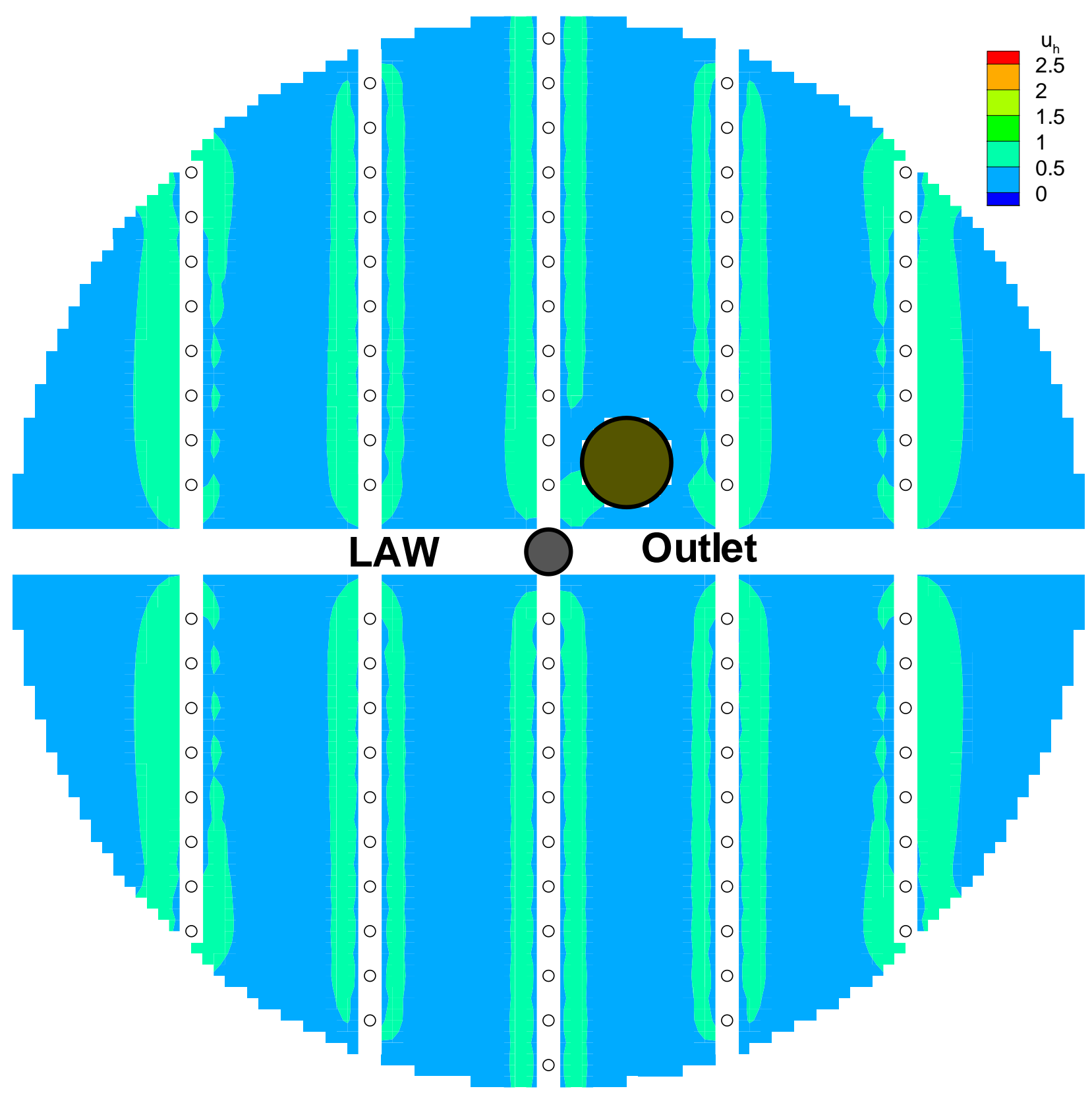

Figure 4-13. Contour plot of normalized horizontal velocity 1 inch above the elevation of the LAW outlet distributor. The inlet liquid feed flow is $17 \mathrm{gpm}(2.6 \mathrm{BV} / \mathrm{hr})$ or 5.6 $\mathrm{cm} /$ min superficial velocity. 


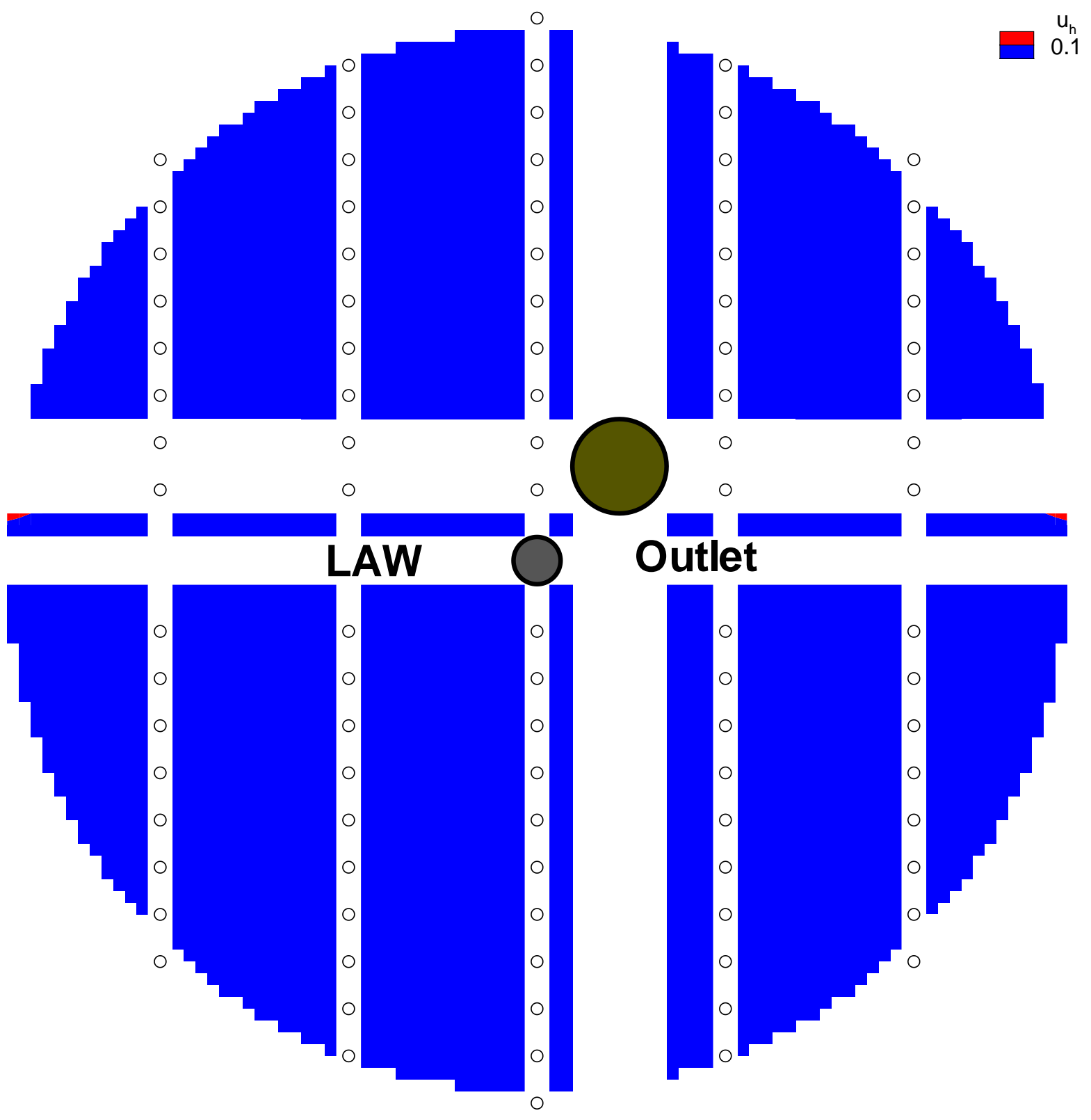

Figure 4-14. Contour plot of normalized horizontal velocity 9 inches below the elevation of the LAW outlet distributor. The inlet liquid feed flow is $17 \mathrm{gpm}(2.6 \mathrm{BV} / \mathrm{hr})$ or 5.6 $\mathrm{cm} /$ min superficial velocity. 


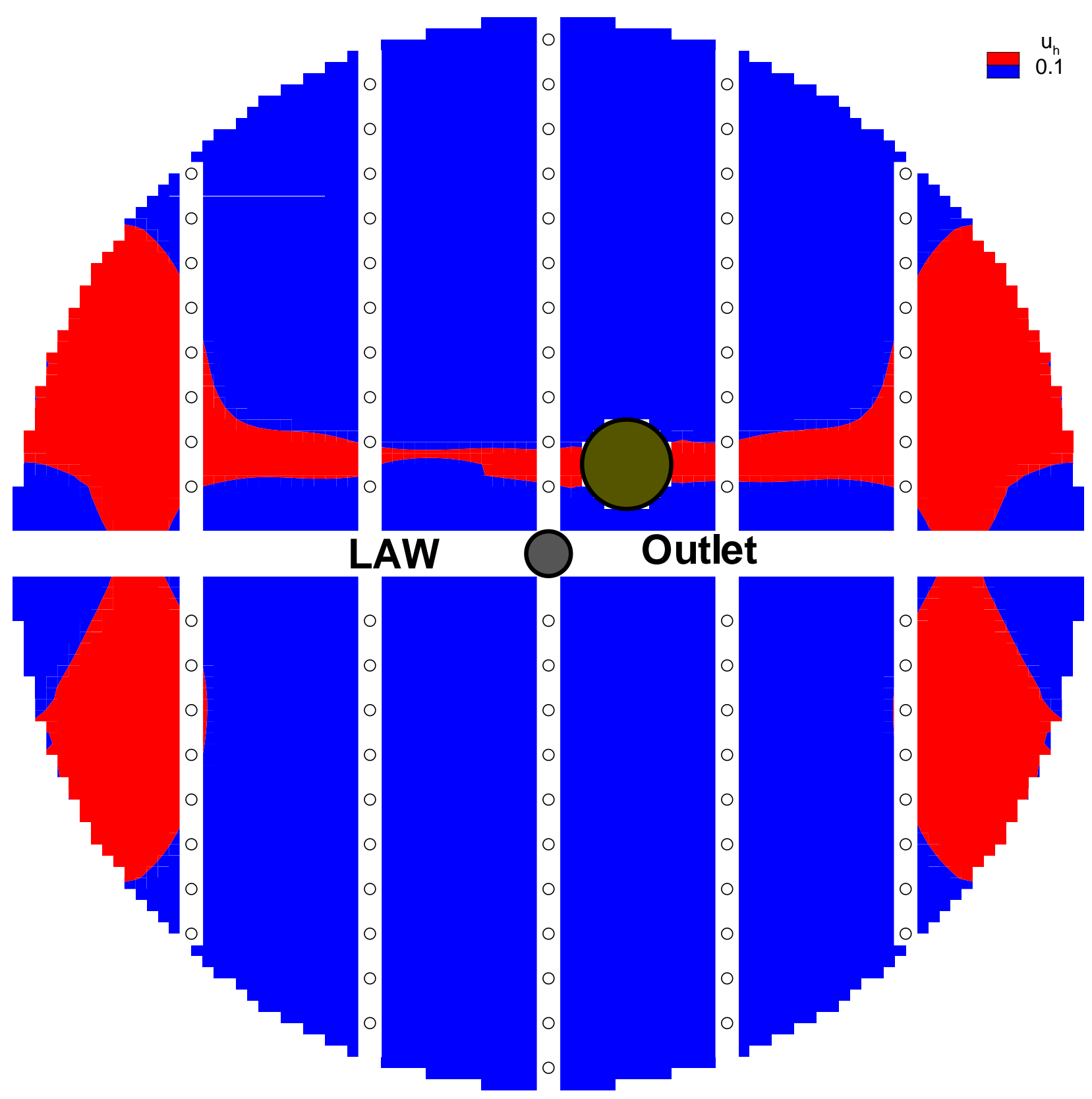

Figure 4-15. Contour plot of normalized horizontal velocity 6 inches below the elevation of the LAW outlet distributor. The inlet liquid feed flow is $17 \mathrm{gpm}(2.6 \mathrm{BV} / \mathrm{hr})$ or 5.6 $\mathrm{cm} /$ min superficial velocity. 


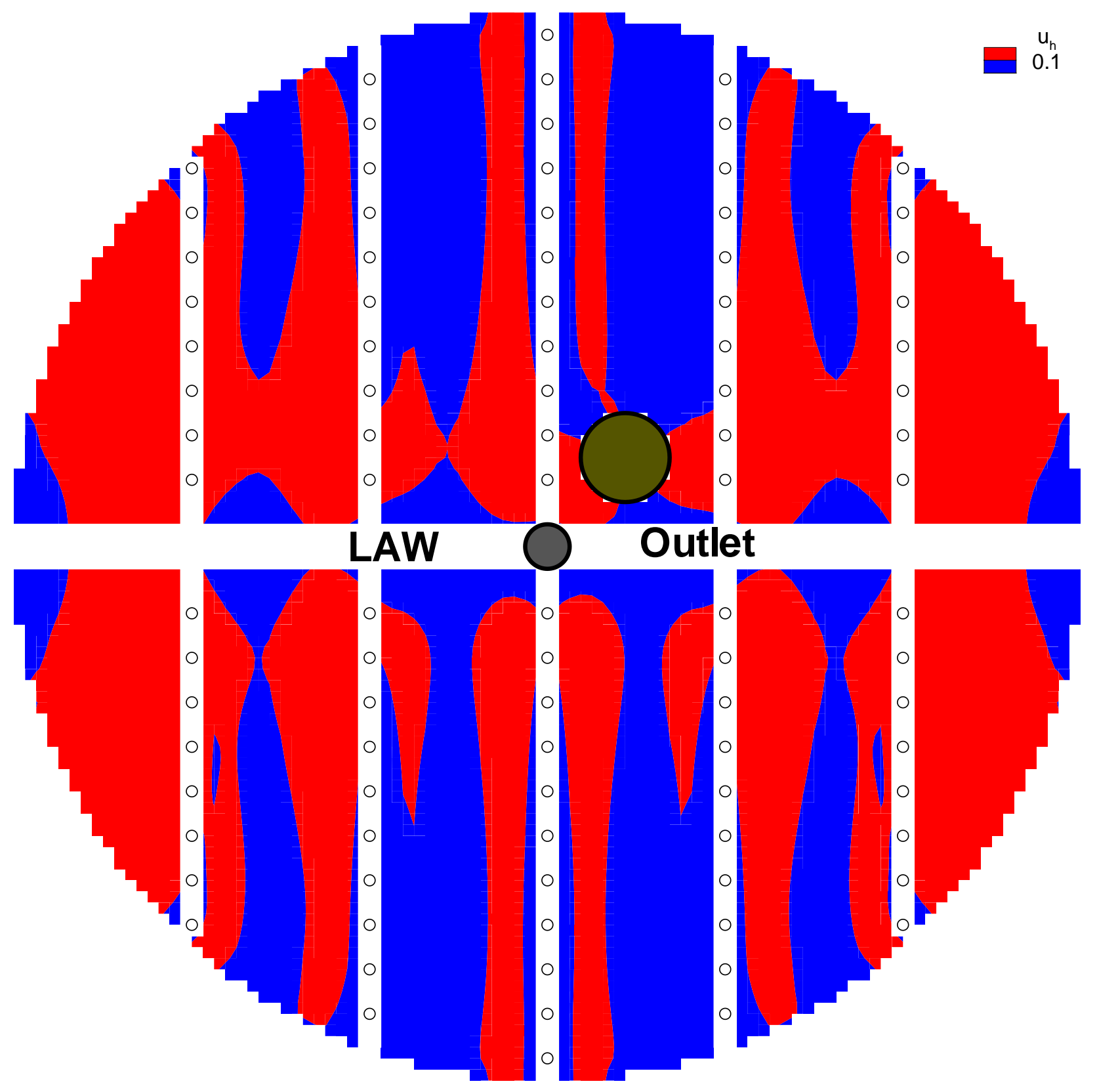

Figure 4-16. Contour plot of normalized horizontal velocity 3 inches below the elevation of the LAW outlet distributor. The inlet liquid feed flow is $17 \mathrm{gpm}(2.6 \mathrm{BV} / \mathrm{hr})$ or 5.6 $\mathrm{cm} /$ min superficial velocity. 


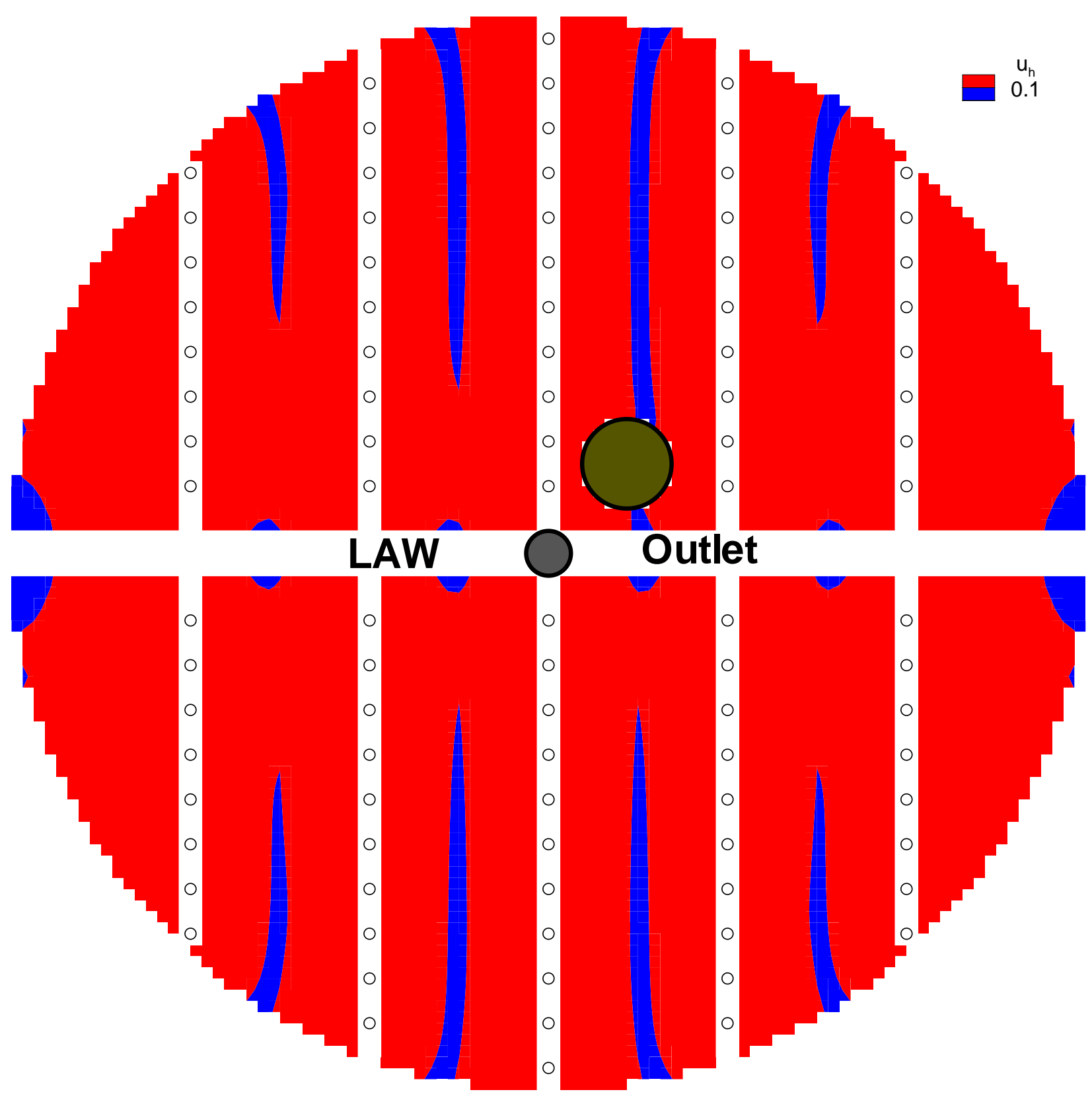

Figure 4-17. Contour plot of normalized horizontal velocity at the elevation of the LAW outlet distributor. The inlet liquid feed flow is $17 \mathrm{gpm}(2.6 \mathrm{BV} / \mathrm{hr})$ or $5.6 \mathrm{~cm} / \mathrm{min}$ superficial velocity. 


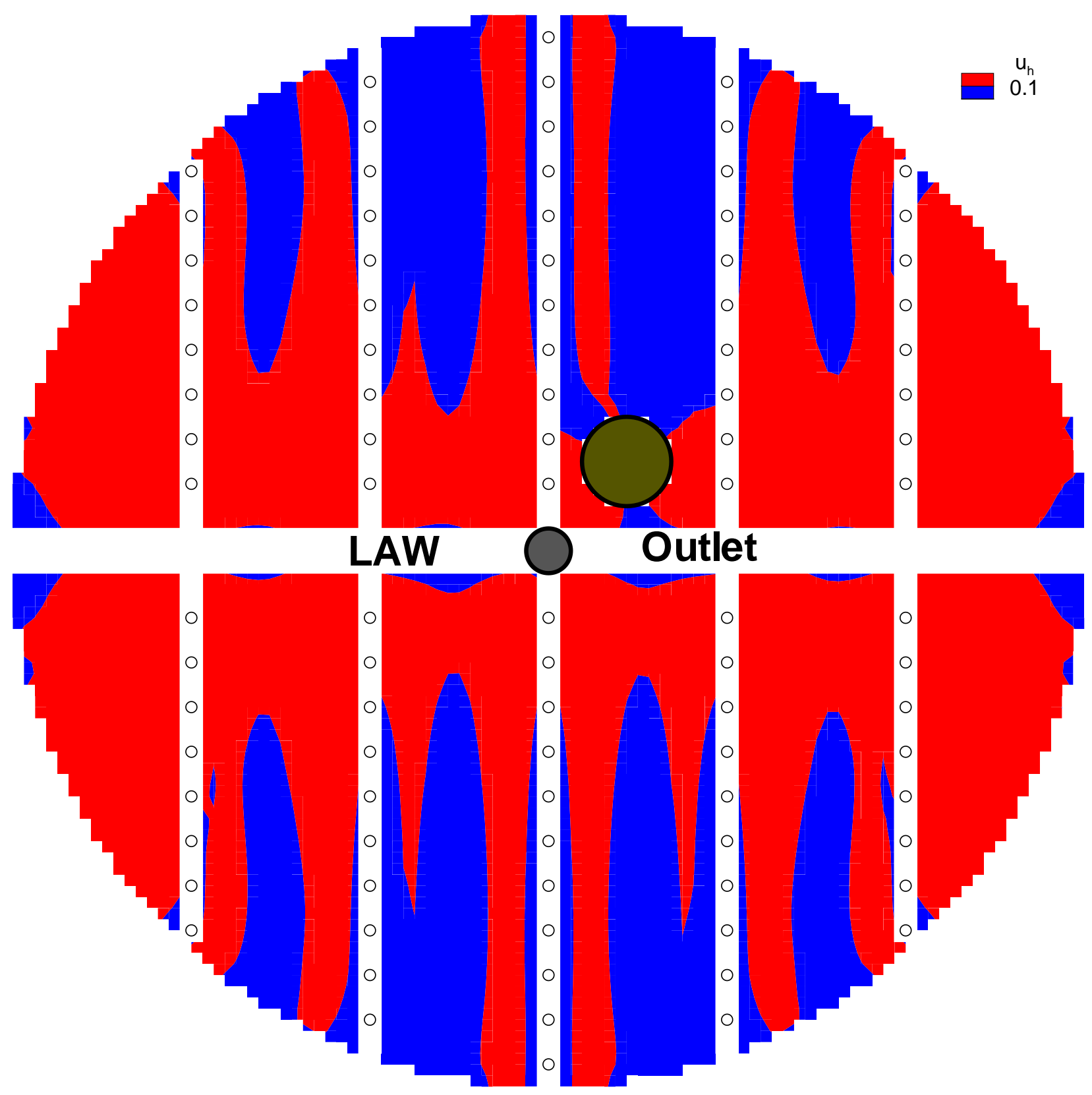

Figure 4-18. Contour plot of normalized horizontal velocity 3 inch above the elevation of the LAW outlet distributor. The inlet liquid feed flow is $17 \mathrm{gpm}(2.6 \mathrm{BV} / \mathrm{hr})$ or 5.6 $\mathrm{cm} /$ min superficial velocity. 


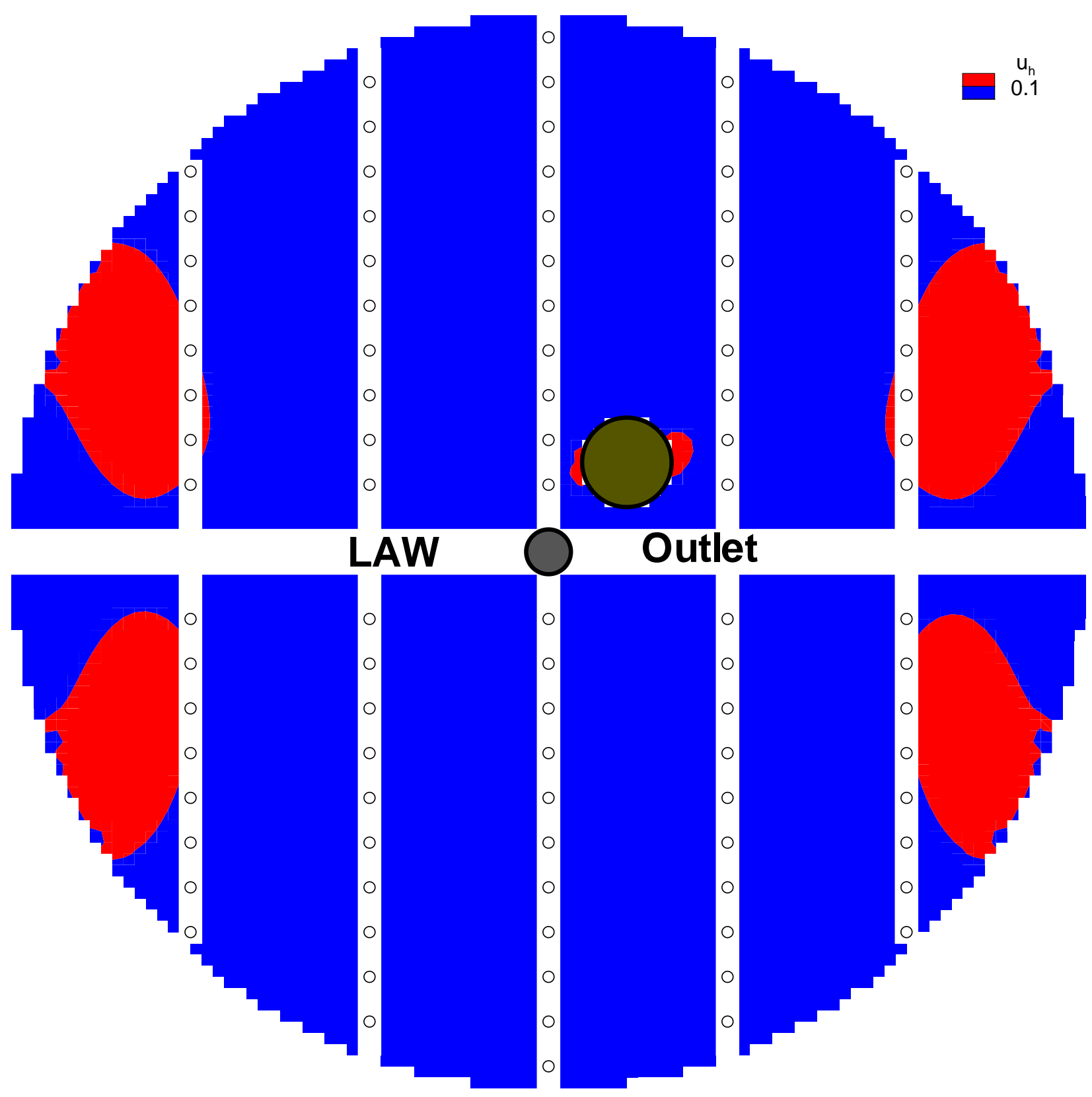

Figure 4-19. Contour plot of normalized horizontal velocity 6 inch above the elevation of the LAW outlet distributor. The inlet liquid feed flow is $17 \mathrm{gpm}(2.6 \mathrm{BV} / \mathrm{hr})$ or 5.6 $\mathrm{cm} / \mathrm{min}$ superficial velocity. 


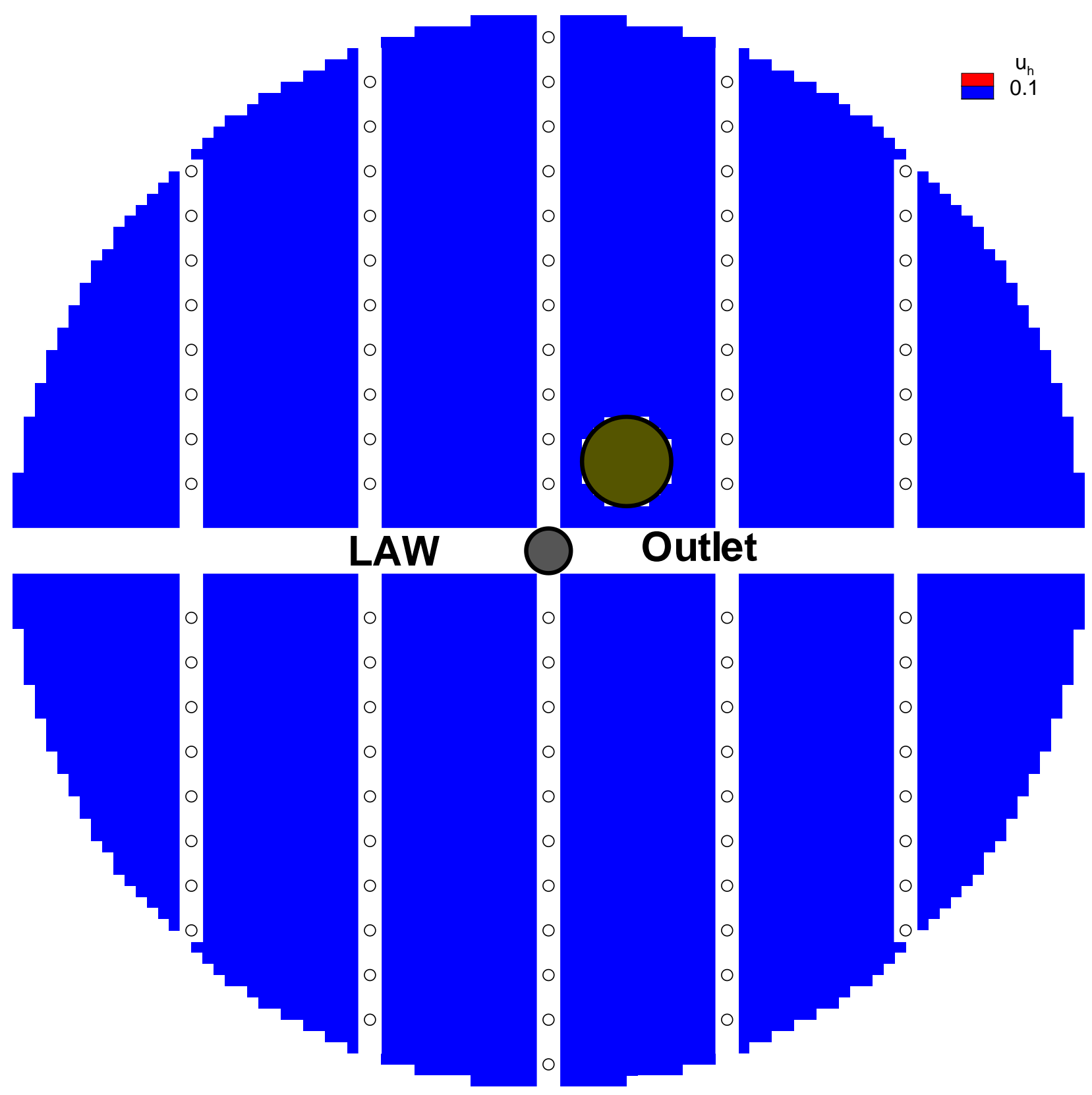

Figure 4-20. Contour plot of normalized horizontal velocity 9 inch above the elevation of the LAW outlet distributor. The inlet liquid feed flow is $17 \mathrm{gpm}(2.6 \mathrm{BV} / \mathrm{hr})$ or 5.6 $\mathrm{cm} /$ min superficial velocity. 


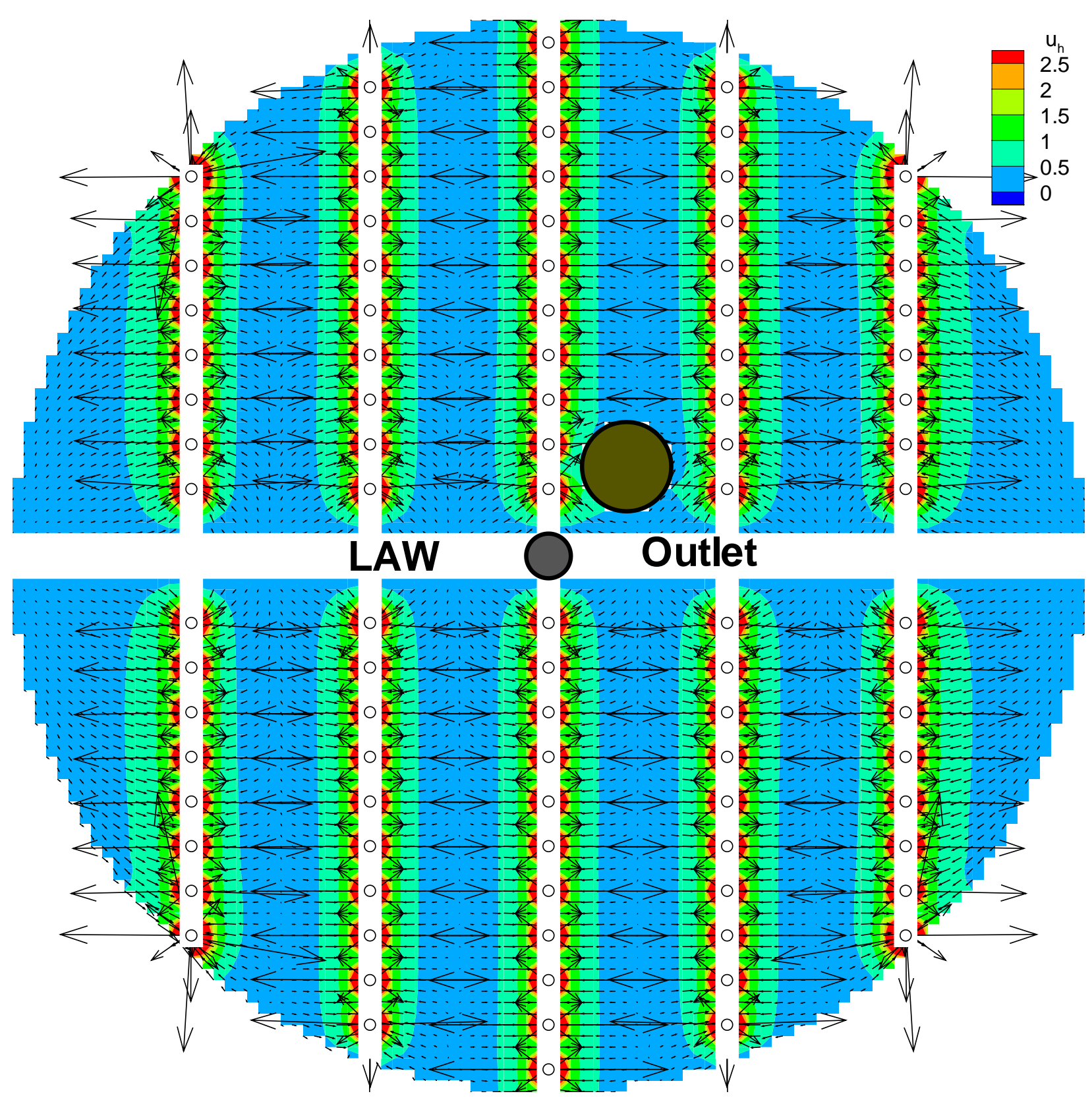

Figure 4-21. Contour and vector plot of normalized horizontal velocity at the elevation of the LAW outlet distributor. The inlet liquid feed flow is $17 \mathrm{gpm}(2.6 \mathrm{BV} / \mathrm{hr})$ or 5.6 $\mathrm{cm} /$ min superficial velocity. 


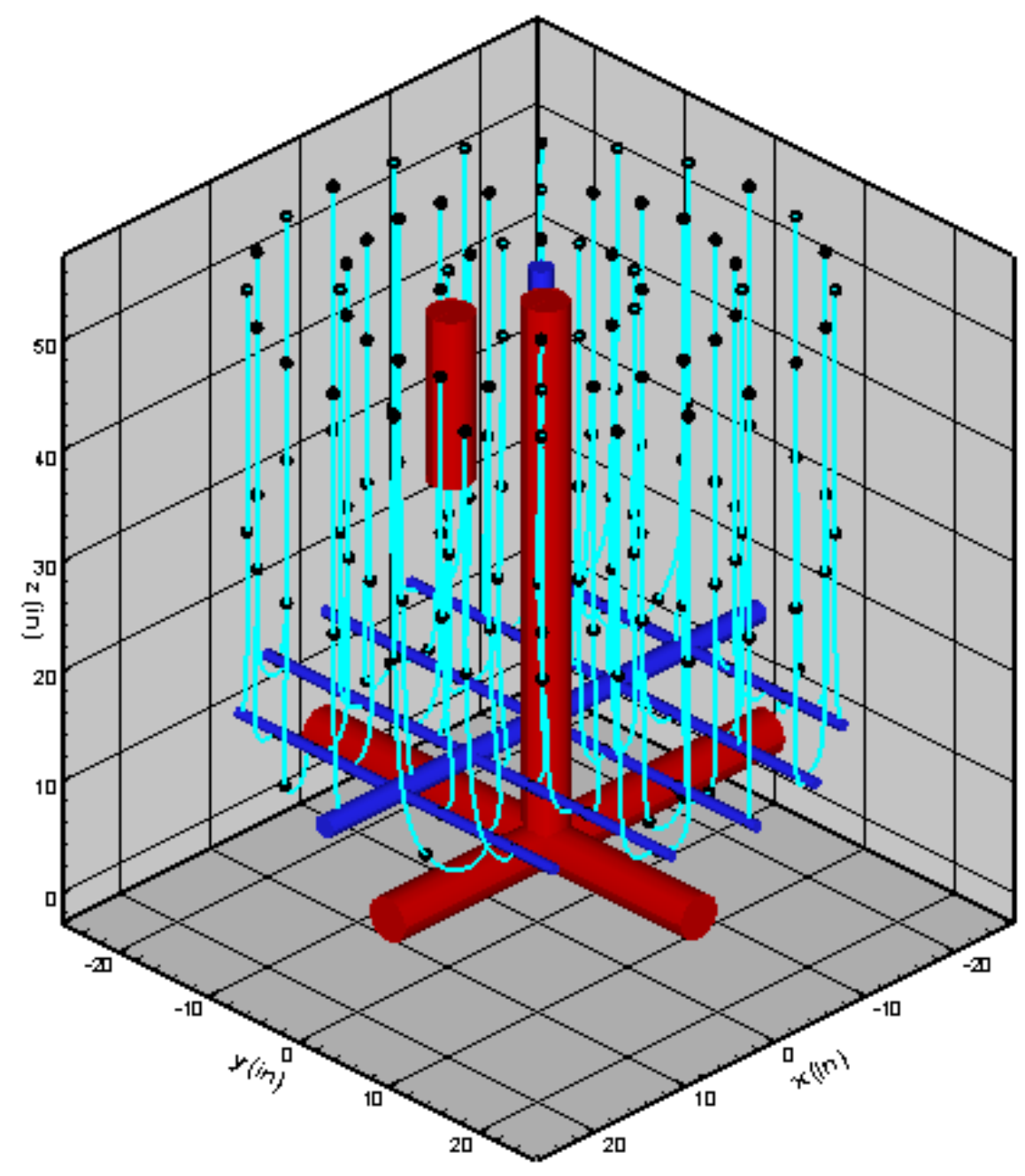

Figure 4-22. 3-dimensional streamtraces from the inlet of the packed bed to the LAW outlet distributor. Timing markers (black circles) are plotted every 10 minutes. The inlet liquid feed flow is $17 \mathrm{gpm}(2.6 \mathrm{BV} / \mathrm{hr})$ or $5.6 \mathrm{~cm} / \mathrm{min}$ superficial velocity. 

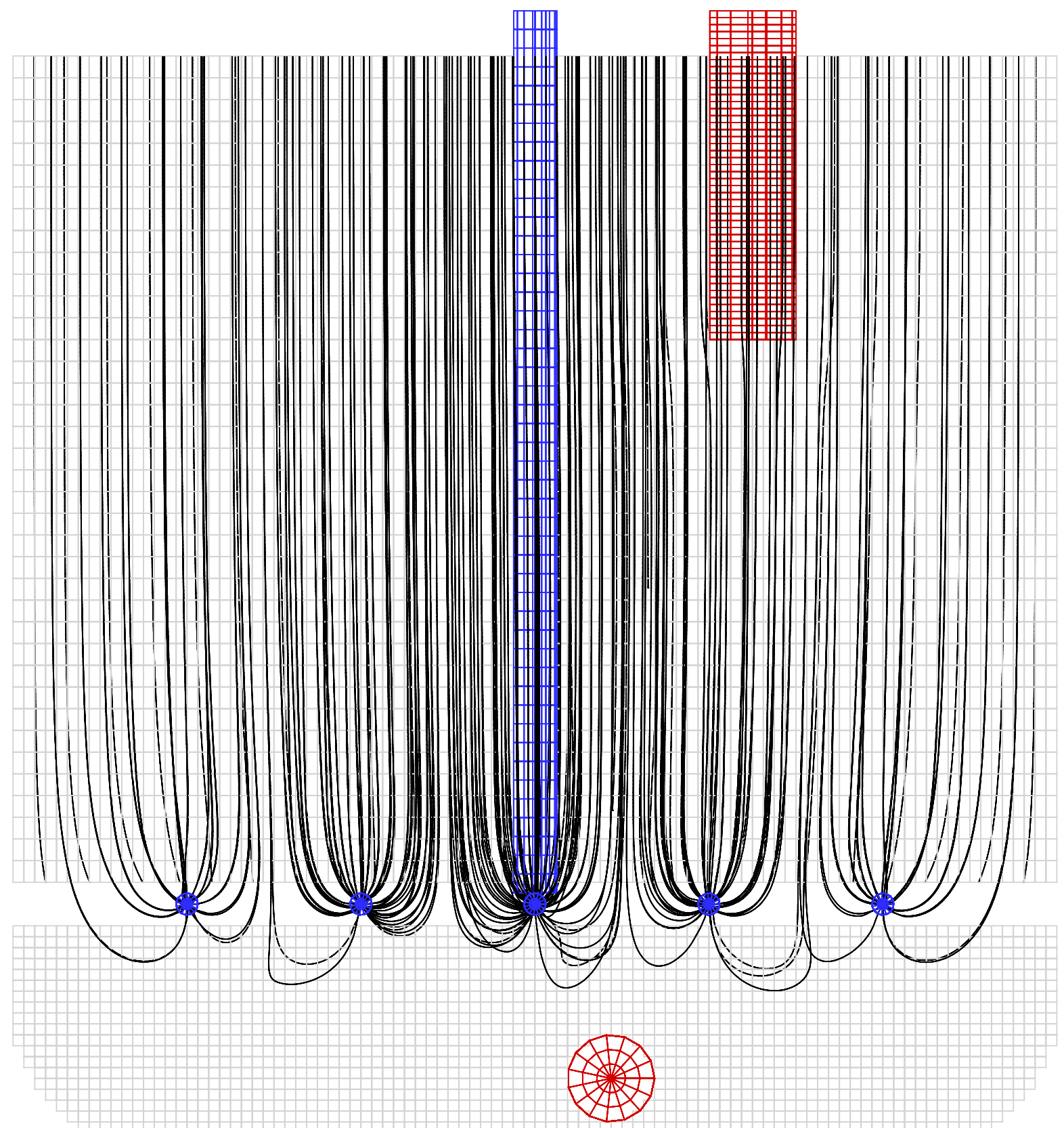

Figure 4-23. $\mathrm{X}-\mathrm{Z}$ projection (at $\mathrm{Y}=2$ inches) of 3-dimensional streamtraces from the inlet of the packed bed to the LAW outlet distributor. The inlet liquid feed flow is 17 gpm $(2.6 \mathrm{BV} / \mathrm{hr})$ or $5.6 \mathrm{~cm} / \mathrm{min}$ superficial velocity. The outlet distributor components are shown in blue and the resin distributors in red. 


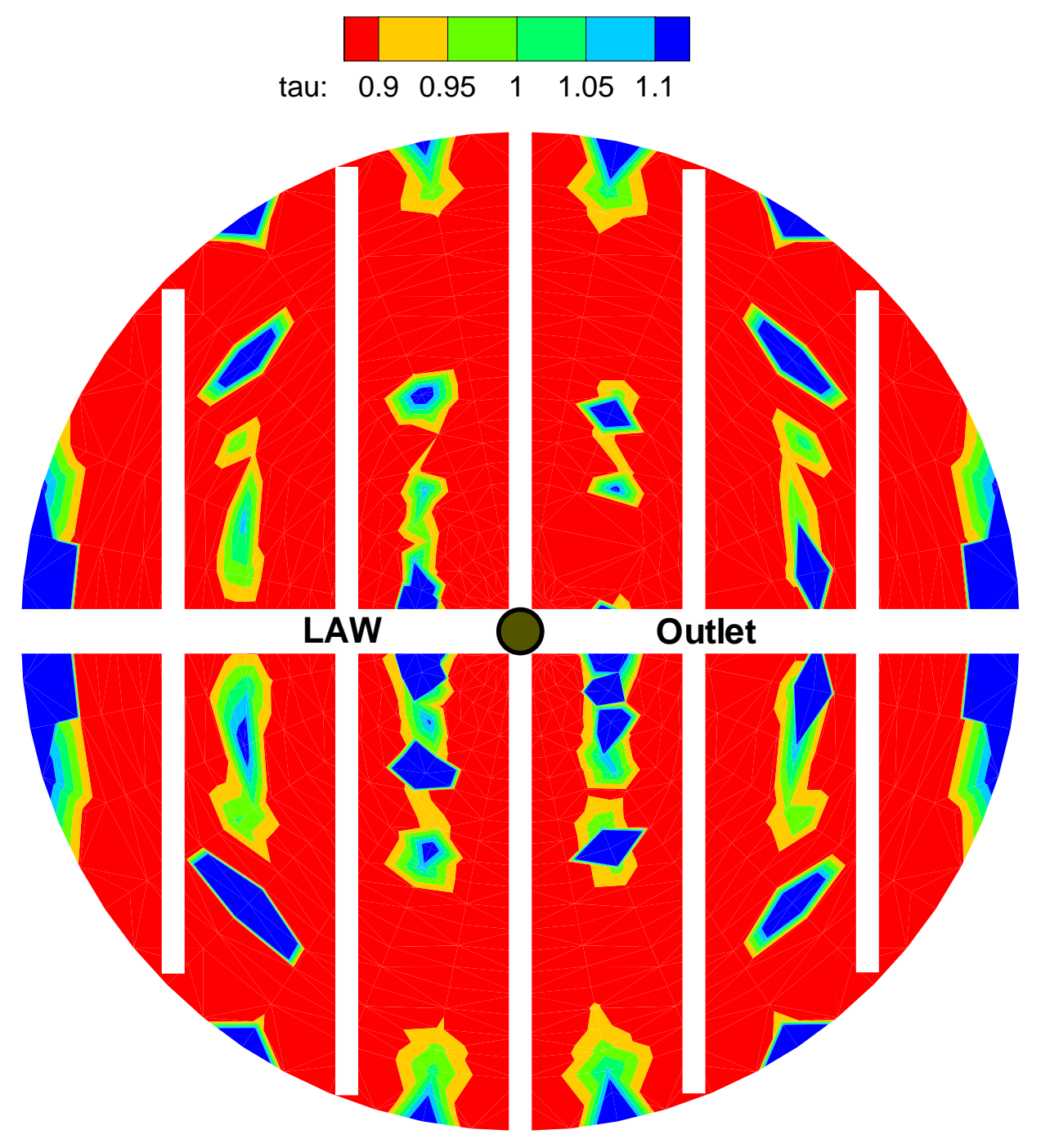

Figure 4-24. Normalized residence times in a SuperLig ${ }^{\circledR} 644$ packed bed. The inlet liquid feed flow is $17 \mathrm{gpm}(2.6 \mathrm{BV} / \mathrm{hr})$ or $5.6 \mathrm{~cm} / \mathrm{min}$ superficial velocity. 


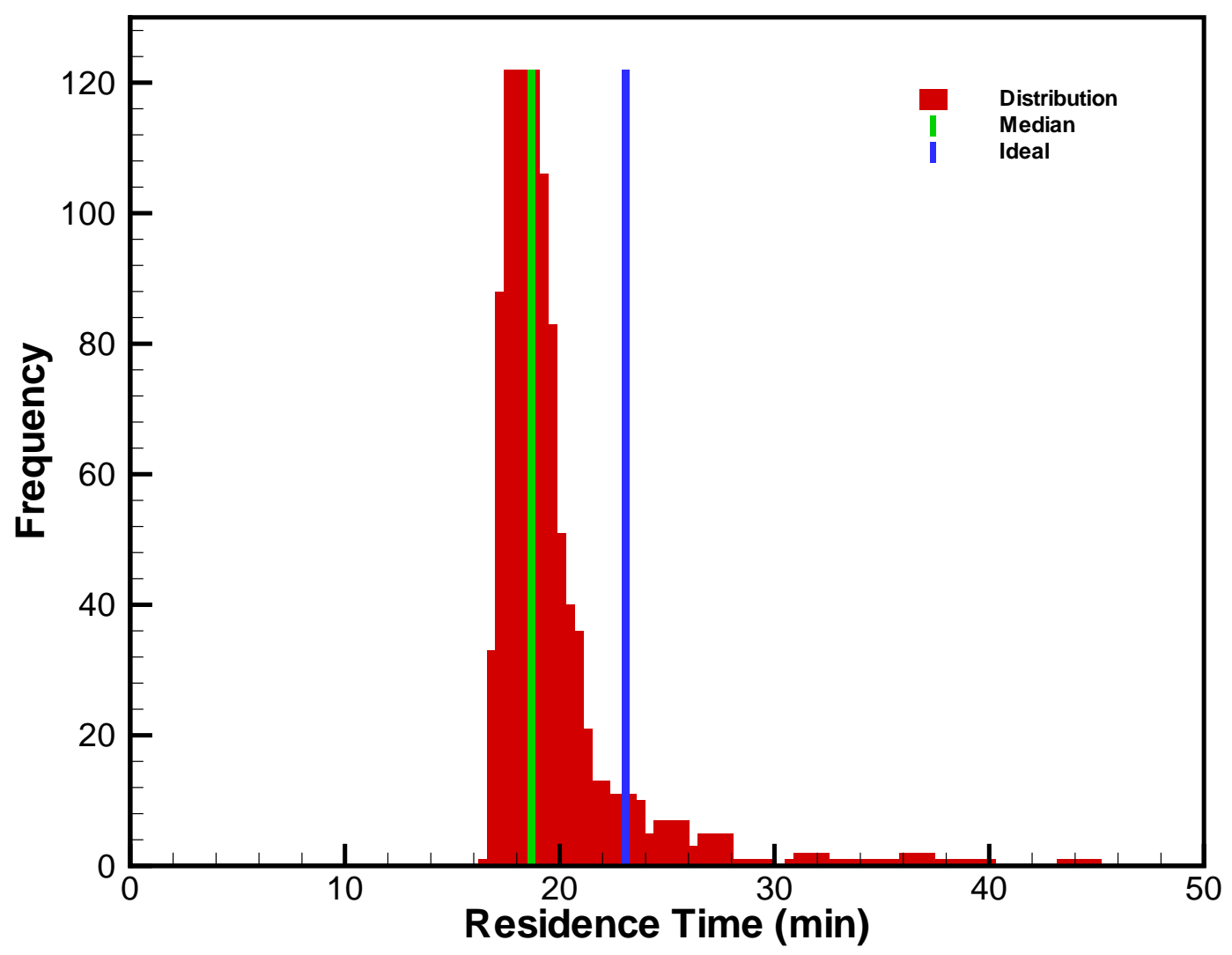

Figure 4-25. Histogram of residence times based on superficial velocity in a SuperLig ${ }^{\circledR} 644$ packed bed. The inlet liquid feed flow is $17 \mathrm{gpm}(2.6 \mathrm{BV} / \mathrm{hr})$ or $5.6 \mathrm{~cm} / \mathrm{min}$ superficial velocity. The median value of the histogram is $18.7 \mathrm{~min}$ in comparison to the ideal packed bed whose residence time is $23.1 \mathrm{~min}$. 


\subsection{References}

Aleman, S. E., 1999. "Certification Package for FACT Version 2.0 (U)," Westinghouse Savannah River Co. document, WSRC-TR-99-00422, Rev. 0 (November).

Amtec Engineering, Inc., 2001. Tecplot ${ }^{\circledR}$ Version 9, Amtec Engineering, Inc., Bellevue, WA. (August 2001)

Berninger, J., R. D. Whitley, X. Zhang, and N.-H.L. Wang, 1991. "A Versatile Model for Simulation of Reaction and Nonequilibrium Dynamics in Multicomponent Fixed-Bed Adsorption Processes," Comput. Chem. Eng., 1991, 15(11), 749-768.

Bird, R. B., W. E. Stewart, and E. N. Lightfoot, 1960. Transport Phenomena, John Wiley and Sons, Inc., New York.Cornish, A. R. H., 1965. "Note on Minimum Possible Rate of Heat Transfer from a Sphere when other Spheres are Adjacent to it," Trans. Instn. Chem. Engrs., Vol. 43, pp. 332-333.

Eager, K. M. to J. Chiaramonte, 2001. "Sizing of Beds of Ion Exchange Contained within the Cesium Ion Exchange Columns," RPP-WTP CCN 023155, October 1.

Gunn, D. J. and J. F. C. De Souza, 1974. "Heat Transfer and Axial Dispersion in Packed Beds," Chem. Engr. Science, Vol. 29, pp. 1363-1371.

Hamm L. L. and S. E. Aleman, 2000. "FACT (Version 2.0): Subsurface Flow and Contaminant Transport; Documentation and User's Guide (U)," Westinghouse Savannah River Co. document, WSRC-TR-2000-00282, Rev. 0 (March).

Hamm, L. L., F. G. Smith, III, and D. J. McCabe, 2000. "Preliminary Ion Exchange Modeling for Removal of Cesium from Hanford Waste Using SuperLig ${ }^{\circledR} 644$ Resin," BNF-003-980220, June 16.

Hamm, L. L., F. G. Smith, and M. A. Shadday, 2000a. “QA Verification Package for VERSELC Version 7.80," Westinghouse Savannah River Co. document, WSRC-TR-99-00238, Rev. 0 (February).

Hamm, L. L., B. J. Hardy and S. E. Aleman, 2002. "Task Technical and Quality Assurance Plan for Ion Exchange Computer Model Upgrades (U)," Westinghouse Savannah River Co. document, WSRC-TR-2002-00041 (SRT-RPP-2002-00014), Rev. 0 (January 2002).

Hamm, L. L., T. Hang, D. J. McCabe, and W. D. King, 2002. "Preliminary Ion Exchange Modeling for Removal of Cesium from Hanford Waste Using Crystalline Silicotitanate Material," WSRC-TR-2001-00400 (SRT-RPP-2001-00134), July.

Kunii, D. and J. M. Smith, 1960. "Heat Transfer Characteristics of Porous Rocks," A.I.Ch.E. Journal, Vol. 6, No. 1, pp. 71-78.

Kunii, D. and J. M. Smith, 1961. "Heat Transfer Characteristics of Porous Rocks: II. Thermal Conductivities of Unconsolidated Particles with Flowing Fluids," A.I.Ch.E. Journal, Vol. 7, No. 1, pp. 29-34.

Kunii, D. and M. Suzuki, 1967. "Particle-to-Fluid Heat and Mass Transfer in Packed Beds of Fine Particles," Int. J. Heat Mass Transfer, Vol. 10, No. 1, pp. 845-852.

Lee, S. Y., 2001. "Heat Transfer Calculations for Normal Operations of a Fixed CST Bed Column," WSRC-TR-2001-00255, May.

Olson, J.W. and M. L. Stewart, 2002a. "System Description for Cesium Removal Using Ion Exchange - System CXP," 24590-PTF-3YD-CXP-00001, Rev B, May 2002, Bechtel National Inc., Richland, Washington. 
Olson, J.W. and M. L. Stewart, 2002b. "System Description for Technetium Removal Using Ion Exchange - System TXP," 24590-PTF-3YD-TXP-00001, Rev B, May 2002, Bechtel National Inc., Richland, Washington.

Pfeffer, R. and J. Happel, 1964. "An Analytical Study of Heat and Mass Transfer in Multiparticle Systems at Low Reynolds Numbers," A.I.Ch.E. Journal, Vol. 10, No. 5, pp. 605-611.

Rowe, P. N. and K. T. Claxton, 1965. "Heat and Mass Transfer from a Single Sphere to Fuild Flowing Through an Array," Trans. Instn. Chem. Engrs., Vol. 43, pp. 321-331.

Ruthven, D. M. (Editor), 1997. Encyclopedia of Separation Technology (Volume 2), John Wiley and Sons, New York. (see Ion Exchange chapter by Charles Dickert)

Steimke, J. L., M. A. Norato, T. J. Steeper and D. J. McCabe, 2000. "Summary of Testing of SuperLig ${ }^{\circledR} 639$ at the TFL Ion Exchange Facility," Westinghouse Savannah River Co. document, WSRC-TR-2000-00302 (SRT-RPP-2000-00008), Rev. 0 (August 2000).

Steimke, J. L. and T. J. Steeper, 2002. "Status Report for Pilot Scale Testing of SuperLig ${ }^{\circledR} 644$ Ion Exchange Resin," Westinghouse Savannah River Co. document, WSRC-TR-2002-00340, Rev. 0 (July 2002).

Toth, J., 2002a. “Test Specification: Ion Exchange Computer Model Upgrades," Bechtel Hanford document, 24590-PTF-TSP-RT-01-004, Rev. 0 (January approved).

Toth, J., 2002b. "Proposed Preliminary Cesium and Technetium Ion Exchange," (internal memorandum CCN 041301 to P. S. Sundar, September 2002), Bechtel National Inc., Richland, Washington.

Whitley, R. D. and N.-H. Wang, 1998. "User's Manual VERSE (VErsatile Reaction Seperation) Simulation for Liquid Phase Adsorption and Chromatography Processes," School of Chemical Engineering, Purdue University, July, 1998. 


\section{Appendix A (Thermal Analyses of SuperLig ${ }^{\circledR} 644$ Resin Beds)}

\section{Analysis Summary}

The major conclusions based on the thermal analysis results presented within this appendix are:

- For Envelope B LAW feeds, a limited operating range on flowrate may exist due to potentially unacceptable temperature rise across the bed and particle temperature variations for flowrates less than $\sim 0.6 \mathrm{BV} / \mathrm{hr}$. For flowrates greater than $0.6 \mathrm{BV} / \mathrm{hr}$ temperature increases above the inlet value are estimated to be within $\sim 3{ }^{\circ} \mathrm{C}$.

- For Envelope A and C LAW feeds, where inlet cesium concentrations are close to an order of magnitude less than for Envelope B feeds, no practical flowrate limitation exists.

- A $\sim 2{ }^{\circ} \mathrm{C} / \mathrm{hr}$ upper bound estimate for adiabatic heatup of the column was conservatively computed.

- During normal column operation, feed flowrates are high enough such that isothermal column operation can be assumed.

\section{Background}

Due to the buildup of ${ }^{137} \mathrm{Cs}$ (who has a radioactive half-life of $\sim 30$ years) within the SuperLig ${ }^{\circledR}$ 644 resin during the loading phase of operation, a decay heat source within the resin particles exist. Under highly loaded conditions, the heat generation within the particles and bed can potentially result in local temperatures in significant excess of the incoming liquid feed temperature. The analyses presented within this appendix attempt to quantified these temperature increases and help provide design guidance on the ranges of acceptable column operation (e.g., inlet volumetric flowrates).

The 3-D flow analyses presented within the main body of this report assume the Darcy flows are at isothermal conditions. Within this appendix analyses are provided that indicate the range of conditions where the isothermal assumption remains valid. The majority of analyses presented below are for near steady-state conditions. However, a transient adiabatic heatup calculation is also provided. Where possible the analyses have been based on available data where appropriate. When data were not available assumptions were made that should be conservative (e.g., the thermal properties for hydrous crystalline silicotitanate material (CST) were used for SuperLig $^{\circledR} 644$ resin properties). Overall, the thermal analysis presented should represent conservative temperature rises.

\section{A.1 Models used in thermal analyses}

During the loading phase 50 to 200 bed volumes (BV) of feed are processed prior to reaching the exit cesium criterion. It is assumed that the inlet volumetric flowrate, composition, and temperature remain essentially constant over this time period. The transport time through a 
column is much faster that the Cs loading on the resin (i.e., as indicated by the large BVs mentioned above). Thus, a quasi-steady-state thermal condition will exist across the resin bed at each point in time. As the loading increases this bed temperature profile will gradually shift over time. Under these conditions it is a reasonable approximation to estimate the temperature profile within the bed based on steady-state inlet conditions and a fixed Cs loading value chosen at some point in time during the operation.

The temperature values of most interest to us are shown in the schematic provided in Figure A-1. Specifically, the temperature difference across the bed is given by:

$$
\Delta \mathrm{T}_{\text {bed }} \equiv \mathrm{T}_{\text {out }}-\mathrm{T}_{\text {in }} \text {, }
$$

where

$$
\begin{array}{ll}
\Delta \mathrm{T}_{\text {bed }} & - \text { Temperature rise across entire resin bed } \\
\mathrm{T}_{\text {in }} & - \text { Inlet fluid temperature to resin bed } \\
\mathrm{T}_{\text {out }} & - \text { Exit fluid temperature from resin bed }
\end{array}
$$

and the temperature difference across a resin particle at a local axial location is given by:

$$
\Delta \mathrm{T}_{\text {part }} \equiv \Delta \mathrm{T}_{\text {cond }}+\Delta \mathrm{T}_{\text {film }}=\left(\mathrm{T}_{\mathrm{c}}-\mathrm{T}_{\mathrm{s}}\right)+\left(\mathrm{T}_{\mathrm{s}}-\mathrm{T}_{\text {bed }}\right),
$$

where

$$
\begin{array}{ll}
\Delta \mathrm{T}_{\text {part }} & \text { - Temperature rise across particle at a local axial location } \\
\Delta \mathrm{T}_{\text {cond }} & \text { - Temperature rise through particle due to thermal conduction } \\
\Delta \mathrm{T}_{\text {film }} & \text { - Temperature rise across stagnant film surrounding particle } \\
\mathrm{T}_{\text {bed }} & \text { - Bed fluid temperature at a local axial location } \\
\mathrm{T}_{\mathrm{s}} & \text { - Surface temperature of particle } \\
\mathrm{T}_{\mathrm{c}} & \text { - Centerline temperature of particle }
\end{array}
$$

Assuming steady-state operating conditions, the overall energy balance across the SuperLig ${ }^{\circledR}$ 644 resin bed becomes:

$$
\dot{\mathrm{m}} \mathrm{C}_{\mathrm{pf}} \Delta \mathrm{T}_{\text {bed }}=\mathrm{q}_{\mathrm{gen}}^{\prime \prime \prime} \mathrm{V}_{\text {bed }} \quad \text { or } \quad \Delta \mathrm{T}_{\text {bed }}=\frac{\mathrm{q}_{\text {gen }}^{\prime \prime \prime} \mathrm{V}_{\text {bed }}}{\rho_{\mathrm{f}} \mathrm{Q}_{\text {flow }} \mathrm{C}_{\mathrm{pf}}},
$$

where

$$
\begin{array}{ll}
\dot{\mathrm{m}} & \text { - Mass flowrate of fluid } \\
\rho_{\mathrm{f}} & \text { - Density of inlet fluid } \\
\mathrm{Q}_{\text {flow }} & - \text { Volumetric flowrate of inlet fluid } \\
\mathrm{C}_{\mathrm{pf}} & \text { - Specific heat at constant pressure for inlet fluid } \\
\mathrm{q}_{\text {gen }}^{\prime \prime \prime} & - \text { Average volumetric heat generation rate within bed } \\
\mathrm{V}_{\text {bed }} & - \text { Total volume of bed (including porosities) }
\end{array}
$$


Assuming steady-state operating conditions, spherical particles, uniformly distributed pores within the particles, and uniformly distributed heat generation, the temperature rise over the particle due to conduction can be expressed by (i.e., solution of the radial heat conduction equation):

$$
\Delta \mathrm{T}_{\text {cond }} \equiv \frac{\mathrm{q}_{\text {gen }}^{\prime \prime \prime}}{24 \mathrm{k}_{\mathrm{p}}\left(1-\varepsilon_{\mathrm{p}}\right)} \mathrm{d}_{\mathrm{p}}^{2}
$$

where

$\varepsilon_{\mathrm{p}} \quad$ - Particle porosity assumed to be uniform within particles

$\mathrm{k}_{\mathrm{p}} \quad$ - Composite thermal conductivity of particles

$d_{p} \quad$ - Spherical equivalent diameter (SED) of particle

The composite thermal conductivity within the particles is computed based on volumetric averaging by:

$$
\mathrm{k}_{\mathrm{p}}=\mathrm{k}_{\mathrm{resin}}\left(1-\varepsilon_{\mathrm{p}}\right)+\mathrm{k}_{\mathrm{f}} \varepsilon_{\mathrm{p}}
$$

where

$$
\begin{array}{ll}
k_{f} & - \text { Thermal conductivity of the feed solution } \\
k_{\text {resin }} & - \text { Thermal conductivity of the solid resin }
\end{array}
$$

For the temperature drop across the stagnant film surrounding an individual particle within a packed bed of particles, Newton's law of cooling is employed in the form:

$$
\Delta \mathrm{T}_{\text {film }} \equiv \frac{\mathrm{q}_{\mathrm{gen}}^{\prime \prime \prime}}{6 \mathrm{~h}_{\mathrm{f}}\left(1-\varepsilon_{\mathrm{b}}\right)} \mathrm{d}_{\mathrm{p}},
$$

where

$$
\begin{array}{ll}
\varepsilon_{b} & \text { - Bed porosity assumed to be uniform throughout the bed } \\
h_{f} & \text { - Particle film heat transfer coefficient for packed beds }
\end{array}
$$

For additional details on the derivation of the above thermal equations see Lee (2001).

To calculate an adiabatic temperature rise for the entire bed, it is assumed that negligible energy loss occurs through the vessel walls or into the liquid spaces above or below the resin bed proper, after the flowrate has been shutoff. A simple control volume based energy balance gives the bulk average temperature rise as:

$$
\hat{\mathrm{T}}_{\text {bed }}(\mathrm{t})-\hat{\mathrm{T}}_{\text {bed }}(0) \equiv \frac{\mathrm{q}_{\text {gen }}^{\prime \prime \prime}}{\rho \mathrm{C}_{\mathrm{V}}}\left(\mathrm{t}-\mathrm{t}_{0}\right),
$$

where

$$
\hat{\mathrm{T}}_{\text {bed }}(\mathrm{t}) \text { - Average bed temperature at time } \mathrm{t}
$$


$\mathrm{t}$ - Time reference from the start of the adiabatic condition

$\rho \mathrm{C}_{\mathrm{v}}$ - Composite heat capacity of the entire bed (fluid plus resin materials)

The composite heat capacity is computed based on volumetric averaging by:

$$
\rho \mathrm{C}_{\mathrm{v}}=\varepsilon_{\mathrm{b}} \rho_{\mathrm{f}} \mathrm{C}_{\mathrm{vf}}+\left(1-\varepsilon_{\mathrm{b}}\right) \rho \mathrm{C}_{\mathrm{vpart}},
$$

where

$$
\rho \mathrm{C}_{\mathrm{Vpart}}=\varepsilon_{\mathrm{p}} \rho_{\mathrm{f}} \mathrm{C}_{\mathrm{f}}+\left(1-\varepsilon_{\mathrm{p}}\right) \rho \mathrm{C}_{\mathrm{Vresin}} \text {, }
$$

and

$$
\begin{aligned}
& \rho C_{\mathrm{Vpart}}-\text { Heat capacity of the entire particle (fluid plus resin materials) } \\
& \rho \mathrm{C}_{\mathrm{Vf}}-\text { Heat capacity of the inlet feed solution } \\
& \rho \mathrm{C}_{\mathrm{Vresin}}-\text { Heat capacity of the solid resin }
\end{aligned}
$$

For the calculations presented in this report the specific heats at constant pressure are used to approximate the specific heats at constant volume.

\section{A.2 Cesium loading on SuperLig ${ }^{\circledR} 644$ Resin}

In order to estimate a conservative heat load for use in the thermal analysis effort the following conservative assumptions were made:

- Based on available batch contact equilibrium data (i.e., including old and new resin batches), a conservative isotherm was generated that essentially bounds the measured values;

- The highest total heat load for a lead column results when it is assumed that the column becomes fully saturated with the inlet feed conditions;

- The gamma redistribution is neglected such that all of the heat generated occurs within the resin particles and no gamma leakage through vessel walls takes place;

- The SuperLig ${ }^{\circledR} 644$ resin particles are assumed to be spherical, which should provide an upper estimate on the temperature rise across the particles; and

- An inlet feed concentration of $5 \times 10^{-4} \mathrm{M}$ in total cesium is assumed that bounds the values for the 16 Phase $1 \mathrm{LAW}$ feeds and a $30 \%$ isotopic mole fraction of ${ }^{137} \mathrm{CS}$ to ${ }^{\text {total }} \mathrm{Cs}$ is assumed.

\section{A.2.1 Maximum cesium loading on SuperLig ${ }^{\circledR} 644$ Resin}

The majority of available batch contact data prior to 2001 is summarized by Hamm et al. (2000, see Figure A-1 in Appendix A of that report). Within those data sets issues associated with the accuracy of the measurements exist. For example, in some cases excess quantities of potassium carbonate were present and for the majority of cases only 24 hour contact times were employed. In both of these examples the measured loadings would be less than the true equilibrium loadings. More recent batch contact data, where many of the concerns with the earlier tests were 
corrected, have also been considered. Figure A-2 shows the composite of the batch contact data taken prior to 2001 (blue squares) and the more recent data taken in 2001-2002 (red circles). The current IBC resin specification is also provided in Figure A-2 shown as a yellow diamond (i.e., a $\mathrm{K}_{\mathrm{d}}$ value exceeding $700 \mathrm{ml} / \mathrm{g}_{\text {resin }}$, based on a phase ratio of $100,0.1 \mathrm{~g}$ of resin, $10 \mathrm{ml}$ of simple simulant, and an initial total cesium concentration of $\left.70 \mathrm{ppm}\left[5.263 \times 10^{-4} \mathrm{M}\right]\right)$. The operating line for the resin specification batch contact test is also shown in Figure A-2.

Based on the selectivity coefficients predicted by Hamm et al. (2000) and assuming a feed composition consistent with AN-105 waste, an isotherm was created where the total ionic capacity for $\mathrm{Cs}, \overline{\mathrm{C}}_{\mathrm{T}}$, was adjusted so that the isotherm would pass through the resin specification value. The solid curve shown in Figure A-2 corresponds to this adjusted isotherm with an apparent total cesium capacity of $\sim 0.2718 \mathrm{mmole} / \mathrm{g}_{\text {resin }}$. The isotherm model used has the form:

$$
\mathrm{Q}_{\mathrm{Cs}}=\frac{\overline{\mathrm{C}}_{\mathrm{T}} \mathrm{c}_{\mathrm{Cs}}}{\mathrm{c}_{\mathrm{Cs}}+\left[\widetilde{\mathrm{K}}_{21} \mathrm{c}_{\mathrm{K}}+\widetilde{\mathrm{K}}_{31} \mathrm{c}_{\mathrm{Na}}\right]} \Rightarrow \frac{\overline{\mathrm{C}}_{\mathrm{T}} \mathrm{c}_{\mathrm{Cs}}}{\mathrm{c}_{\mathrm{Cs}}+\beta},
$$

where

$$
\beta=\widetilde{\mathrm{K}}_{21} \mathrm{c}_{\mathrm{K}}+\widetilde{\mathrm{K}}_{31} \mathrm{c}_{\mathrm{Na}} .
$$

The selectivity coefficient values used are $8.328694 \times 10^{-4}$ and $4.367230 \times 10^{-5}$ for potassium and sodium, respectively. For AN-105 waste, concentration values of $0.125 \mathrm{M}$ and $5.0 \mathrm{M}$ for potassium and sodium, respectively, were assumed. For these values the beta factor becomes $3.2247 \times 10^{-4} \mathrm{M}$.

A conservative isotherm model was created where the apparent total ionic capacity for Cs was increased to $1.0 \mathrm{mmole} / \mathrm{g}_{\text {resin }}$. The selectivity coefficients and competitor concentrations (i.e., the beta factor) were held fixed. The red dashed curve shown in Figure A-2 represents the conservative isotherm. This isotherm essentially bounds all of the available data over the entire composition range.

To compute the maximum possible Cs loading saturated with the inlet feed conditions, a maximum total Cs feed concentration must be specified. Based on the analysis provided by Hamm et al. (2002, see Table A-5 and A-6 in Appendix A of that report), the maximum feed concentration for Cs occurs during the processing of LAW 2a (i.e., AZ-101) with a value of $\sim 4.68 \times 10^{-4} \mathrm{M}$. A total Cs feed concentration value of $5.0 \times 10^{-4} \mathrm{M}$ was chosen for these analyses. The location of this maximum feed concentration is shown in Figure A-2 and this corresponds to a maximum-conservative Cs loading of $0.608 \mathrm{mmole} / \mathrm{g}_{\text {resin }}$.

\section{A.2.2 Total heat load on SuperLig ${ }^{\circledR} 644$ Resin}

Above the maximum expected total cesium loading on the resin was estimated to be 0.608 $\mathrm{mmole} / \mathrm{g}_{\mathrm{resin}}$. In order to estimate the volumetric heat generation rate corresponding to this Cs loading, the following two items must be specified: 
- An assumed $30 \%$ isotopic mole fraction of ${ }^{137} \mathrm{Cs}$ (based on Envelope B which contains the highest total Cs values and also contains the higher isotopic fractions); and

- An estimated specific heat generation rate for ${ }^{137} \mathrm{Cs}$ of $57.58 \mathrm{~W} /$ gmole.

The specific heat generation rate for ${ }^{137} \mathrm{Cs}$ was computed by:

$$
\mathrm{G}_{\text {gen }}=(137 \mathrm{~g} / \text { gmole }) \frac{(87 \mathrm{Ci} / \mathrm{g})}{(207 \mathrm{Ci} / \mathrm{W})}=57.58 \mathrm{~W} / \text { gmole },
$$

The volumetric heat generation rate then can be computed on a bed volume basis by:

$$
\mathrm{q}_{\text {gen }}^{\prime \prime \prime}=\eta_{137} \rho_{\text {bed }} \mathrm{Q}_{\mathrm{Cs}} \mathrm{G}_{\text {gen }}=(0.3)(0.2 \mathrm{~g} / \mathrm{ml})(0.608 \mathrm{mmole} / \mathrm{g})(57.58 \mathrm{~W} / \text { gmole })=2.1 \mathrm{~W} / \mathrm{L}
$$

where

$$
\begin{array}{ll}
\rho_{\text {bed }} & \text { - Bed density of lead column } \\
Q_{C s} & - \text { Total Cs surface solid phase concentration } \\
\eta_{137} & \text { - Isotopic fraction of }{ }^{137} \mathrm{Cs} \text { to }{ }^{\text {total }} \mathrm{Cs}
\end{array}
$$

Note that the generation rate given by Eq. (A-12) applies to the total bed volume (i.e., fluid space contained within the bed and particle pores plus the space occupied by the solid resin). For estimating the temperature rises across the particle, it is assumed that all of the heat generated is deposited within the particles themselves and none within the bed fluid due to gamma redistribution. As Eqs. (A-4) and (A-6) indicate, when looking at the heat generation rate for particle temperature rise, this average volumetric rate for the entire bed is increased by $1 /\left(1-\varepsilon_{\mathrm{b}}\right)$ to account for the conservative assumption made above:

$$
\left\langle\mathrm{q}_{\text {gen }}^{\prime \prime \prime}\right\rangle_{\text {part }}=\frac{\mathrm{q}_{\mathrm{ggen}}^{\prime \prime \prime}}{\left(1-\varepsilon_{\mathrm{b}}\right)}
$$

The value of heat generation rate computed by Eq. (A-13) represents the rate on a particle basis and varies depending upon the local level of total Cs loading achieved. For the thermal calculations to follow, the results are sometimes shown as a percentage of the maximum value as computed in Eq. (A-13).

\section{A.3 Thermal and physical properties used in analyses}

To perform the thermal analyses several physical and thermal properties were required. A listing of these property values is provided in Table A-1. The thermal properties of the CST material were used for estimating those values for the SuperLig ${ }^{\circledR} 644$ resin (i.e., it is believed that these values will be conservative, however no verification of this assumption can be tested at this time). 


\section{A.4 Particle heat transfer coefficient in packed beds}

In order to compute the temperature rise across the stagnant film at the outer surface of a particle, a liquid film coefficient for packed beds at very low superficial velocities is required. A literature review was performed to obtained such a correlation based on applicable heat transfer experiments. As outlined by Cornish (1965), for a single particle contained within an infinite nearly stagnant fluid, the particle's Nusselt number approaches the theoretical minimum value of 2. However, in multi-particle situations, such as in packed or fluidized beds, values of the Nusselt number much less than 2 can be observed.

The experimental data set must be for packed beds at very low superficial velocities that are also based on particles whose diameters are consistent with the fine sized particles of interest. There were only a limited number of such data sets found. The paper by Kunii and Smith (1961) provided the best data set for our purposes (i.e., see their Figure 10 for a comparison). Listed in the reference section of this report are several other published papers with regard to this subject (i.e., Gunn and De Souza [1974], Rowe and Claxton [1965], Pfeffer and Happel [1964], Kunii and Suzuki [1967], and Kunii and Smith [1960]).

In Figure A-3 the data presented by Kunii and Smith (1961) are summarized by the gray shaded region. The data set contained measurements for various gases and liquid water over a wide range of flow conditions and particles sizes (i.e., 109 to $1022 \mu \mathrm{m}$ ). The data were correlated using the dimensionless groups:

- Particle superficial Reynolds number, $\operatorname{Re}_{\mathrm{p}}=\frac{\rho_{\mathrm{f}} \mathrm{Ud}_{\mathrm{p}}}{\mu_{\mathrm{f}}}$;

- Particle Nusselt number, $\mathrm{Nu}_{\mathrm{p}}=\frac{\mathrm{h}_{\mathrm{f}} \mathrm{d}_{\mathrm{p}}}{\mathrm{k}_{\mathrm{f}}}$; and

- Fluid Prandtl number, $\operatorname{Pr}_{\mathrm{f}}=\frac{\mu_{\mathrm{f}} \mathrm{C}_{\mathrm{p}}}{\mathrm{k}_{\mathrm{f}}}$;

where

$$
\mu_{\mathrm{f}} \quad \text { - Dynamic viscosity of inlet feed solution }
$$

U - Superficial velocity within packed bed

A simple power law fit to this database was made, resulting in the Nusselt number correlation:

$$
\mathrm{Nu}_{\mathrm{p}}=0.1 \operatorname{Re}_{\mathrm{p}}^{1.8} \operatorname{Pr}_{\mathrm{f}}^{2}
$$

Equation (A-14) is shown in Figure A-3 as the solid red line. Also highlighted in Figure A-3, is the expected range of particle Reynolds numbers for the SuperLig ${ }^{\circledR} 644$ packed columns. Note that the Prandtl number for air is $\sim 0.7$, for DI water $\sim 7$, and for $5 \mathrm{M} \mathrm{Na}$ feed $\sim 16$. Based on 
particle size distribution (PSD) testing, the SuperLig ${ }^{\circledR} 644$ particles are expected to have SEDs in the range of 100 to $1000 \mu \mathrm{m}$.

\section{A.5 Thermal analysis results}

The current ion-exchange column design has a bed diameter of 48" and a bed height of 54" (i.e., $56.55 \mathrm{ft}^{3}$ or $1601.3 \mathrm{~L}$ ). For the various Phase $1 \mathrm{LAW}$ feeds the volumetric flowrates may vary from $\sim 4 \mathrm{gpm}$ (i.e., $15 \mathrm{~L} / \mathrm{min}$ or $0.56 \mathrm{BV} / \mathrm{hr}$ ) to $\sim 17 \mathrm{gpm}$ (i.e., $65 \mathrm{~L} / \mathrm{min}$ or $2.44 \mathrm{BV} / \mathrm{hr}$ ). In order to cover the entire range of possible conditions, the thermal analyses were performed for flowrates varying from 0 to $4 \mathrm{BV} / \mathrm{hr}$ and for resin particle sizes of 100 to $1000 \mu \mathrm{m}$ in SED.

\section{A.5.1 Steady-state results}

To see the impact of flowrate on the overall temperature rise across the bed, Eq. (A-3) was evaluated for both DI water and 5M sodium feed as the entering fluid. The results are plotted in Figure A-4 and are based on the maximum possible heat load. As illustrated in Figure A-4, the impact of fluid properties is small while for low flowrates (i.e., less than $0.5 \mathrm{BV} / \mathrm{hr}$ ) the temperature rise can become significant. These results indicate that for Envelope B LAW feeds the design flowrates may be approaching too low a value when an operating margin is factored in. The effect of reducing the total heat load on the bed (e.g., more consistent with beds saturated with Envelope A and C LAW feeds) can be seen in Figure A-5. The lowest curve better represents the maximum heat load conditions to be expected for Envelope A and C LAW feeds.

Temperature rise across the particles, as a function of particle diameter and heat load, were computed using Eqs. (A-4) and (A-6). The total temperature rise results, based on Eq. (A-2), are shown in Figure A-6, where the black curve represents the temperature rise of the largest particles closest to the bed exit. This curve represents the extreme in particle temperatures within the bed. For example, at a flowrate of $1 \mathrm{BV} / \mathrm{hr}$ particle temperatures will vary $\sim 2{ }^{\circ} \mathrm{C}$ throughout the resin bed.

The temperature rise results for varying particle size and heat load are plotted as contours in Figures A-7, A-8, and A-9, for the flowrates of $0.56,1.12$, and $2.44 \mathrm{BV} / \mathrm{hr}$, respectively. At a given flowrate the impact of heat load dominates over particle size. Computed particle Biot (Bi) numbers were very low, indicating that the majority of temperature rise occurs over the stagnant film and not due to radial conduction through the particle itself.

\section{A.5.2 Adiabatic heatup results}

As mentioned earlier, a simple adiabatic heatup calculation was performed based on Eq. (A-7). At the point in time where the flowrate is assumed to be zero, the entire resin bed is assumed to be thermally isolated from its surrounding. The entire resin bed includes the fluid contained within the bed pores and particle pores and includes the solid resin material. The thermal inertia associated with the vessel structures is neglected, as well as, the thermal connections at the top 
and bottom of the bed. The results of this conservative calculation are shown in Figure A-10. The estimated heatup rate is $\sim 2{ }^{\circ} \mathrm{C}$ per hour, under the maximum Cesium loading conditions.

Table A-1. Physical and thermal property values ${ }^{\mathrm{a}}$ used in the thermal analyses.

\begin{tabular}{|c|c|c|c|c|}
\hline Property & DI Water & $\begin{array}{c}\text { 5M Sodium } \\
\text { Feed Solution }\end{array}$ & $\begin{array}{c}\text { SuperLig } \\
\text { 644 Resin }\end{array}$ & $\begin{array}{c}\text { CST } \\
\text { Material }\end{array}$ \\
\hline Particle porosity, $\varepsilon_{\mathrm{p}},(-)$ & - & - & 0.614 & - \\
\hline Bed porosity, $\varepsilon_{\mathrm{b}},(-)$ & - & - & 0.450 & - \\
\hline Bed density, $\rho_{\text {bed }},(\mathrm{g} / \mathrm{ml})$ & - & - & $0.20^{\mathrm{c}}$ & - \\
\hline Material density, $\rho,(\mathrm{g} / \mathrm{ml})$ & 0.9965 & 1.250 & 1.58 & - \\
\hline $\begin{array}{c}\text { Thermal conductivity, } \mathrm{k},(\mathrm{W} / \mathrm{m}- \\
\mathrm{K})\end{array}$ & - & 0.68 & - & 0.1554 \\
\hline Specific heat, $\mathrm{C}_{\mathrm{p}},(\mathrm{J} / \mathrm{g}-\mathrm{K})$ & 4.182 & 3.63 & - & 1.0523 \\
\hline Dynamic viscosity, $\mu_{\mathrm{f}},(\mathrm{cp})$ & 0.876 & 3.06 & - & - \\
\hline Bed diameter, $\mathrm{D}_{\mathrm{bed}},(\mathrm{inch})$ & - & - & 48.0 & - \\
\hline Bed height, $\mathrm{H}_{\mathrm{bed}},(\mathrm{inch})$ & - & - & 54.0 & - \\
\hline Inlet temperature, $\mathrm{T}_{\mathrm{in}},(\mathrm{C})$ & 25.0 & 25.0 & - & - \\
\hline
\end{tabular}

a The thermal property values for CST were used for the SuperLig ${ }^{\circledR} 644$ resin.

b The material properties for SuperLig ${ }^{\circledR} 644$ were measured in the Na-form.

c The bed density represents a recent value ( 0.35 to 0.4 was the stated value back when the porosities listed were determined). The total ionic capacity value used is consistent with the lower value of bed density such that the thermal analysis provided remain conservative. 


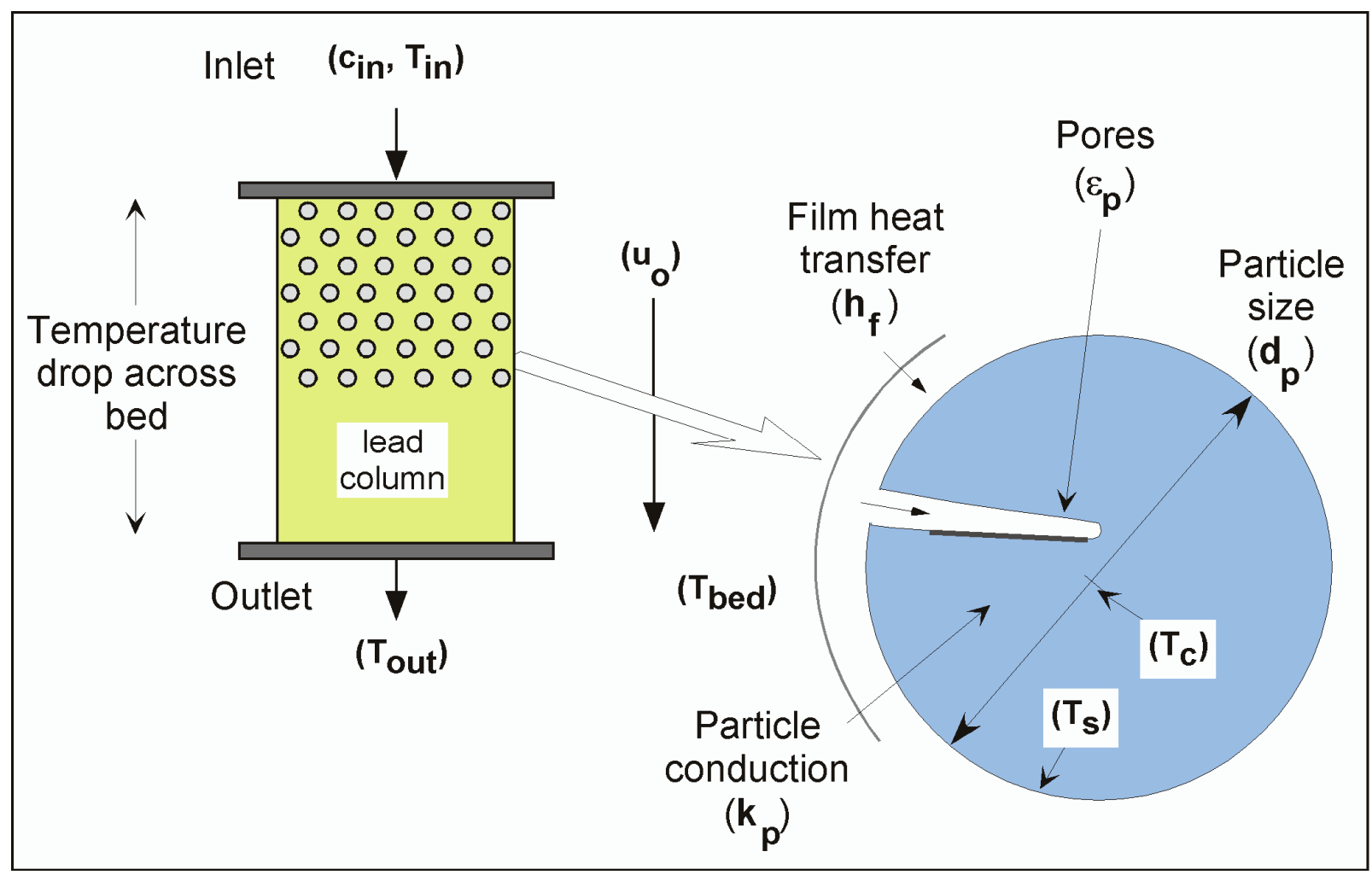

Figure A-1. Schematic illustrating the various components considered in the thermal analyses for SuperLig ${ }^{\circledR} 644$ resin beds and resin particles. The key temperature points are bed inlet and outlet, bed fluid, and particle centerline and surface.

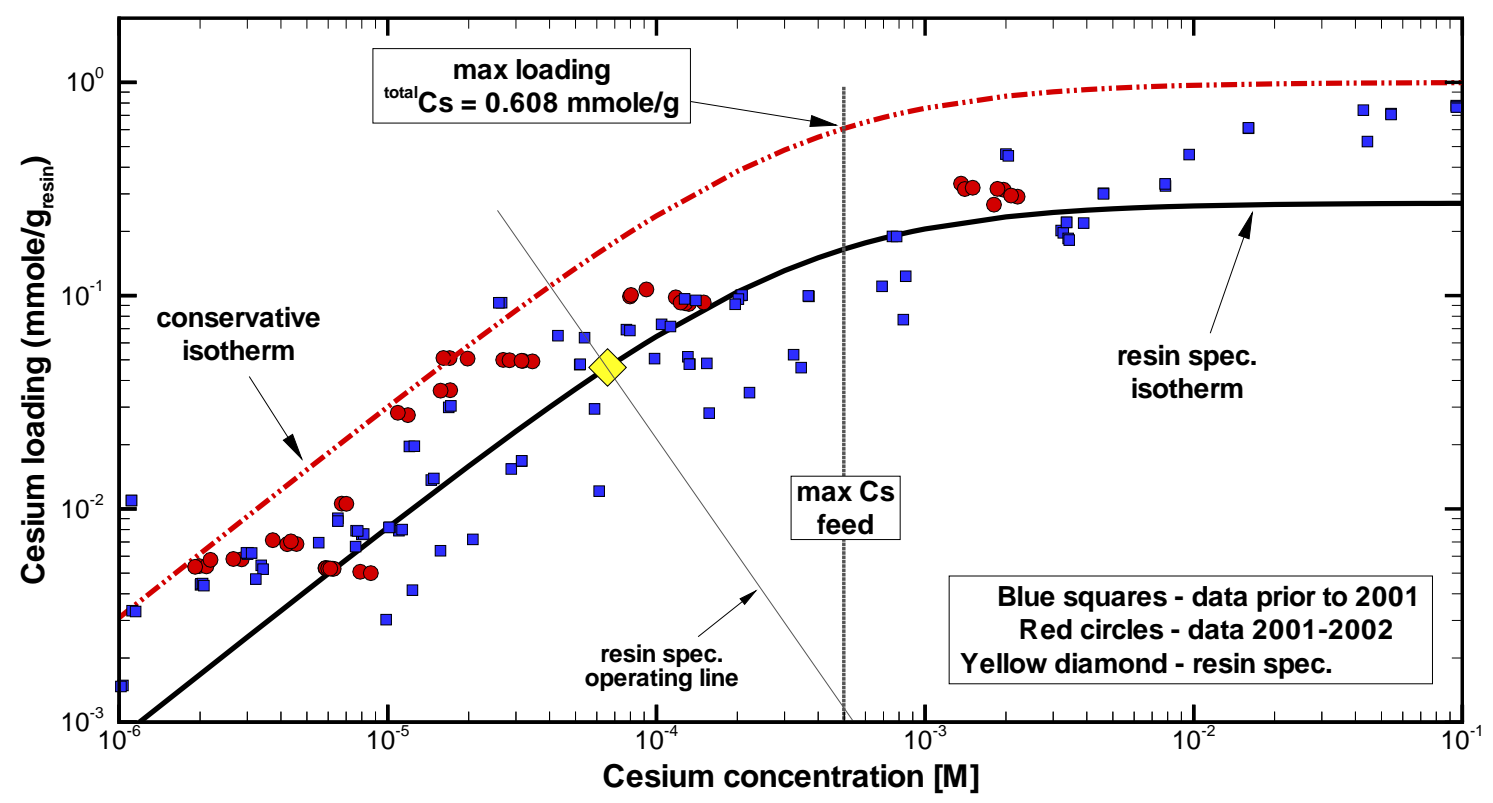

Figure A-2. Total Cs loading curve and data for SuperLig ${ }^{\circledR} 644$ resin showing the maximum loading value used for estimating the expected max heat load for the bed. Data taken prior to 2001 (blue squares), data taken during 2001-2002 (red circles), solid curve the resin specification, and the dashed curve a conservative isotherm. 


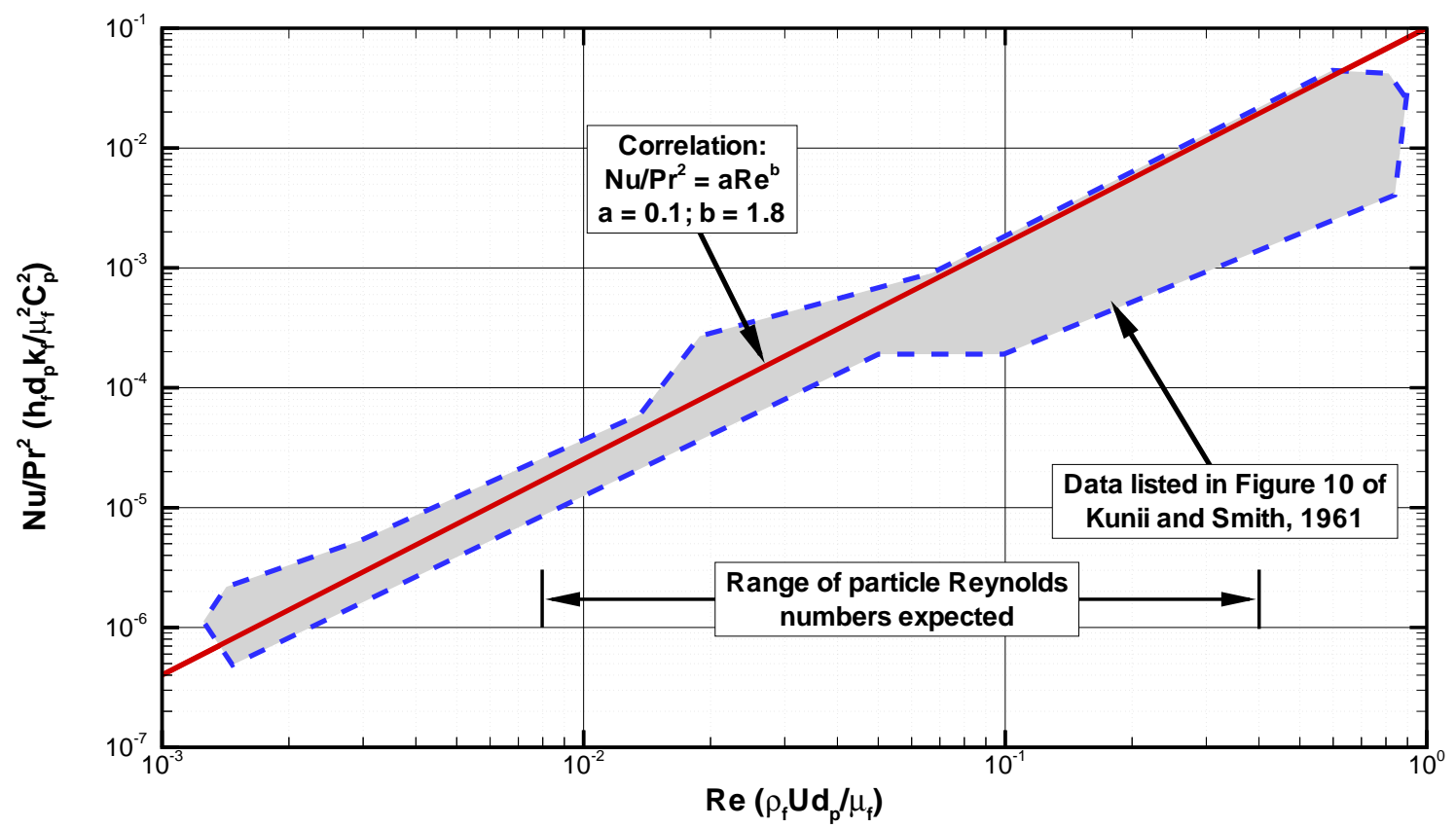

Figure A-3. Nusselt number correlation based on heat transfer data taken from packed beds of spheres at very low Reynolds numbers and valid for a wide range of fluids. Particle size range tested is $109-1022 \mu \mathrm{m}$ where the Reynolds number is based on superficial velocity.

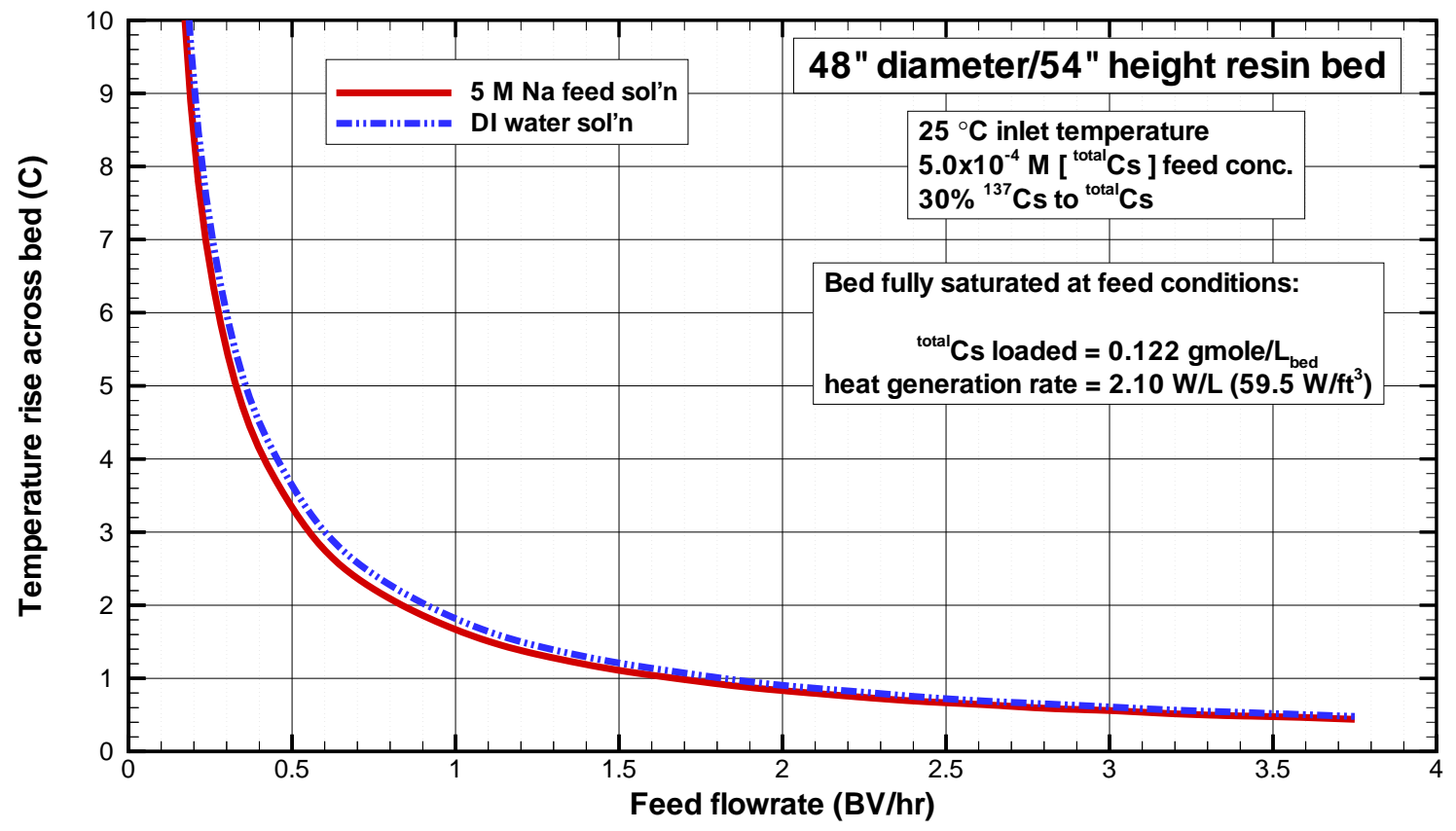

Figure A-4. Estimated temperature rise across a SuperLig ${ }^{\circledR} 644$ resin bed for a broad range of inlet feed flowrates and for a lead column fully saturated at the total cesium feed concentration of $5 \times 10^{-4} \mathrm{M}$. Results for DI water and 5M Na LAW feed solutions are shown. 


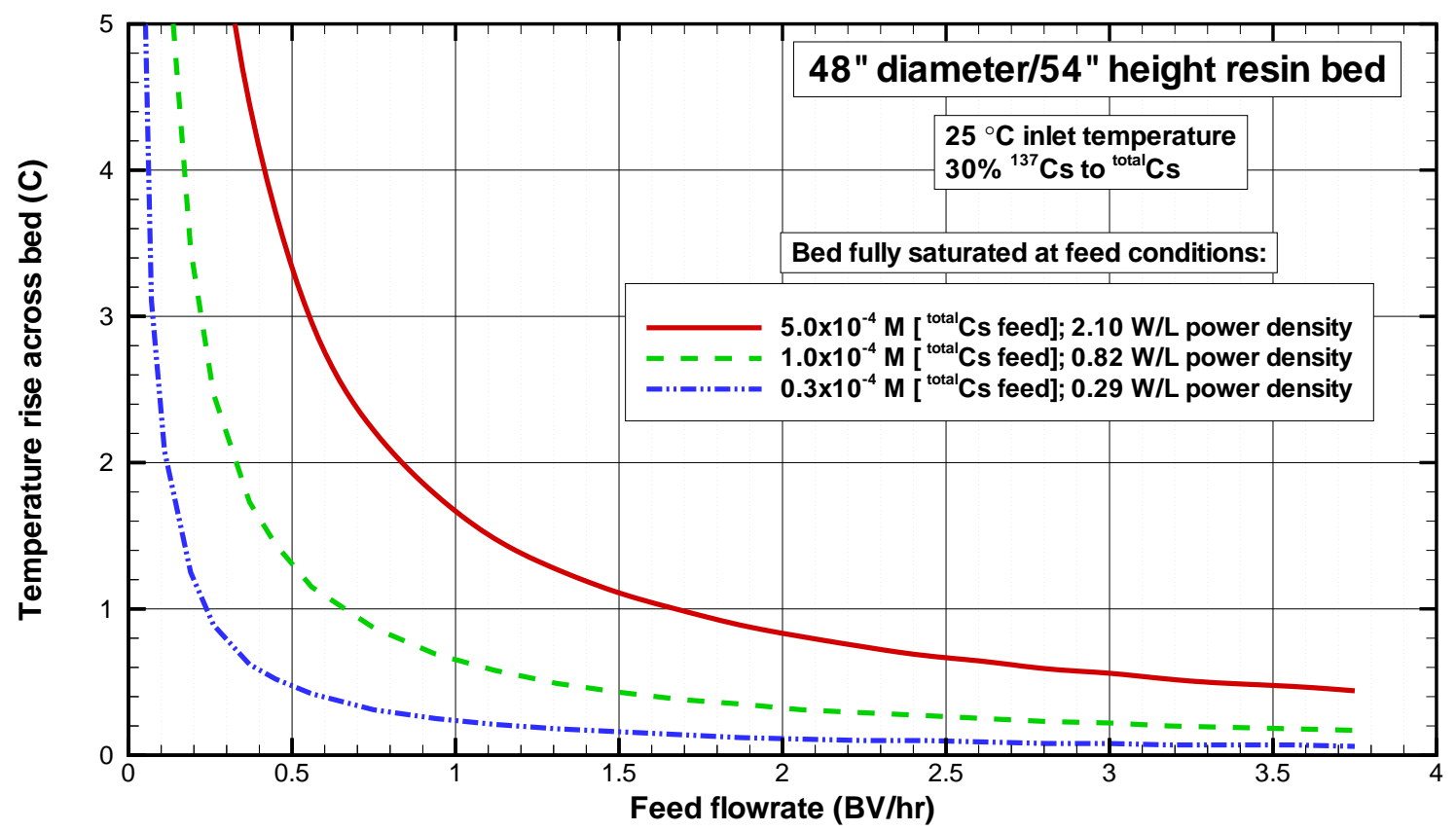

Figure A-5. $\quad$ Estimated temperature rise across a SuperLig ${ }^{\circledR} 644$ resin bed for a broad range of inlet feed flowrates and for a lead column fully saturated at three different total cesium feed concentrations. Results for a $5 \mathrm{M} \mathrm{Na}$ LAW feed solutions are shown.

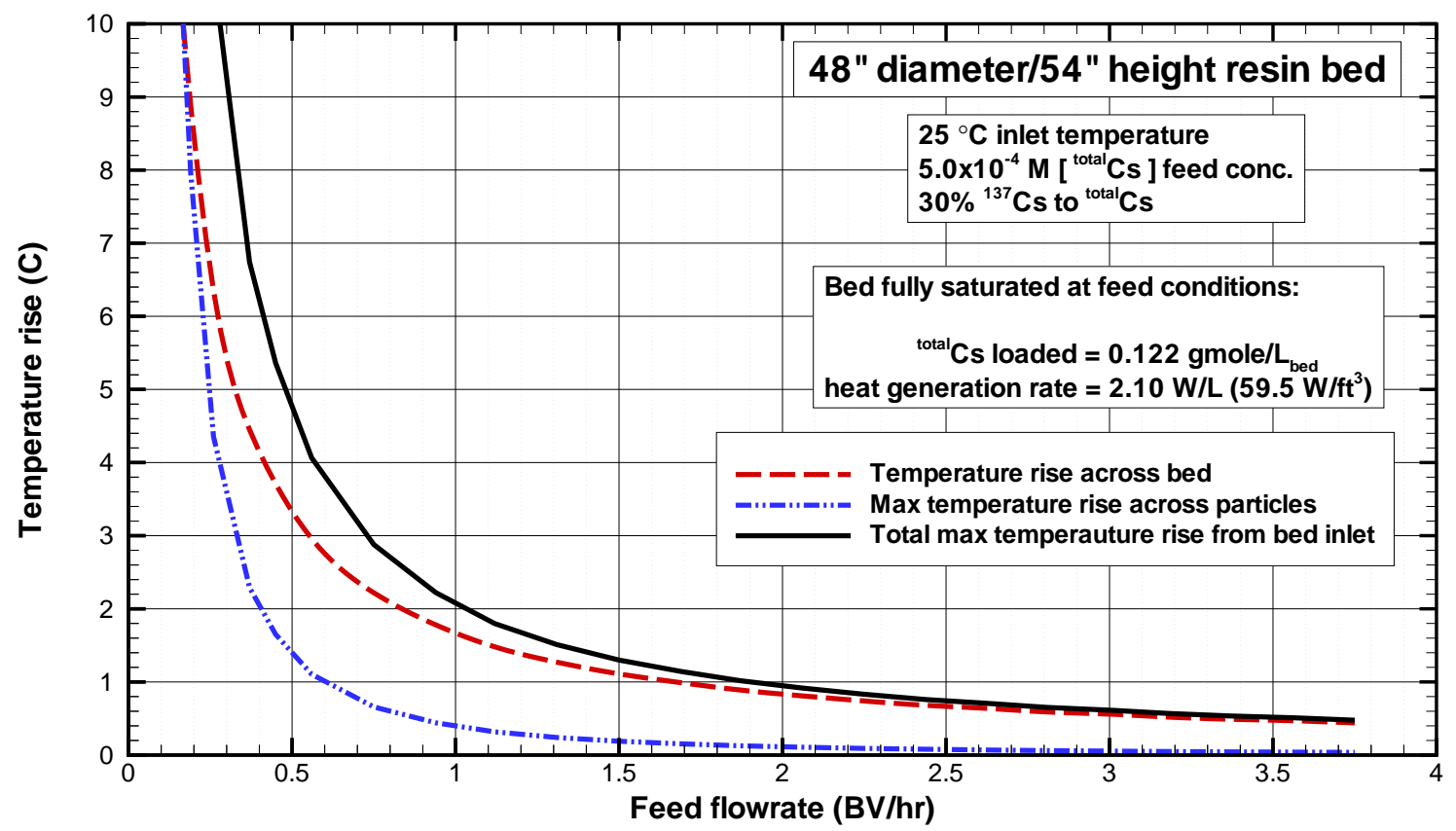

Figure A-6. Estimated temperature rise across a SuperLig ${ }^{\circledR} 644$ resin bed and across a 1,000 $\mu \mathrm{m}$ sized resin particle for a broad range of inlet feed flowrates and for a lead column fully saturated at the total cesium feed concentration of $5 \times 10^{-4} \mathrm{M}$. 


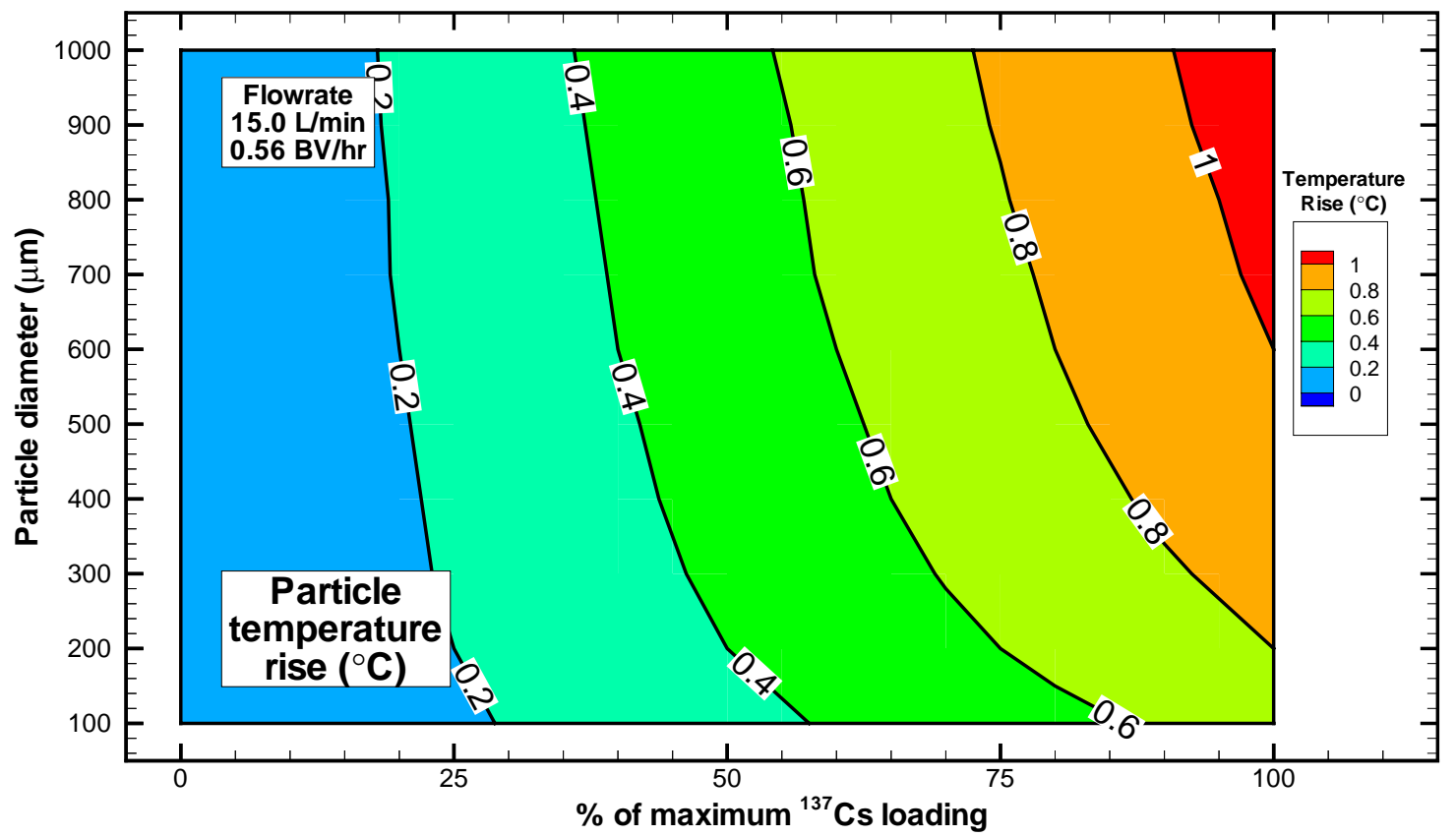

Figure A-7. Estimated temperature rise across a SuperLig ${ }^{\circledR} 644$ resin particle, loaded with a ${ }^{137} \mathrm{Cs}$ heat source, as a function of particle size and degree of saturation. Temperature rise is defined as the difference from the particle centerline to the neighboring bed fluid. Results for a flowrate of $15 \mathrm{~L} / \mathrm{min}$ are shown.

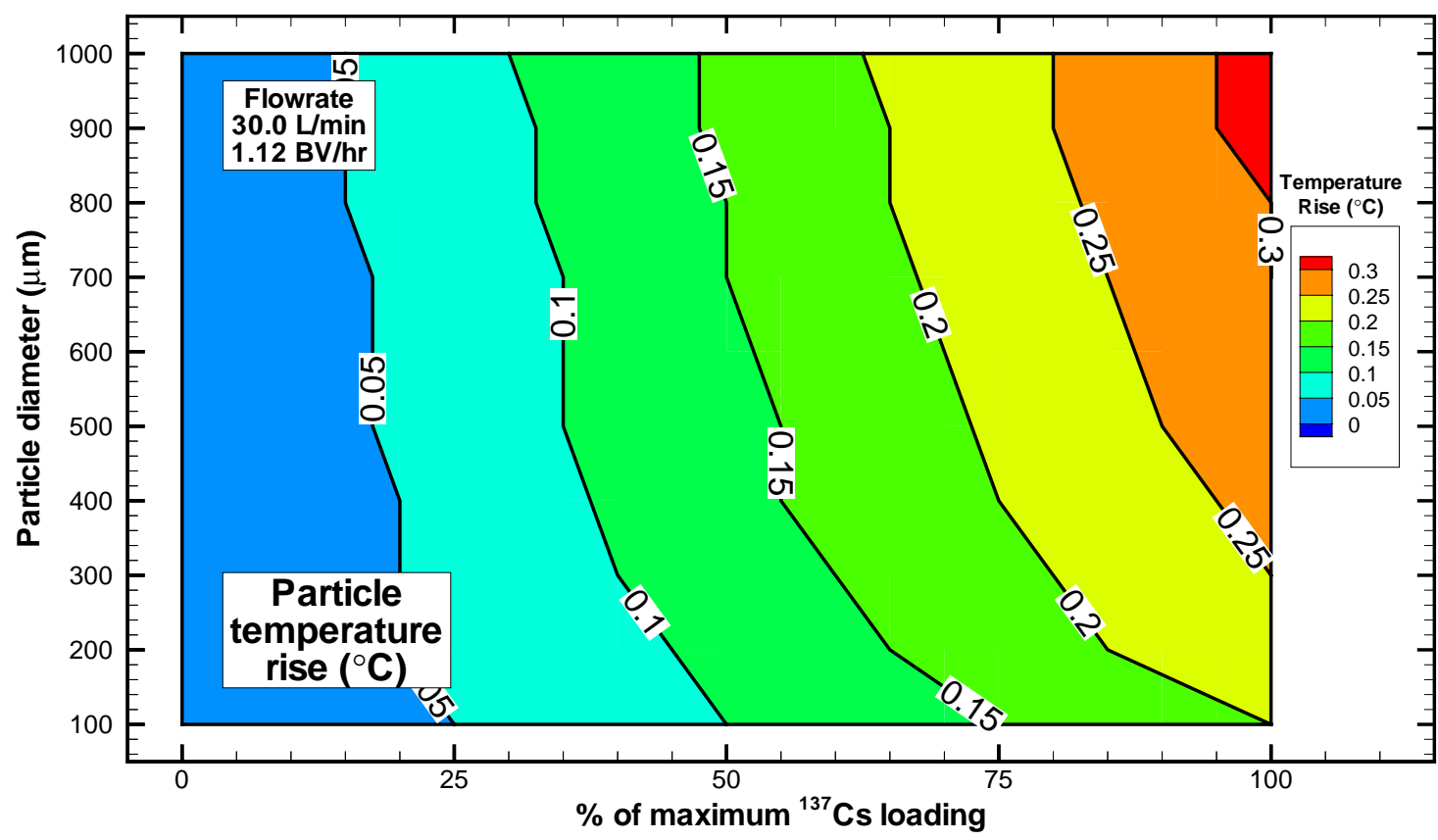

Figure A-8. Estimated temperature rise across a SuperLig ${ }^{\circledR} 644$ resin particle, loaded with a ${ }^{137} \mathrm{Cs}$ heat source, as a function of particle size and degree of saturation. Temperature rise is defined as the difference from the particle centerline to the neighboring bed fluid. Results for a flowrate of $30 \mathrm{~L} / \mathrm{min}$ are shown. 


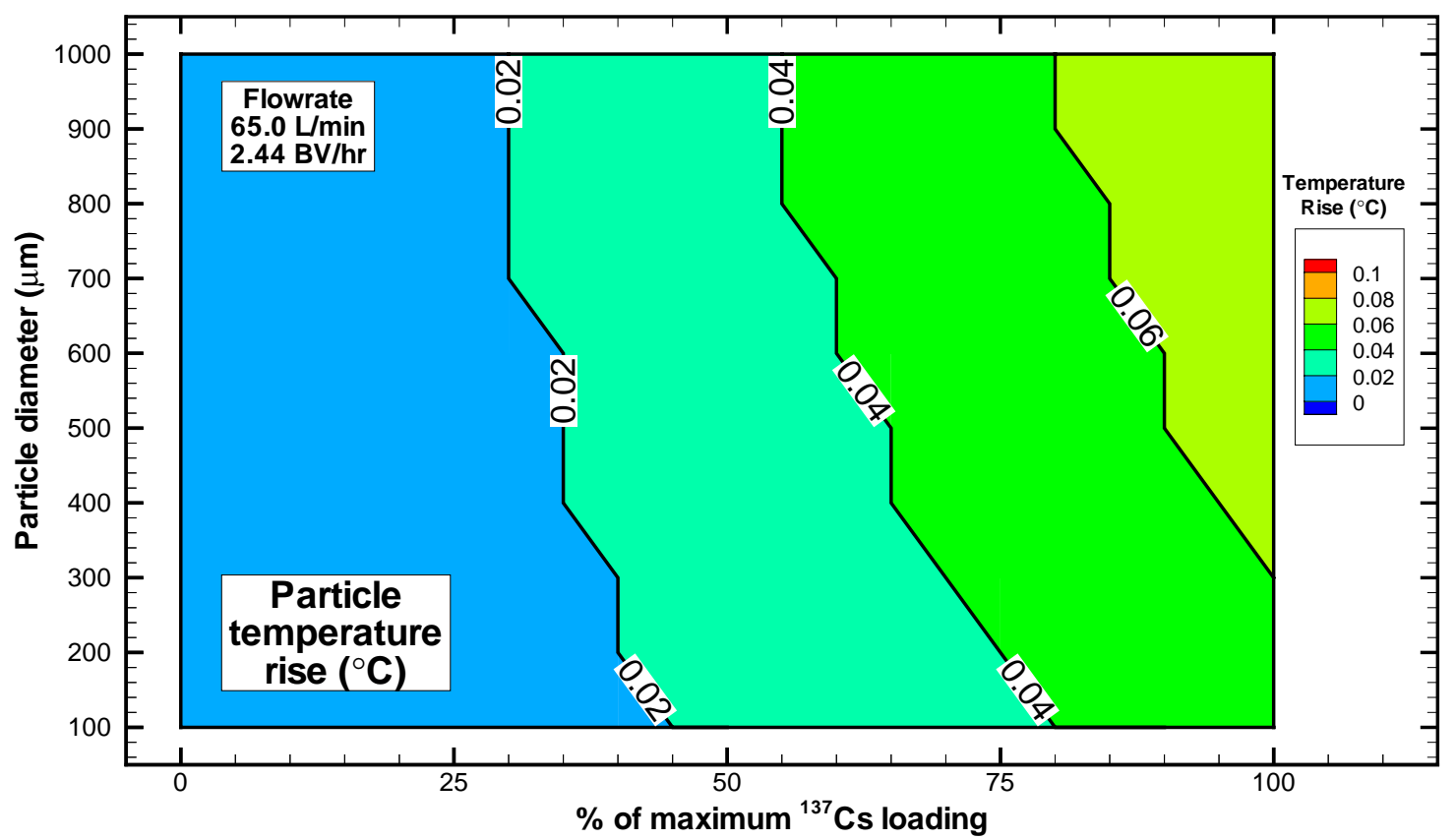

Figure A-9. Estimated temperature rise across a SuperLig ${ }^{\circledR} 644$ resin particle, loaded with a ${ }^{137} \mathrm{Cs}$ heat source, as a function of particle size and degree of saturation. Temperature rise is defined as the difference from the particle centerline to the neighboring bed fluid. Results for a flowrate of $65 \mathrm{~L} / \mathrm{min}$ are shown.

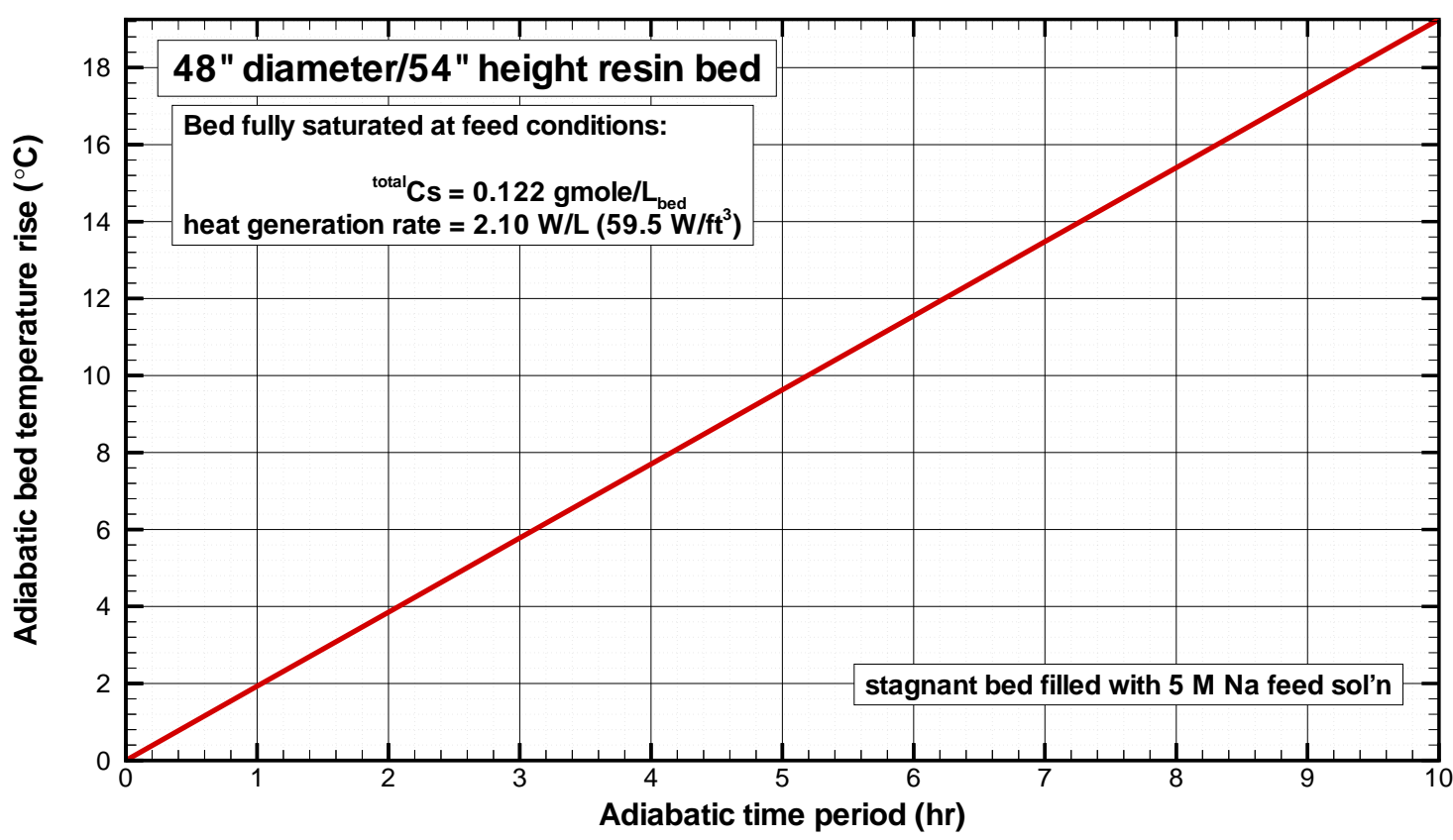

Figure A-10. Estimated adiabatic temperature rise across the SuperLig ${ }^{\circledR} 644$ resin bed under conditions of a fully loaded ( ${ }^{\text {total }}$ Cs saturated) column where the feed total cesium concentration was set to $5 \times 10^{-4} \mathrm{M}$. 


\section{Appendix B (Proposed Hanford WTP IX Column Design)}

\section{CXP Column}

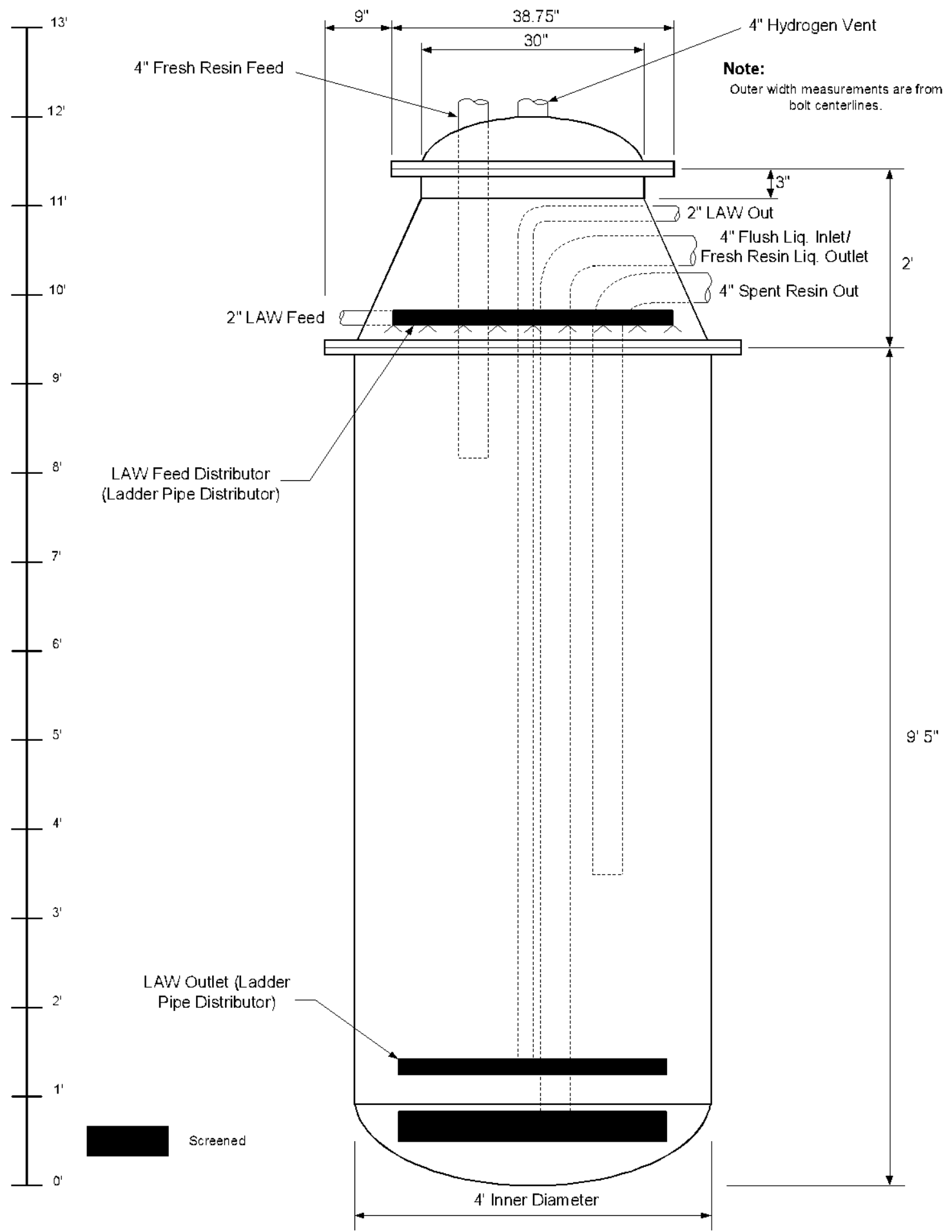

Figure B-1. Schematic diagram of proposed CXP column design provided by WGI personnel. 


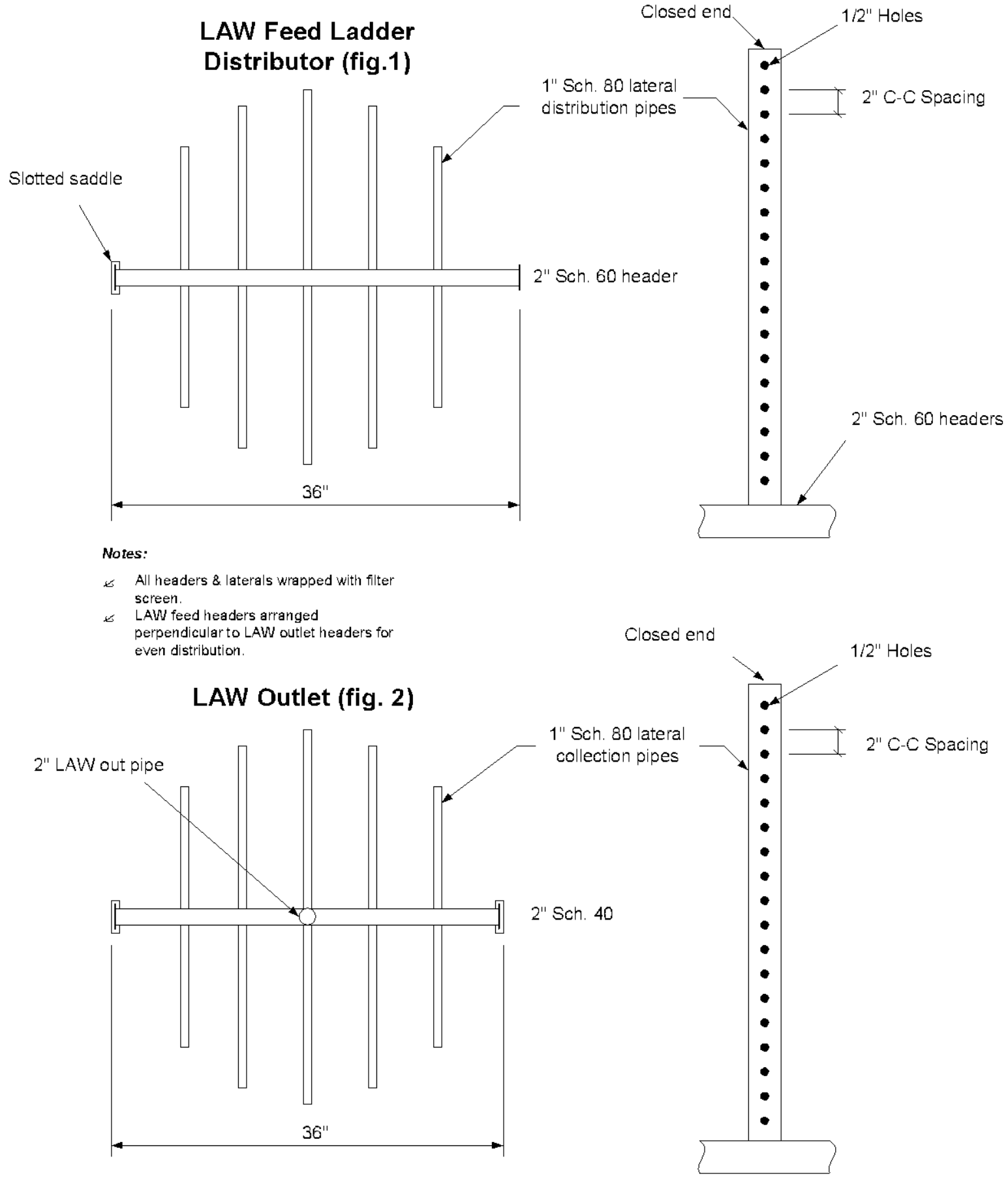

Figure B-2. Design details for the LAW feed ladder distributor and LAW outlet distributor. 